\title{
INVERSE IDENTIFICATION OF ELASTIC MODULI FOR 3D PRINTED PLA, USING IMPULSE EXCITATION TECHNIQUE (IET)
}

\author{
by \\ Mohsin Afridi, \\ Bachelor of Engineering, Ryerson University (2007)
}

\author{
A project \\ presented to Ryerson University \\ in partial fulfilment of the \\ requirements for the degree of \\ Master of Engineering \\ in the program of \\ Aerospace Engineering
}

Toronto, Ontario, Canada, 2019

(C) Mohsin Afridi 2019 


\section{AUTHOR'S DECLARATION FOR ELECTRONIC SUBMISSION OF A PROJECT}

I hereby declare that I am the sole author of this project. This is a true copy of the project, including any required final revisions, as accepted by my examiners.

I authorize Ryerson University to lend this project to other institutions or individuals for the purpose of scholarly research.

I further authorize Ryerson University to reproduce this project by photocopying or by other means, in total or in part, at the request of other institutions or individuals for the purpose of scholarly research.

I understand that my project may be made electronically available to the public. 


\title{
INVERSE IDENTIFICATION OF ELASTIC MODULI FOR 3D PRINTED PLA, USING IMPULSE EXCITATION TECHNIQUE (IET)
}

\author{
Mohsin Afridi \\ Master of Engineering, Aerospace Engineering, Ryerson University, Toronto (2019)
}

\begin{abstract}
3D Printing has recently undergone extensive development due to its lower cost and flexibility. A number of studies have been carried out to determine 3D printed material properties. This study focuses on the determination of the dynamic properties for PLA. The PLA material is processed through the popular FDM method with three different build orientations. A vibration experiment is conducted to evaluate the first modal frequency and Young's modulus. The results are then compared to the FEM modal analysis and finally the traditional tensile testing results. The anisotropy of the 3D printed components, mainly due to the density changes caused by voids and filament alignment, result in the variation of the Young's modulus which is different than the homogenous bulk material. The calculated Young's moduli values are very slightly higher than the tensile test results which is in conformance with the trend documented by earlier studies on similar printed materials using the same techniques.
\end{abstract}




\section{ACKNOWLEDGEMENTS}

This thesis project would not have been possible without the continuous support, guidance and encouragement of Prof. Seyed M. Hashemi, whose extensive knowledge and experience in the areas of Conventional and Dynamic Finite Elements, and Vibration was instrumental.

I would also like to thank Dr Kazem for his 3D printing knowledge and guidance. Ali Froozanfar for his great support and assistance throughout the design and execution of the experimentation.

I would also like to thank Ryerson University and the Aerospace Engineering Department for the access to the Lab and experimentation equipment.

Finally, very special thanks go out to my parents for their perpetual encouragements and support. 
Dedicated to my parents Liaquat Afridi and Khadijah Afridi 


\section{TABLE OF CONTENTS}

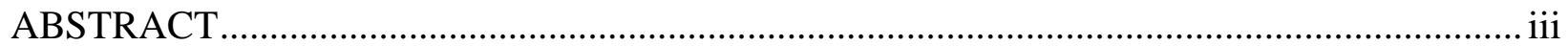

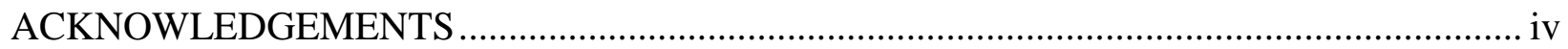

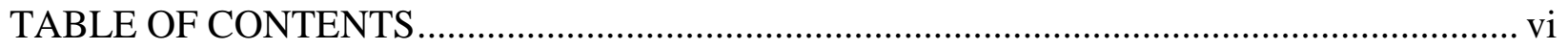

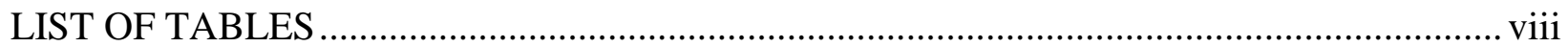

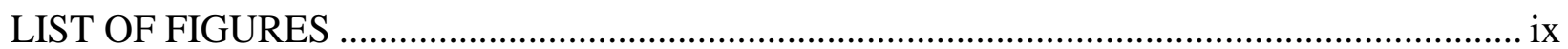

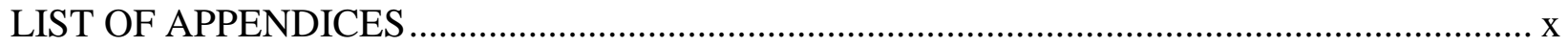

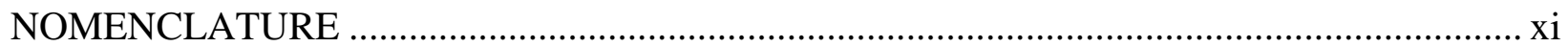

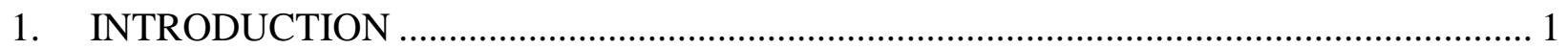

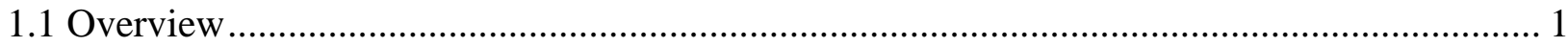

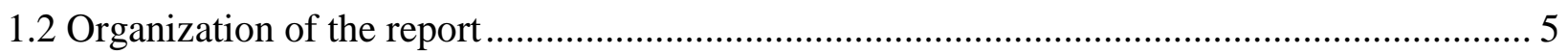

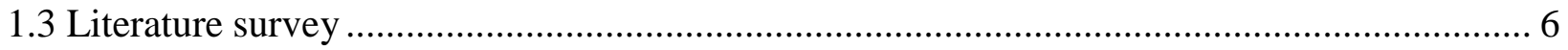

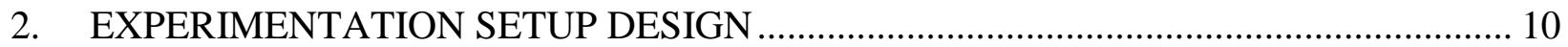

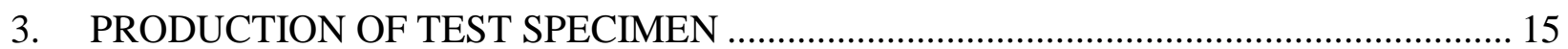

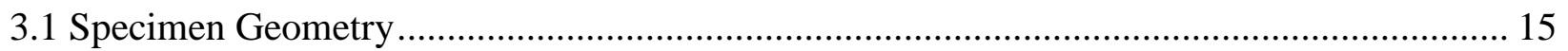

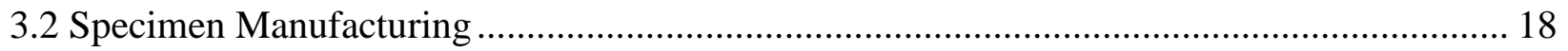

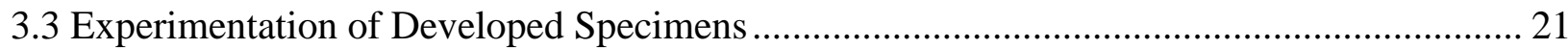

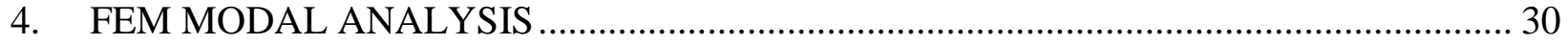




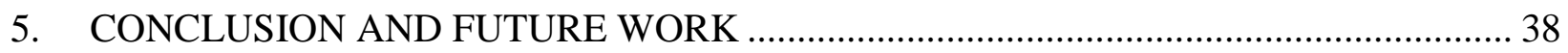

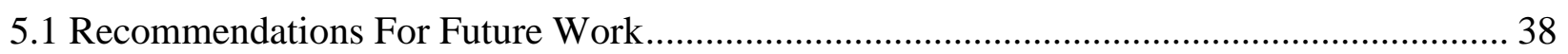

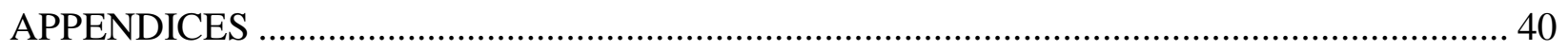

APPENDIX A EXPERIMENTATION SETUP AND RESULTS ...................................... 41

Appendix A1 CAD Designed and Printed Laser Sensor Mount............................................. 42

Appendix A2 3D CAD Experimentation Setup Design ...................................................... 43

Appendix A3 Summary of Reported Test Specimens ................................................... 45

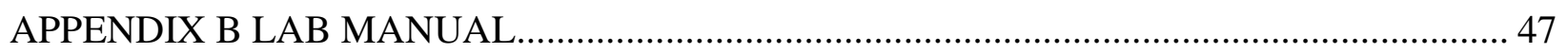

APPENDIX C EXPERIMENTATION RESULTS ..................................................... 74

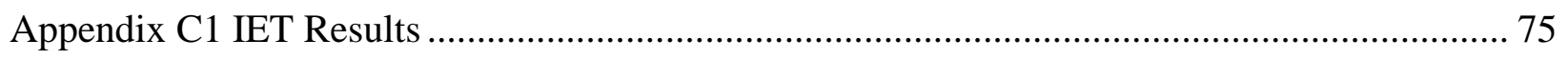

Appendix C2 Tensile Testing Results........................................................................ 76

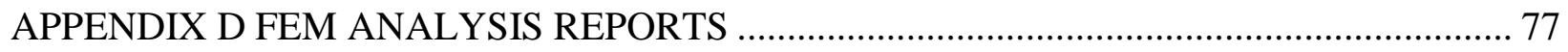

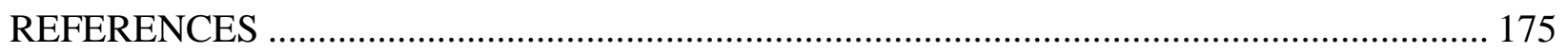




\section{LIST OF TABLES}

Table 1: 3D printer FDM manufacturing parameters used to produce test specimens.

Table 2: Test Specimen mechanical parameters and results.

Table 3: Young's modulus results from tensile testing for each test specimen.....

Table 4: Table of modal frequencies for orientation XYZ 33

Table 5: Modal frequencies table for XZY 34

Table 6: Modal frequencies table for ZXY 35

Table 7: Tensile test results for Young's modulus 36

Table 8: Comparison of Young's modulus results from IET and tensile test 37 


\section{LIST OF FIGURES}

Figure 1: Experimental Setup Schematic 10

Figure 2: 3D Catia V5 design for experimental equipment including sensors and test specimen 12

Figure 3: 3D Printed Test Specimen with characteristic lengths illustrated 16

Figure 4: XZY build orientation 18

Figure 5: 3D printed PLA specimens in three build orientations: 20

Figure 6: Screenshot of Piezoelectric impulse hammer force in time domain 23

Figure 7: Typical FRF result from laser sensor 1 for XYZ build orientation 24

Figure 8: Sample Test run parameters used in DAQ software (CatmanAP) 25

Figure 9: Data Analysis screenshot of DAQ software comparing displacement amplitude from two laser sensors and the impact force from the piezoelectric sensor. 25

Figure 10: FRF of ZXY sample with initial laser 3 position 26

Figure 11: FRF of ZXY sample with laser 3 position moved closer to tip 26

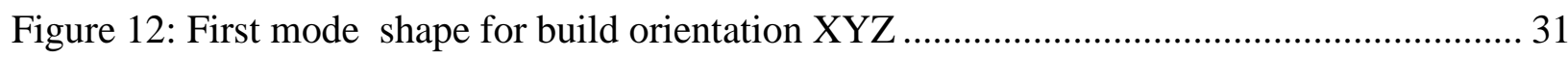

Figure 13: First mode shape for build orientation XZY 33

Figure 14: First mode shape for build orientation ZXY 34 


\section{LIST OF APPENDICES}

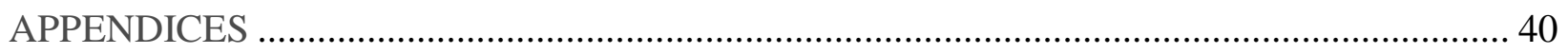

APPENDIX A EXPERIMENTATION SETUP AND RESULTS ............................................... 41

Appendix A1 CAD Designed and Printed Laser Sensor Mount................................................... 42

Appendix A2 3D CAD Experimentation Setup Design ............................................................. 43

Appendix A3 Summary of Reported Test Specimens .................................................................. 45

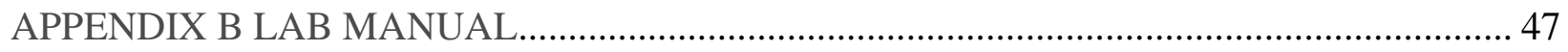

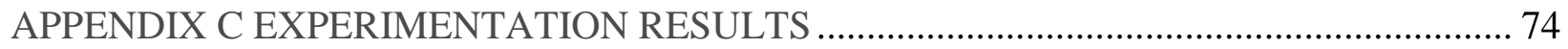

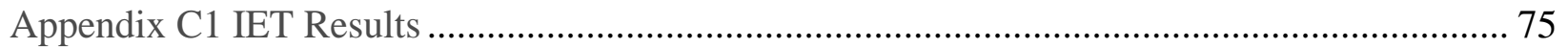

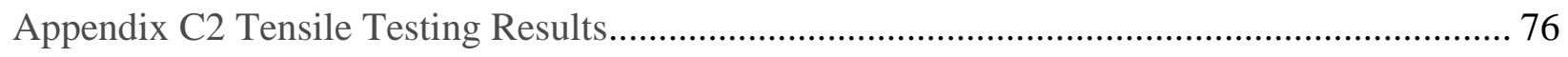

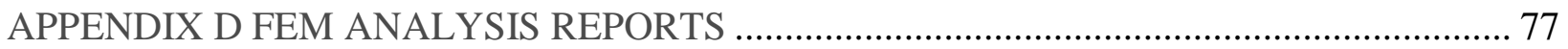




\section{NOMENCLATURE}

$\mathrm{E}=$ Young's modulus of elasticity

$\mathrm{A}=$ Cross-sectional area of beam

$\rho=$ density

$1=$ Free vibration length

$\mathrm{I}=$ Second area moment of Inertia of the beam

$\mathrm{L}=$ length of the beam

$\omega=$ natural frequency

$\lambda=$ non-dimensional natural frequency

$\mathrm{X}, \mathrm{Y}, \mathrm{Z}=$ rectangular Cartesian coordinate system 


\section{INTRODUCTION}

\subsection{OVERVIEW}

Beams are considered as fundamental components of intricate system models and complex structures. Any structure when subjected to dynamic loads transmits vibration that can result in fatigue or even catastrophic failure through the resonance phenomena. In aerospace design, the aircraft wing, for example, can experience aerodynamic loads and vibrations that can result in phenomena such as flutter or buffeting that can damage or even compromise the structure. Every structure has at least one natural frequency that can be analyzed and help determine the modal parameters of the structure. Since dynamic characteristics of a system are determined by mass, stiffness, damping and the boundary conditions, any change to these can affect the modal frequency. The dynamic response of the structure excited by any stimulus can help determine the modal parameters and therefore inherent elastic properties of the beam material.

Weight is a major factor in aerospace design and results in a constant shift towards lighter materials that can be cheaply and readily manufactured. Forming and Subtractive manufacturing have traditionally been the processes of choice for the industry but additive manufacturing has now become the focus of development and research due to its capacity to revolutionize manufacturing with its flexibility and efficiency. Several technologies and manufacturing approaches have resulted from this push towards 3D printing, the most popular of which is the Fused Deposition Method (FDM) that can deploy a range of plastic materials.

Due to the rise in environmental concerns, the sustainable materials requirement has resulted in an industry wide drive to develop and adopt biodegradable materials to replace the use of oil based polymers and plastics. Poly Lactic acid (PLA) is a bioactive thermoplastic, aliphatic 
polyester derived from renewable natural resources such as cornstarch in North America and other natural starch sources, e.g. sugarcane, readily available around the world. PLA, a 100\% biopolymer and biodegradable material, has already found many uses in the biomedical and pharmaceutical application due to its biocompatible properties. Other application scope is in the automotive and aerospace industries where research is underway to tailor and improve the thermophysical and mechanical properties as multifunctional polymeric composites. PLA therefore was an early candidate for the 3D printing FDM process.

The FDM method for 3D printing is the most widely used and involves heating the material and a printer base plate after which a bottom up, sequential layered approach is used to place the material filament is carried out, through a numerically controlled nozzle. The heated material solidifies as soon as it comes out of the nozzle (Wenzheng Wu, 2017).

Unlike its constituent homogeneous material, the 3D printed components display anisotropy due to the filament alignment in certain directions, inter-layer and inter-filament voids (also known as inter-bead, intra-bead and interfacial bead) (Haque., 2018, ) to name a few, somewhat similar to fibres in a composite material matrix. Recent research through traditional tensile tests (Y. Song, (2017) ) (ASTM International , 2015) show an elasto-plastic, orthotropic mechanical response with a strong asymmetry between both tension and compression. A large effort by recent available research literature has been to understand manufacturing parameters and other external factors to improve the mechanical properties of 3D printed polymers. The results of literature review section briefly delves in some of the different properties and reasoning behind their deviation from the bulk material. This project is focused on the determination of the resulting dynamic properties that are characteristic of the 3D printed PLA components. 
Free vibration analysis has been used to determine a range of material properties, such as elastic constants (Young's modulus and Shear modulus), damping coefficient, etc. The method, also known by names such as Impulse/Impact excitation, resonance, vibration, eigenfrequency, and ping test, is a non-destructive (ND) material characterization technique in which elastic solid is lightly struck with a hammer or projectile, giving it energy to vibrate at its natural frequency (D. Ridley-Ellis, 2018).

Most experiments reported in the open literature are specific to an application where the determination of certain properties can help evaluate the material better than others are. For example, a material such as a polymer to be considered for damping purposes focuses on the timedependent amplitude decay that can be extracted from a mechanical vibration as a result of a suitable impulse. Such experimentation to determine the Q factor and damping ratio is independent of dimensions therefore no specific test specimen form is required as long as the required frequency is obtained from the component. A number of other experiments have also been applied to determine various properties, such as storage modulus, loss modulus (Wei Sun, (2018) ) etc. These properties can also be determined through both the traditional mechanical static methods such as tensile testing, four point bending and nanoindentation (N.B. Podymova, 2013) and dynamic methods such resonant ultrasound spectroscopy (Davide S. Paolino, 2017) and Impulse Excitation Test (IET). The IET technique, easy to perform and efficient, provide an attractive methodology to obtain the intended parameters. Extensive successful corroborating work has already been performed using the methodology referenced in the literature review section.

This methodology requires picking up the vibrational signals, analyzing the vibrational signals and determining the resonant frequency. The simple geometries used such as rectangular beams have been extensively used with formulas available in literature. These researches have 
focused on temperature and geometrical variations based on simple rectangular beams and rods. Since no studies have evaluated the dynamic properties of the PLA 3D printed parts through a vibration analysis, there is a requirement to carry out experimental investigation using IET. FEM simulations and traditional mechanical axial testing results are used for verification of the IET results for this project. Based on the literature review in Section 1.2, this experimentation study has selected the determination of the first fundamental frequency of 3D printed PLA beams and the Young's modulus as the objective for this dynamic investigation. The Young's modulus is extensively used in engineering and science applications to determine the dynamic response of the material to external forces and can be used to compare material quality as presented in the literature review section.

In a homogeneous, isotropic material, the longitudinal loaded tensile test results for the elastic modulus are the same as those obtained through IET based. Both testing methodologies follow the Hook's law. It is also well known that due to the flexing, the surface is placed under more stress than the test specimen center. If due to a stiffness gradient present in the thickness, for example in this case the voids (beads and micro-cracks) close to the surface, then the results of the IET in flexural mode are different and more precise. Due to this reasoning IET is very suitable for porous and brittle materials such as ceramics and 3D printed polymers. As also stated by earlier publications (HEYLIGER, 2001) (CHO, 2007).

IET is also versatile since the amount of deformation involved is minute because of the small elastic strains imparted by the impulse excitation, which allows repeatability of experimentation in relatively quick and simple tests. IET works well with the simplified assumptions on which simple beam theory such as the Euler-Bernoulli is based on. IET can be conducted over a wide range of temperature and provide insight on the microstructure along with 
the already mentioned mechanical properties. The IET is widely used in the ceramic, wood and aluminum, industry due to its simple non-destructive testing nature and applicability in quality control, apart from research. The literature review section discusses some of the recent studies that were conducted to expand the scope of the quality control aspect of IET.

Various types of sensors have been used in recent studies including traditional contact sensors such as accelerometers and piezoelectric sensors or non-contact sensors including microphone and laser sensors, to determine the Young's modulus using an IET setup. This project has implemented the available laser displacement sensors as part of the non-contact and nondestructive experimentation process.

\subsection{ORGANIZATION OF THE REPORT}

Followed by the Chapter 1 section 1.1 introduction, this section 1.2 explains the arrangement of this project report. Section 1.3 presents a broad literature review that briefly compiles and lists the recent research studies conducted for a number of topics affecting this project. The topics include material characteristic research of 3D printed materials including PLA, the applicable theories and methodologies that can be used for verification of the experimental results. The literature review section emphasizes the specific dynamic analysis methodologies and techniques that have been used for various materials characterizations.

Chapter 2 specifies the equipment setup designed for the experimentation process. Schematics and Illustrations are provided for better understanding of the equipment, technique and the process of experimentation to be carried out for the project. 
Chapter 3 further discusses the manufacturing of the test specimens and the FDM process parameters used. The test specimen physical and dimensional characteristics are also presented in this section.

The Chapter 4 explains the FEM modal analysis method employed using the ANSYS software to generate the natural frequencies and the mode shapes generated.

Chapter 5 presents the conclusion of the report, followed by suggested areas of future research. The report ends with the appendices.

\subsection{LITERATURE SURVEY}

The aim of this section is to survey the theoretical, experimental and finite element backgrounds of this research project in respect of the vibrational analysis of the 3D printed PLA rectangular beam samples.

The bending vibration of beams characterized by Euler-Bernoulli model of a slender (i.e., thin, engineering, long, etc.) beam, can be considered as a special case of the Timoshenko beam theory, obtained by neglecting the shear and rotary inertia effects, have been well studied and documented. The mathematical modeling of beam dynamics using the simple linear EulerBernoulli theory has been selected for this project due to its simplicity, conventional use and availability of formulas that can provide good results considering the assumptions of deflections in a transversely loaded beam with little or negligible shear deformations etc. (S.M. Hashemi, 1987) (Gang Wang) (Ewen., 2007). 
This literature review is focused on the latest developments in experimental vibration analysis of 3D printed components. The objective was to get a better insight into the existing approaches and select the one that would suit our research in the vibration analysis of 3D printed PLA components.

A literature review of the recent developments in mechanical characterization of the 3D printed materials was conducted by (John Ryan C. Dizon, (2018), p. 45), who have listed several works from the extensive fields of application for the printed materials such as construction, apparel, dentistry, medicine, electronics, automotive, robotics, military, oceanography, aerospace, and satellites. The "3D printing industry amounted to 13 billion dollars in 2016. The automotive industry applications amounted to over 3.9 billion and 2.4 from aerospace. Considerable higher revenues are reported from the medical and dental applications for 2016. With an annual growth rate forecast of $22.3 \%$ for next few years and 29 billion of revenues expected in 2020".

A number of works have limited the scope of their mechanical characterization studies to polymer materials. The polymer materials, though much lower in strength than metals, are much lighter with lower densities and have higher strains at failure. In some cases, plastics have demonstrated higher strength per unit weight than metals (Y. Song, (2017) ).

Another more specific study on measurements of mechanical response of unidirectional 3D-printed PLA was carried out that characterized the elasto-plastic materials as orthotropic with a strong asymmetry and toughness in the extrusion direction as transverse direction. The results claim toughness increase for the 3D printed parts when compared to the homogeneous injectionmoulded PLA (Y. Song, (2017) ). 
The Impulse Excitation Test (IET) technique selected for the experimentation project has been successfully employed in numerous research works for a variety of non-isotropic materials. In one of the recent publications (Wenlei Song, (2017) ), the IET was applied to identify the mechanical parameters of laminated composites, in comparison with the results obtained from FEM analysis. With acceptable variation of under 4\%, the methodology served as a reference for this project (Wenlei Song, (2017) ). Another recent study that used IET in comparison with tensile test results to attain Young's modulus value, recorded a 10\% mean standard deviation between the two methods (Lotfi Toubal, 2018).

IET was used to determine the residual Young's modulus for damaged composite laminates in a recent study (Davide S. Paolino, 2017). When compared with standard tensile tests, the study proved IET to be a rapid and effective method for measuring longitudinal Young's modulus. IET results were not affected by local inhomogeneity in thick composite laminates, as it was categorized as a global technique that was better suited to determine the overall Young's modulus of damaged composites. Another useful conclusion made in reference (Davide S. Paolino, 2017), was that the Young's modulus evaluated through IET are on average slightly higher than those obtained from the standard tensile tests are.

A diagnostic study was conducted earlier by (P Chiariotti, 2013) to exploit the IET determination of Young's modulus for detection of brake pad assemblies. The study proved the Young's modulus determination robust enough to identify the damage and concluded that additional properties such as the damping ratio or Q factor (used as a basis for diagnostic methods) does not increase the robustness of the employed methodology. The results recorded $40 \%$ decrease of effective Young's modulus in damaged pads. 
Other similar recent IET applications include the efforts to determine small changes in elastic moduli and damping in wood (D. Ridley-Ellis, 2018) (Guan, (2016) ) (Walunj Prashant S, (2015) )

The major sources of error for the IET experimentation have been evaluated by (M.F. Slim and A. Alhussein, 2017) as the test specimen thickness followed by density. In conclusion, the IET has proven to be an excellent method to determine the Young's modulus for a wide variety of materials including metals, composites, ceramics, coatings etc. (D. Ridley-Ellis, 2018) (N.B. Podymova, 2013) (Davide S. Paolino, 2017) (HEYLIGER, 2001) (Gang Wang) (Guan, (2016) ) (M.F. Slim and A. Alhussein, 2017) (Wei Sun, (2018) ) (Lotfi Toubal, 2018) (Monti., (2017) ) (Ramesh., 2015) (Somen K. Bhudolia, (2017) ). 


\section{EXPERIMENTATION SETUP DESIGN}

This section explains the methodology adopted to perform the dynamic investigation on the 3D printed material samples. The experimental test set up design and the modal analysis was carried out in compliance to the ASTM E1876-15 (ASTM International , 2015) and E756 - 05 (ASTM International, 2017) standards. The basic setup schematic block diagram is illustrated in Figure 1. The $3 \mathrm{D}$ representation of the final physical equipment design setup is illustrated in Figure 2 . The test specimen dimensions are discussed in detail in Chapter 3.

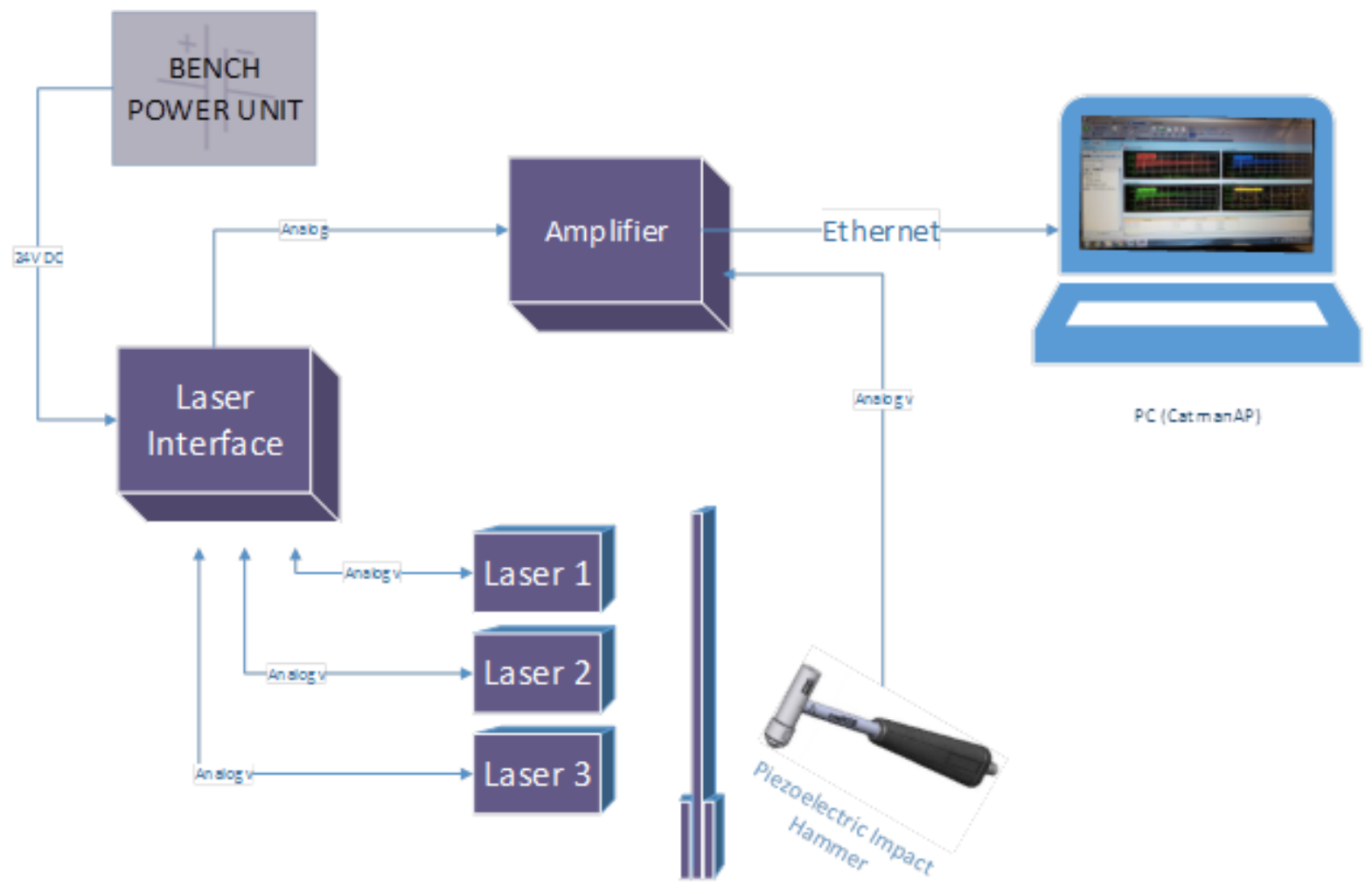

Figure 1: Experimental Setup Schematic 
A simple yet modular experimental setup is devised which includes a rigid horizontal extrusion attached to a metal table. Another rigid vertical extrusion is fixed onto the center rail using brackets that house three Laser displacement sensors (Mitak 3). The heavy steel table provides an isolated platform for the sensors and modular measurement equipment. The rest of the experiment test equipment including the PC, Amplifier unit (HBM X400A), Laser Interface (Durham Instruments) and the Bench Power Supply (BK Precision 673) were all setup on a separate lab desk.

The sensor base or 'mounts' were designed using 3D CAD (Catia V5), per sensors external dimensions and then converted to STL (Stereo lithography format) for 3D printing to hold the sensors firmly. This configuration provided easy adjustment of the sensor height along the specimen and could accommodate for different test specimen lengths. The Sensor mount design is illustrated in Appendix A1.

The distance between the laser sensors to the test specimen was set to an optimal value of $50 \mathrm{~mm}$, as per manufacturer specs for exploiting the complete range of vibration-triggered displacements of the test specimen. The bracket facing the sensors was fixed to maintain the set distance while the rear bracket was tightly clamped through a C-Clamp after aligning the test specimen centre line along the incident laser sensor beams and clamp limit as illustrated in Figure 2: 3D Catia V5 design for experimental equipment including sensors and test specimenand Appendix A2. Appendix B contain the lab manual developed for the efficient use of the test equipment in future with the objective of reducing the setup time, through systematic documentation for the conduction of IET experimental hardware and the Data Acquisition (DAQ) CatmanAP software. 


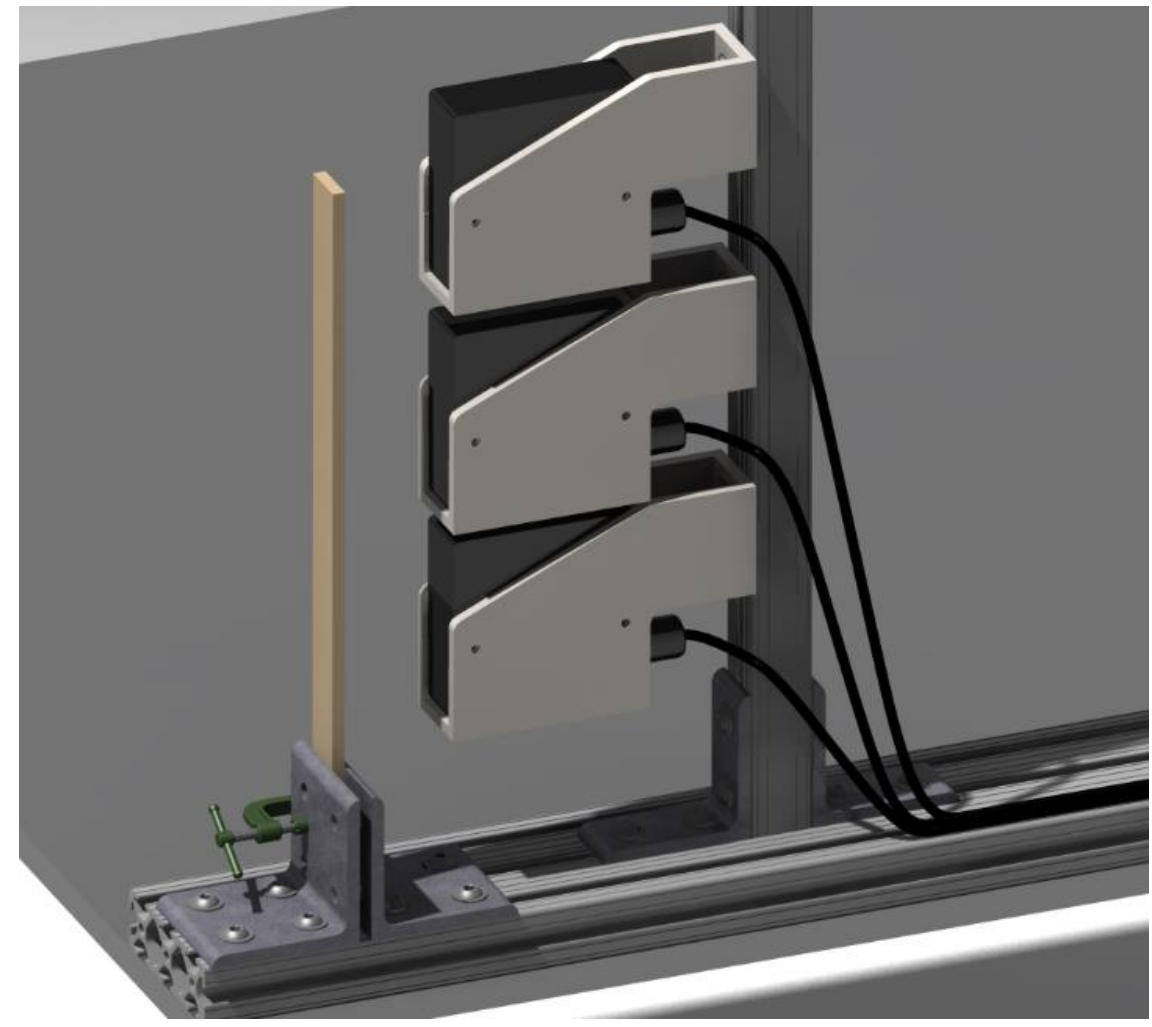

Figure 2: 3D Catia V5 design for experimental equipment including sensors and test specimen

There are a number of boundary conditions that can be used for vibration analysis of a beam as discussed in the literature review section. The cantilever boundary conditions (which is considered to be the most demanding case for practical applications) (Ewen., 2007) is selected for this experimentation. In case of the cantilever, it is important to note that the node position of the mode shape is defined by the fixed boundary condition. Well-established formulas in conjunction with, the specimen dimensions that provide a good aspect ratio can be used to determine anisotropic material properties (D. Ridley-Ellis, 2018).

The IET method selected can provide very good approximation results with the use of Euler-Bernoulli model of a cantilever beam. With the use of non-destructive laser sensors along 
with the DAQ capable of measuring at very high frequencies and nanoscale displacement measurements, a simple piezoelectric impulse hammer can be used to force induce very light impulses that can accurately determine the Frequency Response Functions (FRFs) for the first resonant frequency.

The clamping force in the fixed boundary conditions (BC) can have an effect on the stiffness of the test specimen and can result in slight variation of frequency results. To acquire a better understanding of the frequency variation experienced during multiple test setup and testruns for the same sample, the clamping force was considered. Confined by the in-availability of a torque measuring setup in the lab, a methodology based on rough estimates was also developed to simulate partially clamped and fully clamped conditions based on the number of turns applied to tighten the C-clamp placed over the brackets.

Result readings were measured with the different simulated clamping conditions and the variation in results was recorded. The variability in the frequency results due to the clamping conditions was calculated to be $2 \%$. This variation was acceptable as it ensured the factor for the boundary condition would not have a major impact on the experimental results. The detailed analysis of the data leading to this result is beyond the scope of this report.

Different clamping lengths as marked on Figure 3: 3D Printed Test Specimen with characteristic lengths illustrated were used to generate results with two sets of clamping areas. This allowed the beam to simulate two sets of free vibration lengths, which would result in different resonant frequencies for the same test specimen. Using non-dimentionalized equation (1) shown below, the results were compared for each set of values to determine the variation in the resonant frequency results for the same sample. 
The sensor setup was designed to capture measurements along the centre line of the test specimen in an attempt to isolate and capture the first modal frequency for the test specimen. The redundant sensors are used to ensure that only the targeted flexural mode frequencies are detected by all sensors.

To trigger the vibration, a Piezoelectric Impact hammer (Dytran Dynapulse 5800B4) was used with a soft silicone tip, to gently tap the test specimen. The impacts location was kept close to the fixed end about approximately $20 \mathrm{~mm}$ above the clamped boundary, as this ensured enough amplitude for the specimen free edge to be recorded by the sensors range and minimized double tap impulses. The impulse hammer taps were restricted to the test specimen's centre line to induce a pure bending resonant frequency to mitigate as much as possible any bending-torsion coupled frequencies. For future research it is pertinent to mention here that similar setups such as suggested in (Lotfi Toubal, 2018) and (ASTM International , 2015) can also be used to measure shear values.

The bench power unit step-down voltage set to $24 \mathrm{~V}$-DC powers the Laser sensors through a Laser Interface. The Analog output volt1age from the Laser Interface is delivered to the HBM X400A Amplifier that delivers the measurements to the PC based DAQ software. A Piezoelectric Impact hammer is used to induce the forced vibrations. Finally, the time domain and frequency domain results of the test specimen beams are obtained using the HBM CatmanAP software. Figure 7: Typical FRF result from laser sensor 1 for XYZ build orientation shows a typical output received from the CatmanAP DAQ system by conducting IET experimentation. 


\section{PRODUCTION OF TEST SPECIMEN}

\subsection{SPECIMEN GEOMETRY}

The Section 8 of the ASTM E1876-15 standard specifies a minimum ratio value of at least 5 between the length and the thickness of the IET test specimen beam. For ease in calculation, the standard does state preference for a ratio of 20 to 25 . As mentioned earlier this project has focused on the simple relationship based on the Euler-Bernoulli beam theory. As a result, the minimum criteria associated with a slender beam to be considered an Euler-Bernoulli beam is a ratio of 10 between the length and the thickness and studies have been conducted to a ratio of 100 to extract better results. A brief literature survey of the similar IET experimental tests published was conducted to document the breadth of dimensional ranges used for the test specimen (Davide S. Paolino, 2017) (Wenlei Song, (2017) ) (Guan, (2016) ). Based on the type of the material the relevant ranges of the test specimen lengths were determined to be 200 to $500 \mathrm{~mm}$, width of 10 to $50 \mathrm{~mm}$ and thickness ranging from 2 to $5 \mathrm{~mm}$. The literature survey table is presented in Appendix A3. More information can be found in the references and further reporting on the data has been omitted here for the sake of brevity.

The laser sensors stacked vertically across the test specimen centerline along with the designed mounts required a minimum test specimen length of $260 \mathrm{~mm}$ for the designed setup, if all three are used to provide redundant resonant frequency measurements. Finally, the 3D printing equipment limitations were also considered before selecting the dimensions some of which are illustrated in Figure 3, which are discussed in detail in the Section 3.2. One of the build orientation due to the printer hardware limitation could only be printed to a maximum length of $245 \mathrm{~mm}$. This is illustrated Figure $3 \mathrm{~b}$. The other two build orientations as per Figure $3 \mathrm{a}$ were printed to a length 
of $270 \mathrm{~mm}$. These provide a length to thickness ration of 70 and 77 , which meet the Euler-Bernoulli beam criteria. The designed width was selected as $20 \mathrm{~mm}$ and a thickness of $3.5 \mathrm{~mm}$ was selected for all build orientations.

Other than the length of the specimen, the clamped area boundary and centerline are also marked on the specimen in Figure 3 that are used to ensure proper alignment of all specimens in the rigid test fixture (Somen K. Bhudolia, (2017) ).

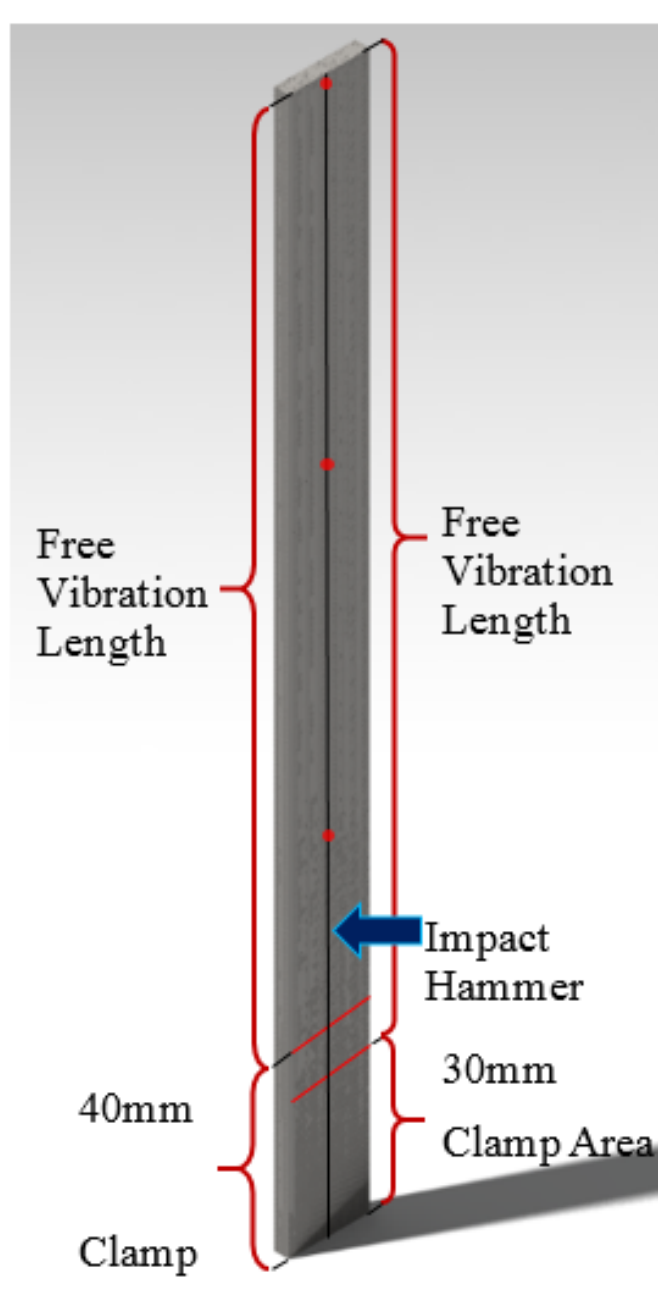

a. $\mathrm{YZ}$ and $\mathrm{XZY}$ build orientations
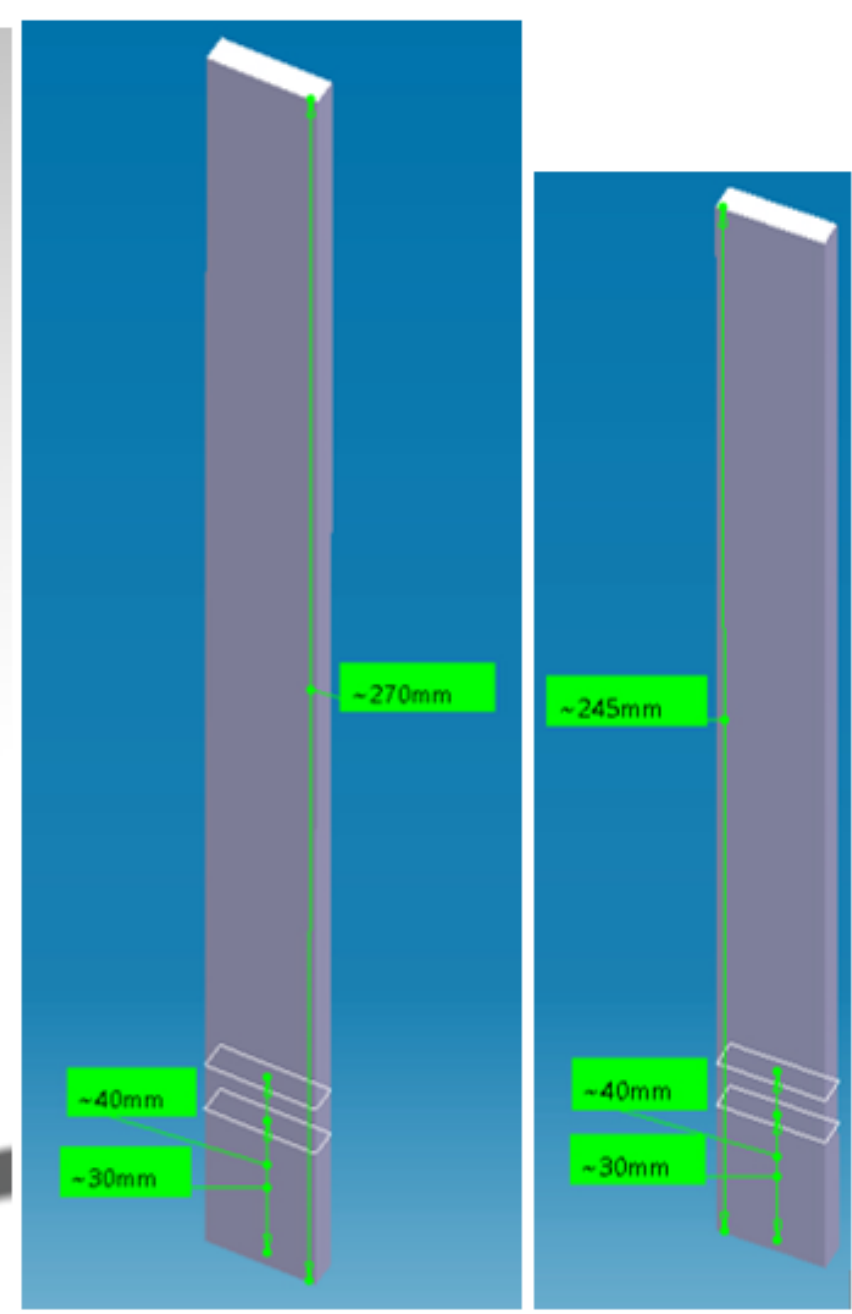

b. ZXY build orientation

Figure 3: 3D Printed Test Specimen with characteristic lengths illustrated 
It is important to note that two sets of clamped lengths for the sample were used for this experimentation as discussed in Chapter 2 above.

The test specimen dimensions were measured using a Vernier caliper and a micrometer was used to measure the thickness of the samples. A number of measurements were taken for each sample and averaged to help factor in the variability of each sample 3D printed using layers of the PLA filament. Based on the specimens' weight, lengths, and dimensions of the cross-sectional areas the densities were calculated. These densities are then used in the formulas listed in Section 3.3 to determine the Young's modulus.

A few recent studies that examined the transparent PLA specimens with others containing pigmentation resulting in a variation of properties and material finish concluded the transparent PLA without pigmentation to be stronger and more precise dimensionally (Valerga. A. , (2017) ) (Juliana Breda Soares, (2018)).

Since the PLA test specimen used were transparent for this experimentation, it did provide an unforeseen result for test specimen of orientation XZY. All test specimen of the XZY build orientation failed to register any reading through the laser sensors. Through a number of test iterations other causes for the failure of the sensors to register readings were ruled out. It was observed that the incident laser beam underwent diffraction which could probably be attributed to the FDM filament pattern on the XZY samples (without pigmentation). A number of work around were tested to enable the acquisition of readings for XZY samples, these included using markers and lead pencils on the beam incident points as well as using small stickers shown below in Figure 4. 


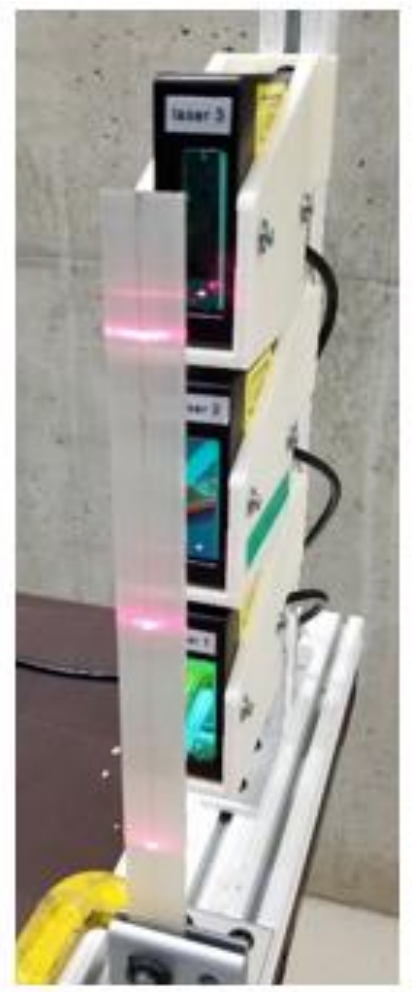

a. Laser diffraction

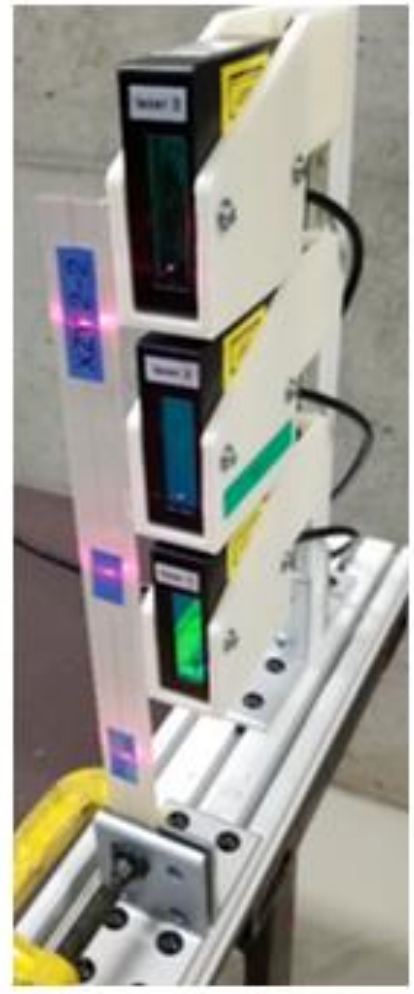

b. Workaround using stickers

Figure 4: XZY build orientation

\subsection{SPECIMEN MANUFACTURING}

A total of 11 test specimen were 3D printed using Prusa i3 MK2S printer. The manufacturing process and design parameters are presented in Table 1. 
Table 1: 3D printer FDM manufacturing parameters used to produce test specimens

\begin{tabular}{|l|c|c|c|}
\hline \multicolumn{1}{|c|}{$\begin{array}{c}\text { Manufacturing / } \\
\text { design Parameter }\end{array}$} & Value & $\begin{array}{c}\text { Manufacturing / } \\
\text { design Parameter }\end{array}$ & Value \\
\hline Material & PLA & Bed temperature & $60^{\circ} \mathrm{C}$ \\
\hline Print direction & XYZ/XZY/ZXY & Layer height & $0.14 \mathrm{~mm}$ \\
\hline Raster angle & $0^{\circ}$ & Printing speed & $2400 \mathrm{~mm} / \mathrm{min}$ \\
\hline Filament diameter & $2.85 \mathrm{~mm}$ & Cooling & $\begin{array}{c}\text { No fan } \\
\text { cooling }\end{array}$ \\
\hline Nozzle diameter & $0.4 \mathrm{~mm}$ & infill & $100 \%$ \\
\hline Nozzle temperature & $205^{\circ} \mathrm{C}$ & & \\
\hline
\end{tabular}

Figure 5 below illustrates the build orientation of 3D printed PLA specimens printed flat (XYZ), on-edge (XZY), and upright (ZXY). All manufactured specimens are tested using the apparatus described in section 2 and results are presented in Section 3. 


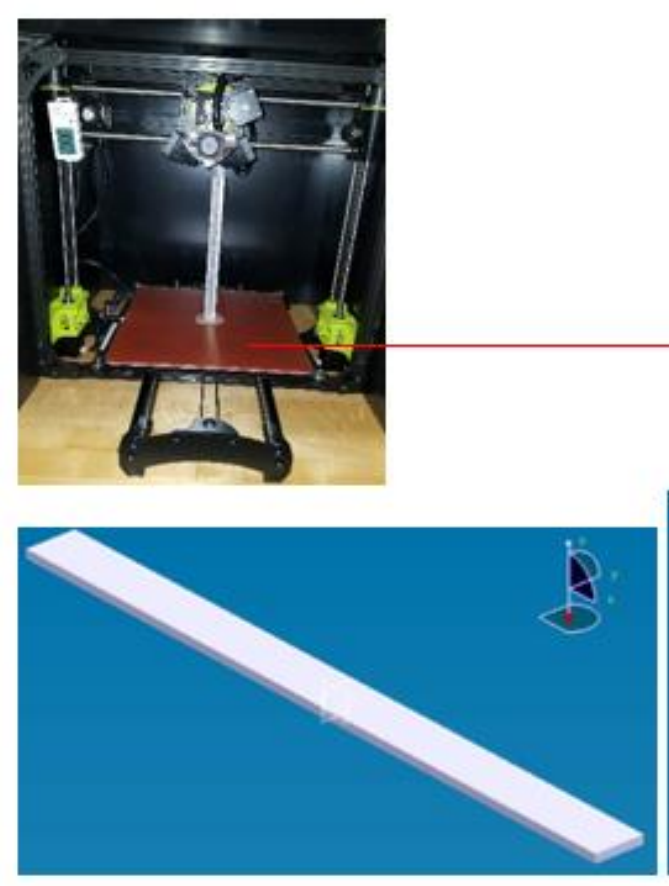

(a) flat (XYZ):

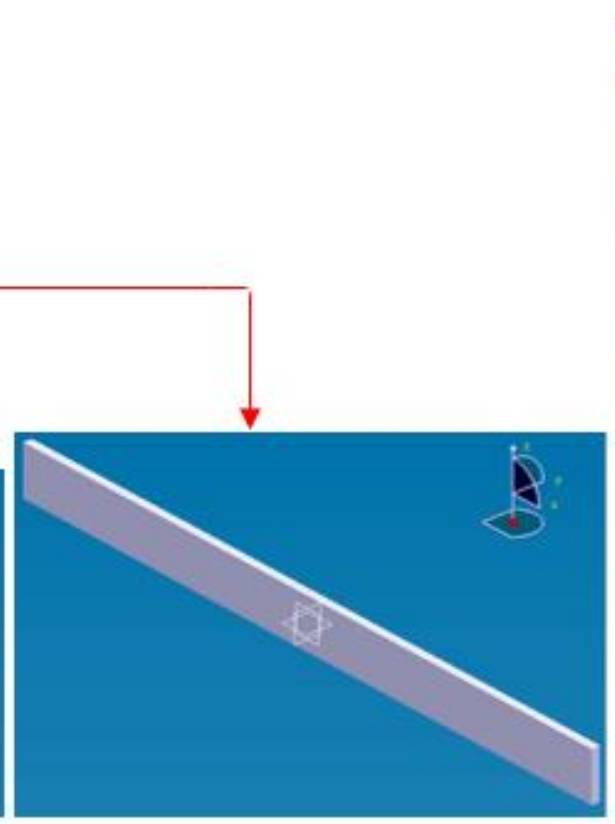

(b) on-edge (XZY):

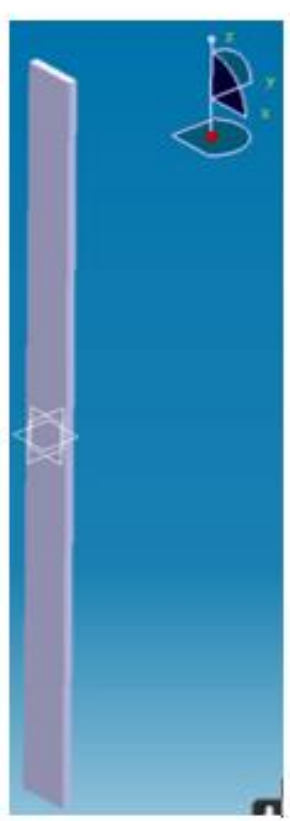

(c) up-right (ZXY).

Figure 5: 3D printed PLA specimens in three build orientations:

Tensile testing per ASTM D638 was performed to evaluate the Young's modulus along the specimen length. Test specimen are 3D printed per ASTM D638-14 type I. All manufacturing and design parameters for dynamic samples were also used for these tensile specimens 3D printing. This way, Young's modulus of dynamic samples can be obtained accurately using tensile testing and there is no need to rely on data sheet information from the filament provider. To ensure material uniformity the same batch of the filament was used in the printing of all specimens. No surface treatment or finishing of any sort was applied (Davide S. Paolino, 2017) to the test specimen. 


\subsection{EXPERIMENTATION OF DEVELOPED SPECIMENS}

Using the setup discussed in previous sections along with the manufactured test specimens, the experimentation was carried out systematically as per the instruction manual documented and attached in Appendix C. The Frequency Response Functions (FRFs) were recorded along with the specimen mechanical and dimensional parameters to determine factors such as density and beam moment of Inertia.

To reduce the impact of the sensors' mass on the structural dynamic characteristics, laser sensors are adopted to realize a non-contact test. In addition, to ensure that the resonance frequencies can be excited as much as possible in the considered frequency range, the excitation point was kept close to the clamped end to avoid double taps and enable an elastic impulse to be imparted to the specimen. The picking vibration points were chosen carefully (Wei Sun, (2018) ) as illustrated in Figure 3 to ensure that the same resonant frequency is detected by redundant sensors. After recording consistent results, the sensor positioning was altered by shifting all the laser sensors by $20 \mathrm{~mm}$ to see if any variation in sensor results could be detected. With all sensors at the new positions, as expected, the setup provided the same resonant frequency values with a difference in amplitudes. This consistency with the change in sensor positioning is illustrated through FRF plots in Figure 8 and Figure 11.

Using the placement of the sensors at multiple locations the modal shapes could also be graphed. For such applications, a continuous scanning Laser Vibrometry equipment would be a better choice. Similarly, the damping characteristics could also be calculated from the scope results generated during the IET. The focus of this experimentation though remains limited to the determination of the fundamental first natural frequency of the 3D printed PLA beam specimen in 
order to generate the Young's modulus. Once the experimentation results for all specimens are determined then the next step is to model the beams in ANSYS using actual specimen dimensions and carry out Modal Analysis on all build orientations illustrated in Figure 5. These results are compared to the experimentation results attained through the following steps in the next chapter and finally the traditional tensile test results.

Similar to the fact that restricting the number of moving parts in a machinery can raise dramatically the reliability of the machinery, this experimentation procedure is selected to harness the non-contact property of lasers for measuring the minute displacements introduced through measured, forced impact hammer induced pulses.

By limiting any changes to the test specimen's mass or any other characteristic property by attaching an accelerometer or any other sensor etc. the probability of better test results is improved. A simple setup as described in Sections 2 and 3 requires a cantilever beam with one end rigidly fixed and the other vibrating freely.

To determine the frequency response function (FRF) of the specimen, the impact hammer test is performed using the DAQ acquisition software (CatmanAP) as illustrated in the experimentation manual in Appendix C. A typical output is illustrated in Figure 6. The three laser sensors aligned along the centerline provide redundant FRF results with varying amplitudes to confirm the modal frequency acquired from the test. A centerline and clamping limits were marked as illustrated earlier in Figure 3 to align the laser incidence points along the same line in order to isolate the first modal frequency. Care was also taken to induce a forced impulse transversely through the impact hammer on the same centerline in order eliminate any force causing the test specimen to twist laterally resulting in an incorrect modal frequency. The impulse force was 
recorded and varieties of force values were used to measure the amplitude and resulting frequency. Figure 6 shows the screenshot result from the piezoelectric impulse hammer using the DAQ software.

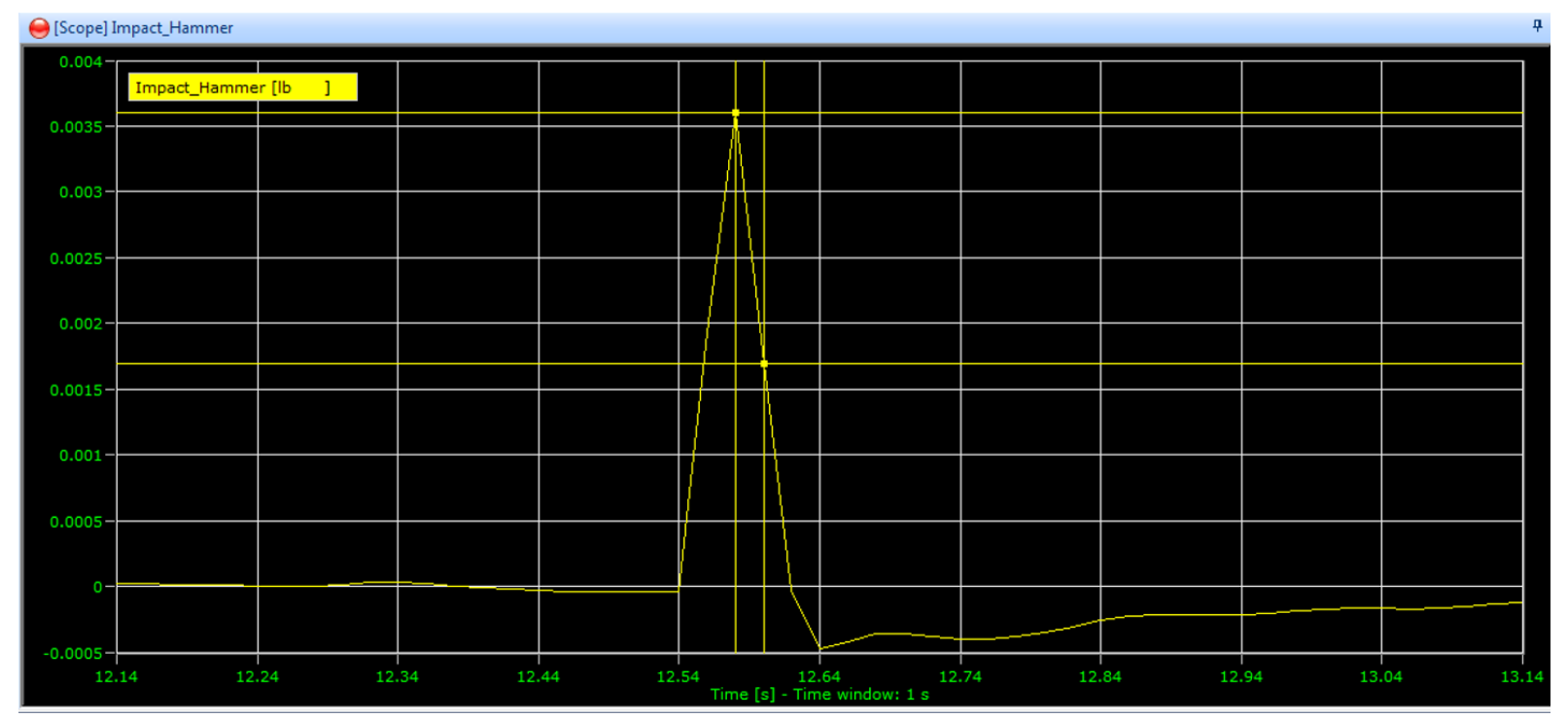

Figure 6: Screenshot of Piezoelectric impulse hammer force in time domain

An effort was made to conduct all the initial sets of tests with the focus on analyzing real time live FRFs and scope results for all channels (three laser sensors and the impact hammer) rather than waiting for the final large amount of data gathered from multiple test runs. This provided the opportunity to process real-time results on the spot and change or tweak any factor that had an adverse impact on the results. Following the same methodology of closely monitoring each aspect of the experiment, a number of factors were analyzed and improved e.g. the Clamping force and the impact impulse force induced. These factors along with the selected test parameters illustrated in Figure 8, were tweaked to produce clear, optimized and replicate-able results. 
Through trail and error an optimum impulse excitation force was determined to enable acquisition of clear frequency results for all build orientations. The data analysis option in the DAQ software provides the user with the means to add any amount of required test runs data in a single analysis window to compare all the results on the timeline. The user can control a cursor back and forth on the timeline and analyze all resulting graphical peak values from all channels simultaneously. Figure 9 presents an example of a data analysis screenshot from the DAQ illustrating the impact force peaks on the timeline along with the maximum values for each channel, i.e., all three lasers and the impact hammer. It was observed that slight changes in the free lengths (as low as $1 \mathrm{~mm}$ ) could result in small deviations of natural frequency, e.g., $0.19 \mathrm{~Hz}$, in this case.

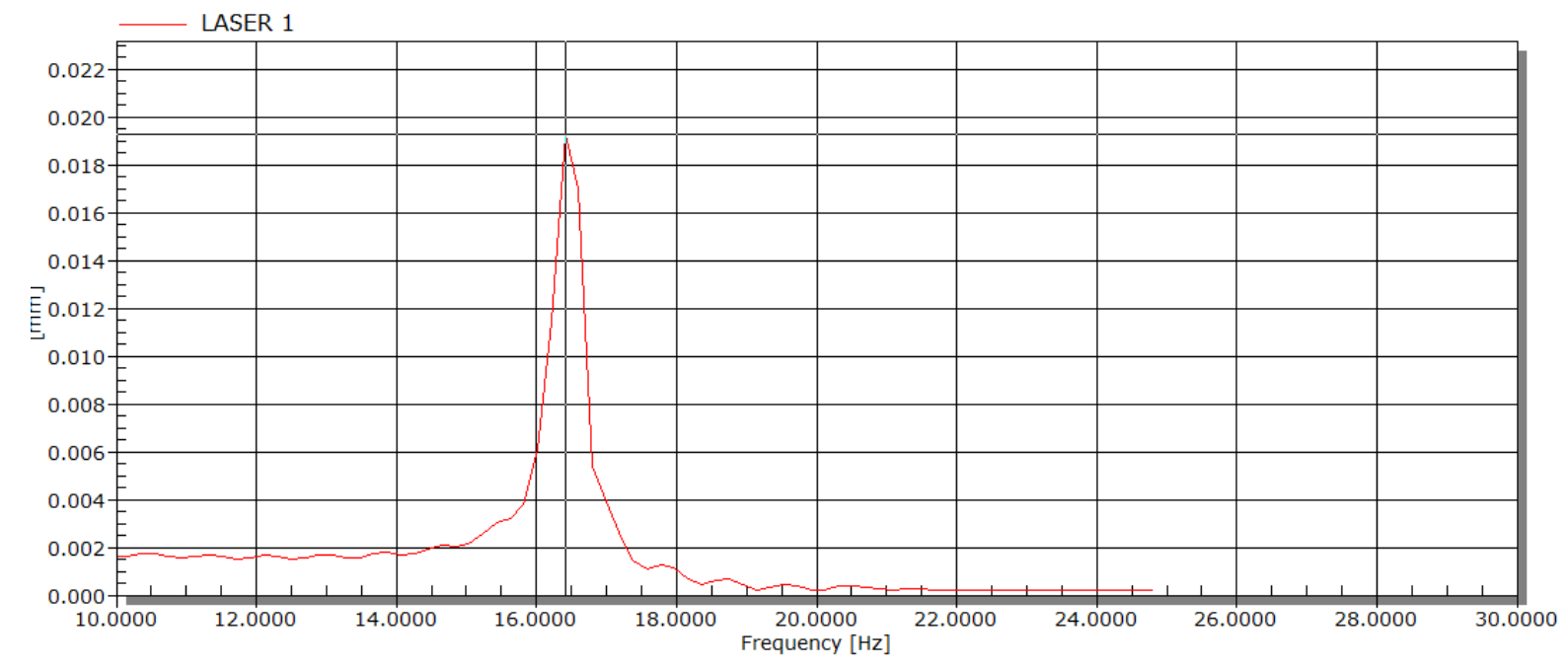

Figure 7: Typical FRF result from laser sensor 1 for XYZ build orientation 


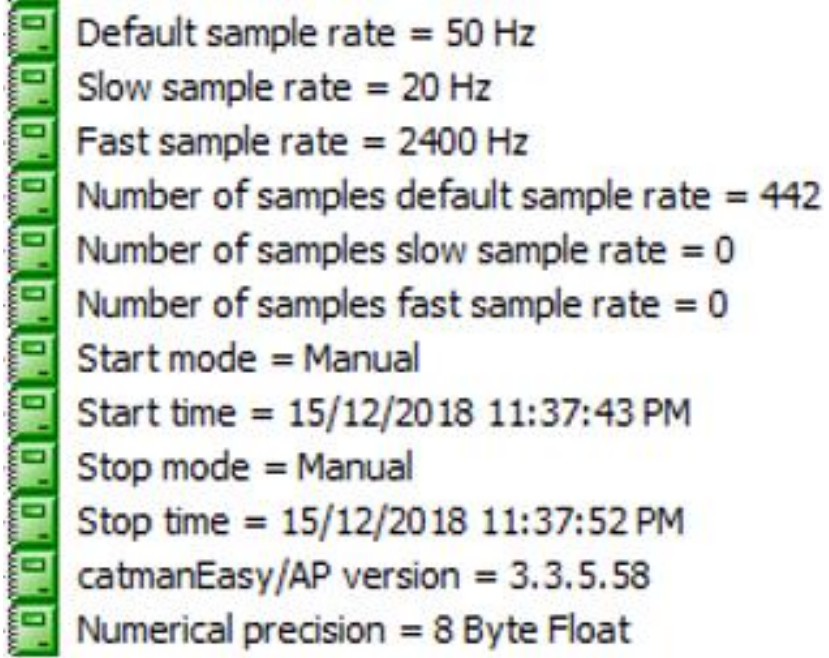

Figure 8: Sample Test run parameters used in DAQ software (CatmanAP)

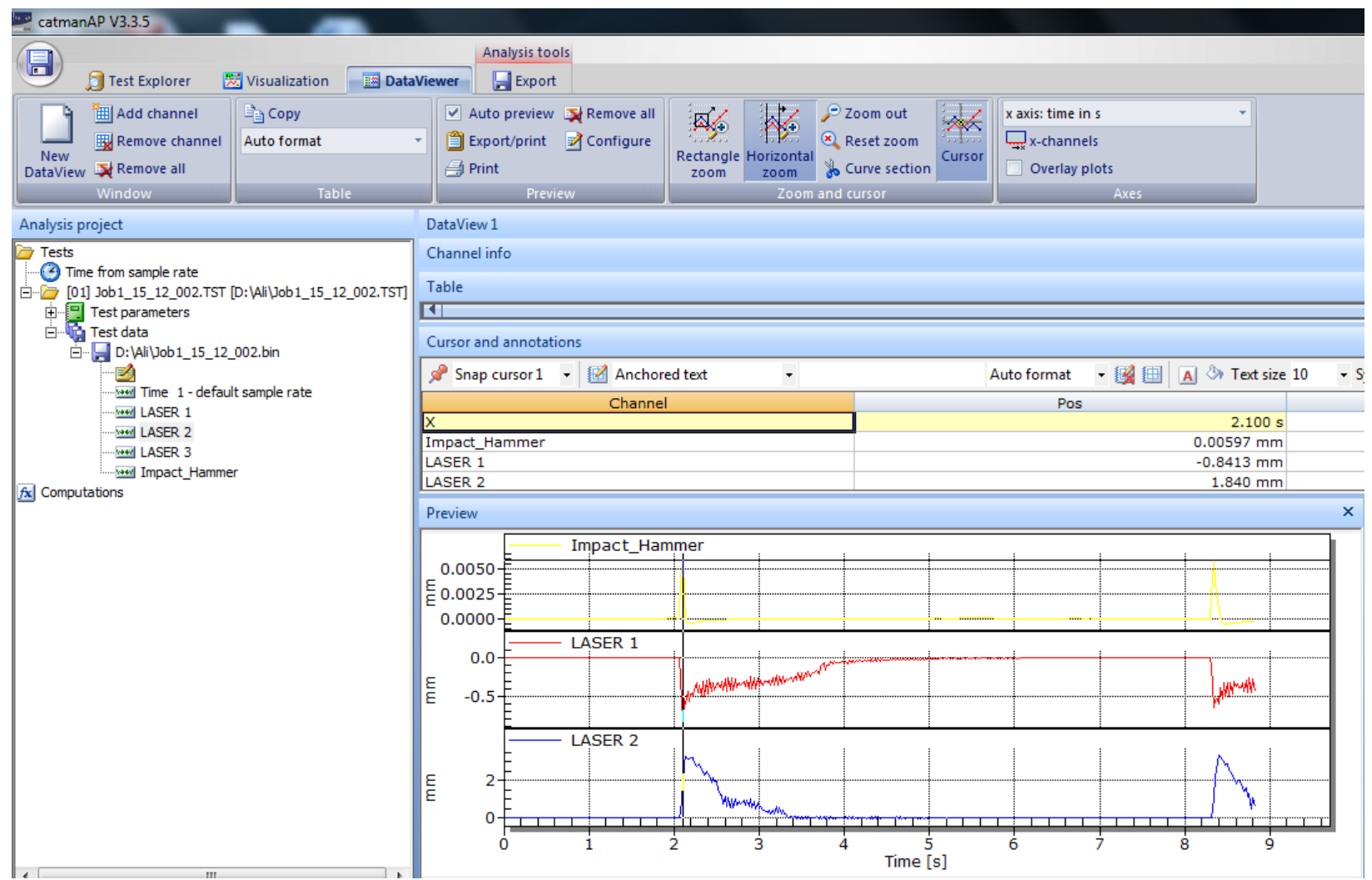

Figure 9: Data Analysis screenshot of DAQ software comparing displacement amplitude from two laser sensors and the impact force from the piezoelectric sensor 
To demonstrate the consistency and repeatability of the results, a ZXY build orientation sample with an FRF value is illustrated in Figure 8 below. The same sample when tested again with the laser sensor moved closer to the free end tip of the test specimen beam can be seen to provide the same result with an increased maximum displacement (see Figure 9).

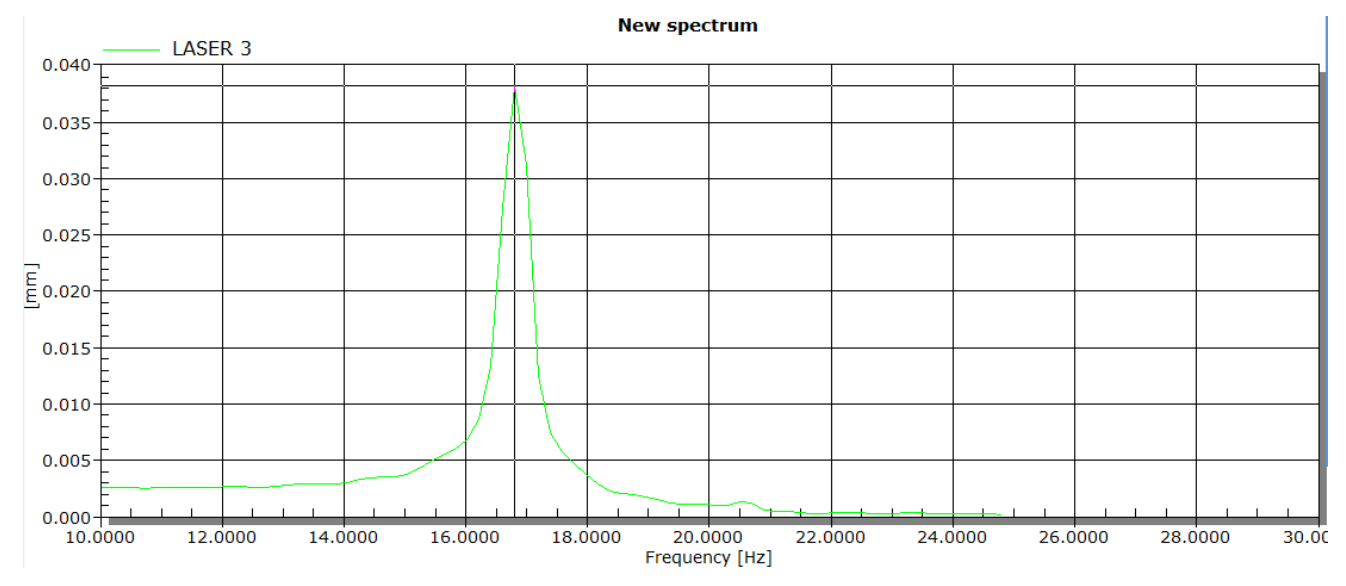

Figure 10: FRF of ZXY sample with initial laser 3 position

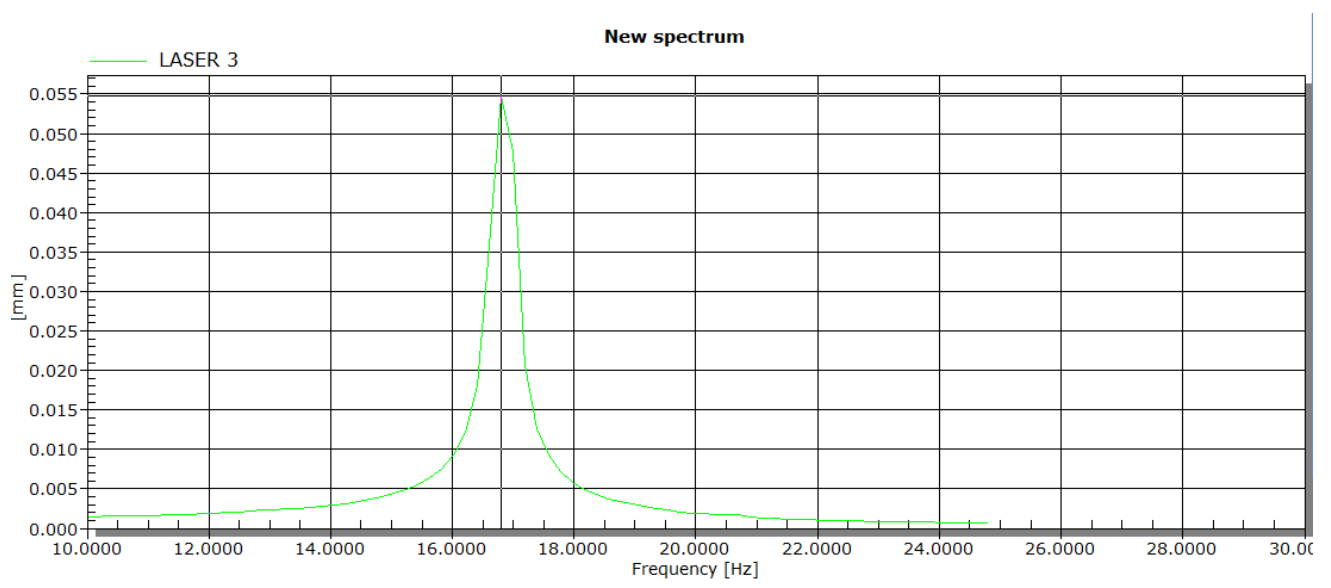

Figure 11: FRF of ZXY sample with laser 3 position moved closer to tip

As mentioned earlier, the 3D printed test specimen dimensions were measured at five equidistant spots along the length of the sample and results were averaged. Similarly, the mass was 
measured as listed in Table 2 below, along with the corresponding resultant first modal frequencies obtained through the IET experimentation.

Table 2: Test Specimen mechanical parameters and results

\begin{tabular}{|c|c|c|c|c|c|}
\hline SPECIMEN & $\mathbf{H}$ & $\mathbf{B}$ & $\mathbf{L}$ & $\begin{array}{c}\text { Mass } \\
(\mathbf{m m})\end{array}$ & $\begin{array}{c}\text { Frequency } \\
(\mathbf{m m})\end{array}$ \\
\hline $1-0 \mathrm{~mm})$
\end{tabular}

As discussed earlier, the Young's modulus is a fundamental property and a key parameter in mechanical engineering design to predict material behavior under forced deformation. The reason for selecting the Young's modulus as the main objective of this experimental study, as opposed to the resonance frequencies is due to the proven robustness of elastic modulus as an indicator of the material quality. Studies where factors such as temperature and moisture content have been considered, show little changes in resonance frequencies but can result in marked 
changes in the systems' Young's modulus (Lotfi Toubal, 2018). These factors have little change on the resonance frequency but marked effect on the Young's modulus

The first modal frequencies for the 3D printed specimens, as presented in Table 2 above, are then used to calculate E values for each specimen using the following relationship between the non-dimensional frequency (1) as reported in reference (S.M. Hashemi, 1987);

$$
\lambda^{2}=\frac{\rho A l^{4}}{E I} \omega^{2}
$$

with

$$
\begin{aligned}
& \lambda_{1}=3.5160 \\
& \lambda_{2}=22.0345 \\
& \lambda_{3}=61.6972 \\
& \lambda_{4}=120.902
\end{aligned}
$$

where $\quad I=\frac{b h^{3}}{12}$.

The first nondimensional frequencies listed above are compared to the right hand side of the Equation (1), where $\rho$ is the test specimen density, A is the cross-sectional, $l$ is the free 
vibrating length, $\omega$ is the measured natural frequency, and $\mathrm{E}$ is the Young's Modulus. Equation (1) is used with the dimensional and other test specimen parameters to determine Young's moduli.

Table 3: Young's modulus results from tensile testing for each test specimen

\begin{tabular}{|c|c|}
\hline $\begin{array}{c}\text { Test } \\
\text { Specimen }\end{array}$ & $\begin{array}{c}\mathbf{E} \\
\mathbf{P a})\end{array}$ \\
\hline $1-0 \mathrm{XYZ}$ & $3.402 \mathrm{E}+09$ \\
\hline $1-1 \mathrm{XYZ}$ & $3.417 \mathrm{E}+09$ \\
\hline $1-2 \mathrm{XYZ}$ & $3.154 \mathrm{E}+09$ \\
\hline $1-3 \mathrm{XYZ}$ & $3.382 \mathrm{E}+09$ \\
\hline $1-4 \mathrm{XYZ}$ & $3.397 \mathrm{E}+09$ \\
\hline $2-1 \mathrm{XZY}$ & $3.009 \mathrm{E}+09$ \\
\hline $2-2 \mathrm{XZY}$ & $3.089 \mathrm{E}+09$ \\
\hline $2-3 \mathrm{XZY}$ & $3.074 \mathrm{E}+09$ \\
\hline $3-1 \mathrm{ZXY}$ & $2.549 \mathrm{E}+09$ \\
\hline $3-2 \mathrm{ZXY}$ & $2.835 \mathrm{E}+09$ \\
\hline $3-3 \mathrm{ZXY}$ & $3.018 \mathrm{E}+09$ \\
\hline
\end{tabular}

The results presented in Table 3 above are the Young's modulus evaluated through the IET experiment for each 3D printed test specimen. 


\section{FEM MODAL ANALYSIS}

The FEM analysis is the fastest tool to determine the modal frequencies of the 3D printed PLA beams since it only requires modeling of the beams using test specimen design dimensional data and input of other available mechanical material properties. Even if all the required properties are not accurately input, the FEM method can still be used with the available bulk material data available to determine the modal frequencies. Although not very accurate, the FEM provides useful results to validate the preliminary IET experimental frequencies.

The 3D test specimen build orientation illustrated inFigure 1Figure 5 above, were modeled in ANSYS using the design data selected for the 3D printed PLA beams. Modal Analysis was then conducted for all three build orientations.

With the printing of all IET test specimen completed and dimensions carefully recorded, the average dimensional values for all three buid orientations were then used to update the ANSYS models. Material's mechanical properties determined through tensile tests were also used as input to further develop simulation test specimen as close to the actual IET test specimen as possible. A list of all the measurements and properties used to define the ANSYS models are provided in the ANSYS report presented in Appendix D.In what follows, the final ANSYS modal analysis results for the three build orientations are presented. 

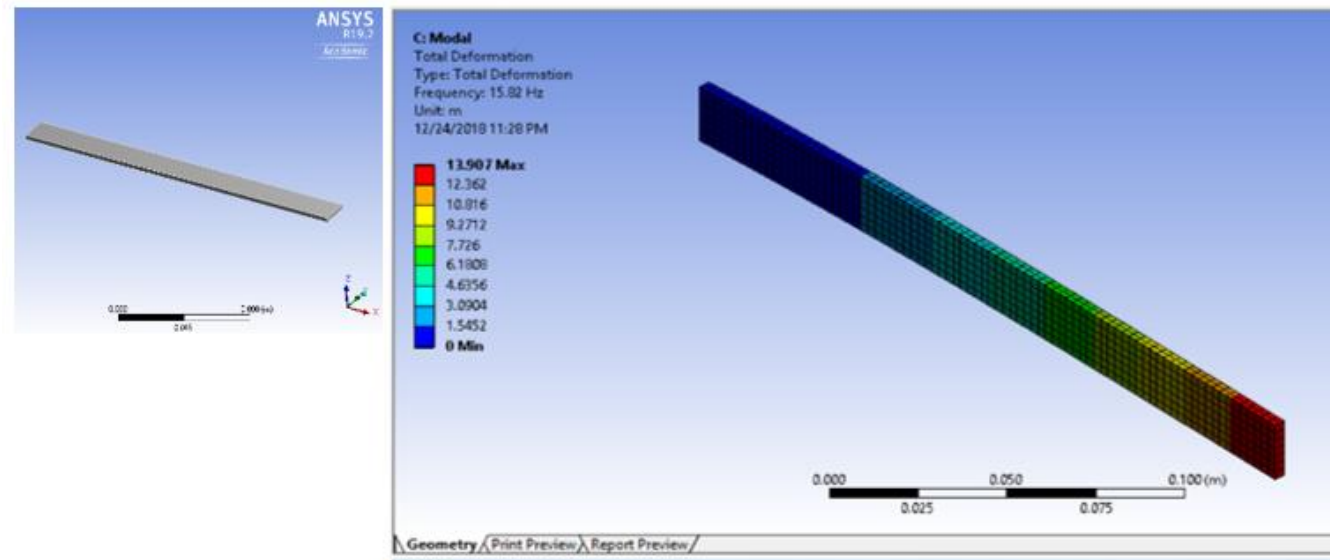

\section{ANSYS} Acodermic
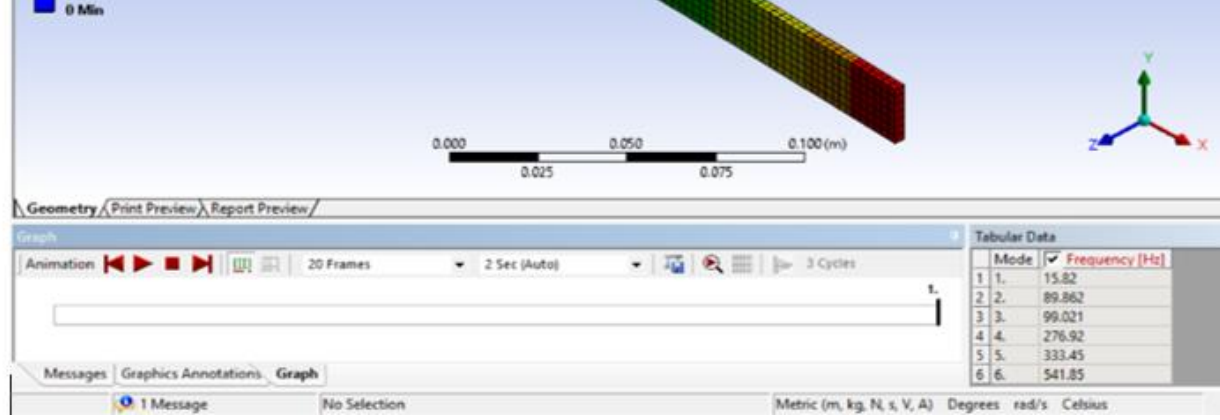

Figure 12: First mode shape for build orientation $X Y Z$

The FEM results conducted in Ansys can also readily generate the mode shapes for visual validation of results. Since the software can easily determine a range of modal frequencies and shapes, the user can then select and isolate the results for the first modal frequency that does not display any twist or torsion. The bending mode shape associated with the fundamental frequency for the XYZ orientation, only contains bending and (no twist), as can be seen in Figure 12.

The FEM analysis was conducted for all build orientations, with actual 3D printed test specimen dimensions, modeled and simulated for the final modal frequency analysis presented in Table 4, 
Table 5 andTable 6, and Figure 12Figure 13 andFigure 14. 
Table 4: Table of modal frequencies for orientation $\mathrm{XYZ}$

\begin{tabular}{|c|c|}
\hline Mode & $\begin{array}{c}\text { Frequency } \\
{[\mathrm{Hz}]}\end{array}$ \\
\hline 1. & 15.82 \\
\hline 2. & 89.862 \\
\hline 3. & 99.021 \\
\hline 4. & 276.92 \\
\hline 5. & 333.45 \\
\hline 6. & 541.85 \\
\hline
\end{tabular}

The second sample was modelled with build orientaion of XZY.

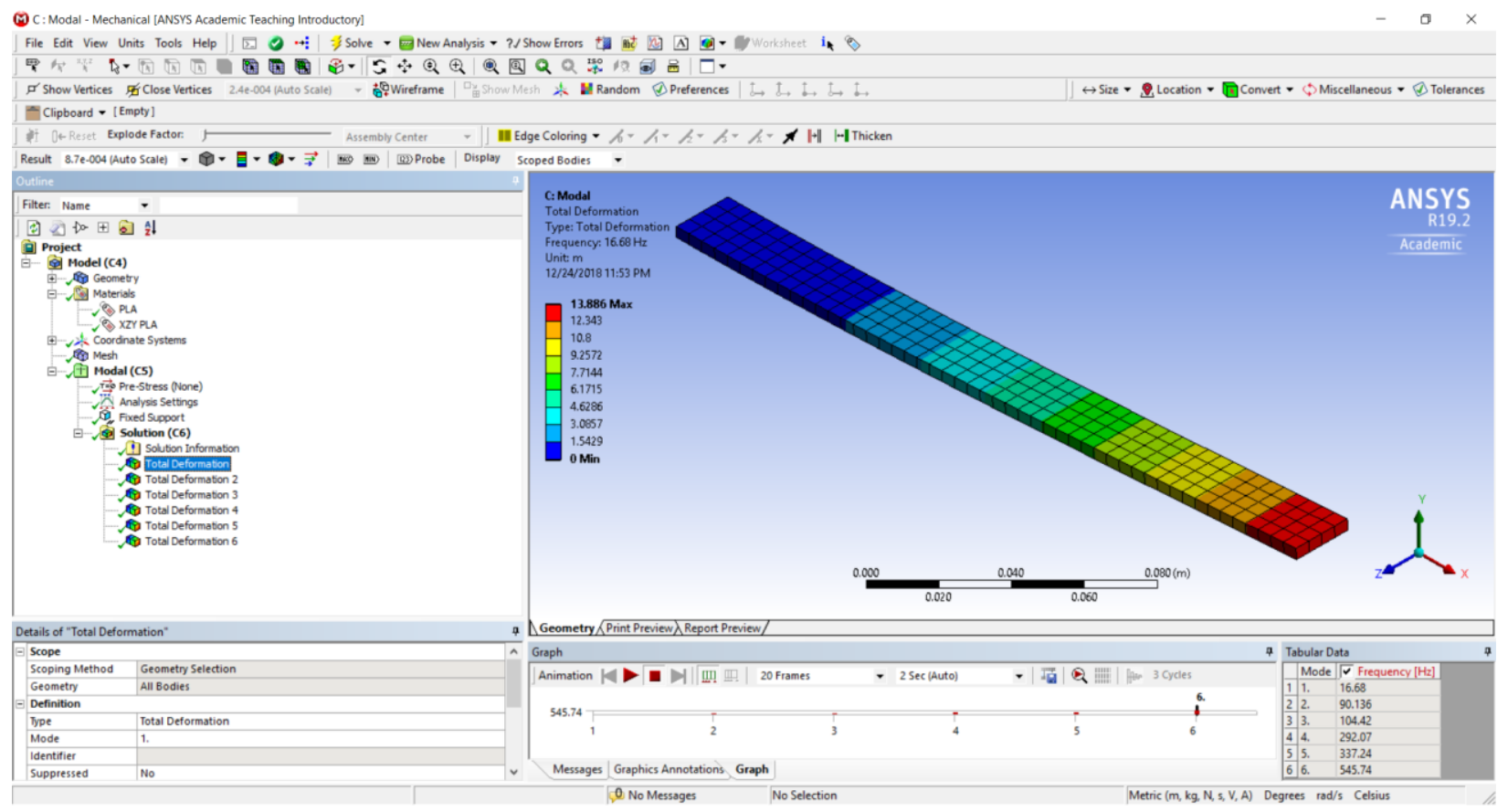

Figure 13: First mode shape for build orientation XZY 
Table 5: Modal frequencies table for XZY

\begin{tabular}{|c|c|}
\hline Mode & $\begin{array}{c}\text { Frequency } \\
{[\mathrm{Hz}]}\end{array}$ \\
\hline 1. & 16.68 \\
\hline 2. & 90.136 \\
\hline 3. & 104.42 \\
\hline 4. & 292.07 \\
\hline 5. & 337.24 \\
\hline 6. & 545.74 \\
\hline
\end{tabular}

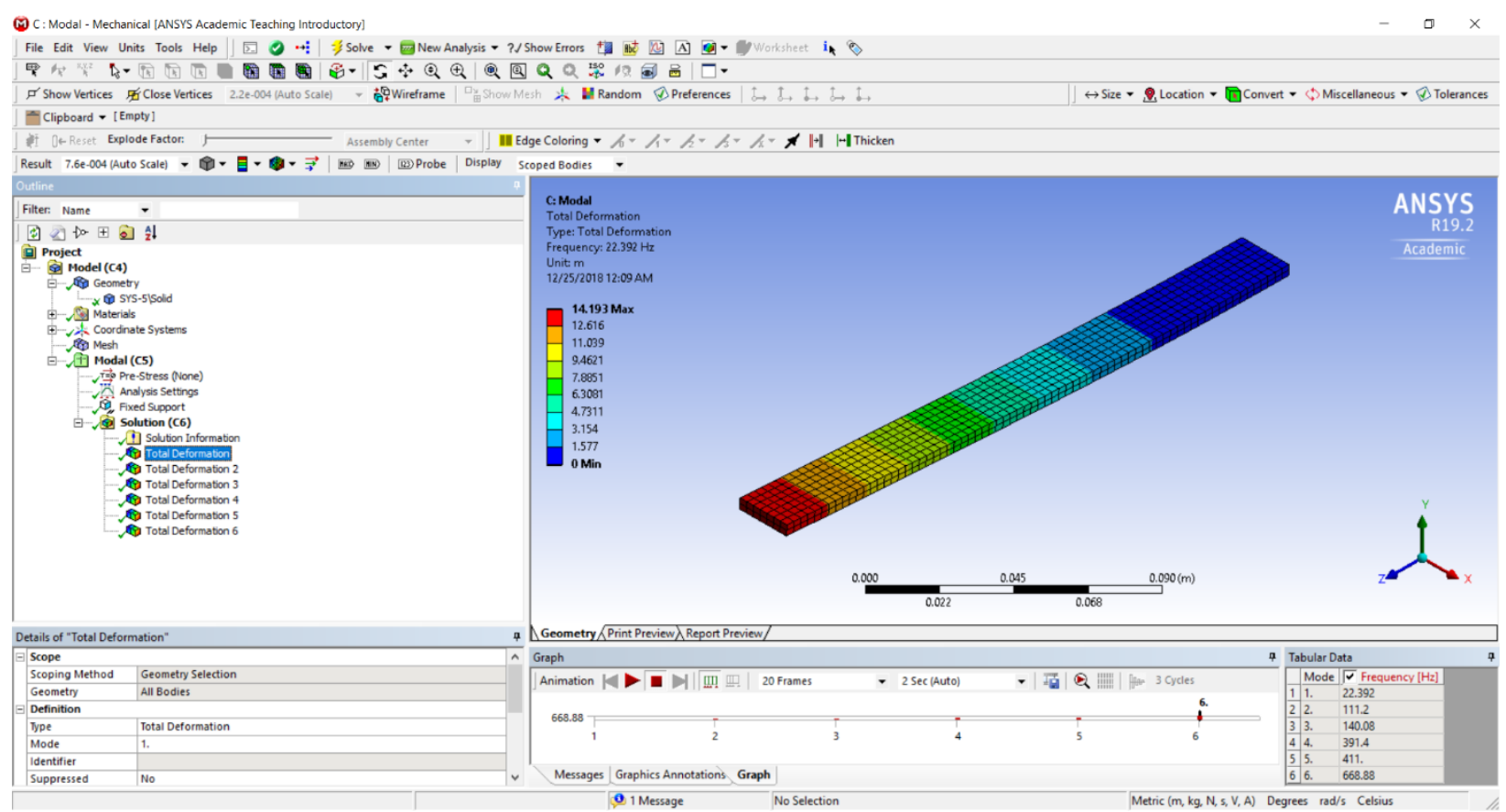

Figure 14: First mode shape for build orientation $Z X Y$ 


\section{Table 6: Modal frequencies table for ZXY}

\begin{tabular}{|c|c|}
\hline Mode & $\begin{array}{c}\text { Frequency } \\
{[\mathrm{Hz}]}\end{array}$ \\
\hline 1. & 22.392 \\
\hline 2. & 111.2 \\
\hline 3. & 140.08 \\
\hline 4. & 391.4 \\
\hline 5. & 411. \\
\hline 6. & 668.88 \\
\hline
\end{tabular}

The Young's modulus results obtained from the traditional tensile test are presented in Table 7. The tensile test results are used as a benchmark for comparison with the IET experimental results. The FEM analysis is also based on the results of the tensile test, as mentioned earlier. 
Table 7: Tensile test results for Young's modulus

\begin{tabular}{|c|c|c|c|c|}
\hline $\begin{array}{c}\text { Build } \\
\text { Orientation }\end{array}$ & $\begin{array}{c}\text { Max force } \\
\text { (lbf) }\end{array}$ & $\begin{array}{l}\text { Failure Stress } \\
\qquad(p s i)\end{array}$ & $\begin{array}{c}\text { Strength } \\
\text { (MPa) }\end{array}$ & $\begin{array}{c}\mathbf{E} \\
(\mathbf{G P a})\end{array}$ \\
\hline XYZ & 633.576 & 8767.719 & 60.4513 & 3.108 \\
\hline XYZ & 581.239 & 8045.874 & 55.474 & 3.026 \\
\hline $\mathrm{XYZ}$ & 543.048 & 7584.888 & 52.295 & 3.295 \\
\hline XYZ & 596.226 & 8354.298 & 57.600 & 3.110 \\
\hline \multirow[t]{4}{*}{ XYZ } & 615.650 & 8613.430 & 59.387 & 3.212 \\
\hline & & Average & 57 & 3.15 \\
\hline & & Standard Deviation & 3.26 & 0.1 \\
\hline & & $\mathrm{CV}$ & $5.70 \%$ & $3.30 \%$ \\
\hline ZXY & 512.349 & 6831.565 & 47.102 & 2.994 \\
\hline ZXY & 485.754 & 6044.210 & 41.673 & 2.866 \\
\hline ZXY & 511.049 & 6390.210 & 44.058 & 2.835 \\
\hline \multirow[t]{4}{*}{ ZXY } & 501.742 & 6709.263 & 46.258 & 2.972 \\
\hline & & Average & 44.8 & 2.92 \\
\hline & & Standard Deviation & 2.43 & 0.08 \\
\hline & & $\mathrm{CV}$ & $5.40 \%$ & $2.70 \%$ \\
\hline XZY & 674.218 & 9194.757 & 63.395 & 3.115 \\
\hline $\mathrm{XZY}$ & 672.535 & 9188.890 & 63.355 & 3.148 \\
\hline $\mathrm{XZY}$ & 666.527 & 9097.895 & 62.727 & 3.090 \\
\hline $\mathrm{XZY}$ & 667.800 & 9047.839 & 62.382 & 3.145 \\
\hline \multirow[t]{4}{*}{$\mathrm{XZY}$} & 668.076 & 9047.410 & 62.379 & 3.091 \\
\hline & & Average & 62.800 & 3.120 \\
\hline & & Standard Deviation & 0.5 & 0.03 \\
\hline & & $\mathrm{CV}$ & $0.80 \%$ & $0.90 \%$ \\
\hline
\end{tabular}


The IET Young's modulus results from Table 4 are averaged for each build orientation (first two results have been omitted for the two extra test specimens printed i.e.1-0 XYZ and 1-1 XYZ, for better accuracy and consistency of samples), and are compared to the average Young's modulus results from Table 7 obtained through the tensile tests (please refer to Table 8.)

Table 8: Comparison of Young's modulus results from IET and tensile test

\begin{tabular}{|c|c|c|c|}
\hline $\begin{array}{c}\text { Build } \\
\text { Orientation }\end{array}$ & $\begin{array}{c}\mathbf{E} \\
(\mathbf{G P a}) \\
\text { IET }\end{array}$ & $\begin{array}{c}\mathbf{E} \\
(\mathbf{G P a})\end{array}$ & $\begin{array}{c}\text { Deviation } \\
\text { Tensile }\end{array}$ \\
\hline $\mathrm{XYZ}$ & 3.31 & 3.15 & 5.1 \\
\hline $\mathrm{XZY}$ & 3.06 & 3.12 & 2.0 \\
\hline $\mathrm{ZXY}$ & 2.80 & 2.92 & 4.1 \\
\hline
\end{tabular}

As can be seen from Table 8 , the comparison provides a very good agreement of results with the most deviation recorded as $5.1 \%$ in the $\mathrm{XYZ}$ build orientations. 


\section{CONCLUSION AND FUTURE WORK}

The IET experimentation carried out was found to be a rapid, global, result oriented technique for accurately finding the Young's modulus for 3D printed PLA Euler-Bernoulli beams. Compared to the traditional tensile tests, IET provided unlimited repetitive results due to the non-destructive nature of the experimentation. In corroboration of previous IET works, the experimentation for this project provided excellent results.

The tests and numerical modeling were carried out for 3D printed PLA, with three build orientations namely, XYZ, XZY and ZXY. The build orientation XZY proved challenging in generating results through the use of the laser sensor. This could be associated with the laser beam diffraction observed in printed material. This issue was addressed by adding small stickers to the beam incidence point. The results from the IET experimentation, the tensile tests and the FEM Modal analysis were found to be in close agreement with each other with a maximum error of $5.1 \%$.

\subsection{RECOMMENDATIONS FOR FUTURE WORK}

The IET as discussed in the project can be used to evaluate various elastic properties for a wide variety of materials included 3D printed. This can include thin films and coatings that can be produced much cheaply and still provide results readily. Other factors such as temperature and moisture, already the focus of some research, can also be tested without relying on manufacturer specs for the bulk material. Apart from elastic properties damping characteristics can be evaluated with applications for passive damping materials in aircraft interior components and fittings to structural design for specific components marked for weight saving initiatives. As 
indicated earlier, in this report the same data for this project can also be used to calculate the damping properties of the 3D printed PLA beams.

Another applicable area can be testing of MEMs components, using the same equipment sensors, by measuring displacement on a nano-scale; the DAQ can capture frequencies up to 20 $\mathrm{kHz}$.

Research can also focus on comparison between different boundary conditions, and other variations of the experimentation methodology, to develop a better understanding of the technique's applicability.

The IET's health diagnostic capabilities can be exploited for performing model-based damage detection using the current experimental setup along with DAQ. 
APPENDICES 
APPENDIX A EXPERIMENTATION SETUP AND RESULTS 
3D model for laser sensor mount in Catia V5 and 3D printed result

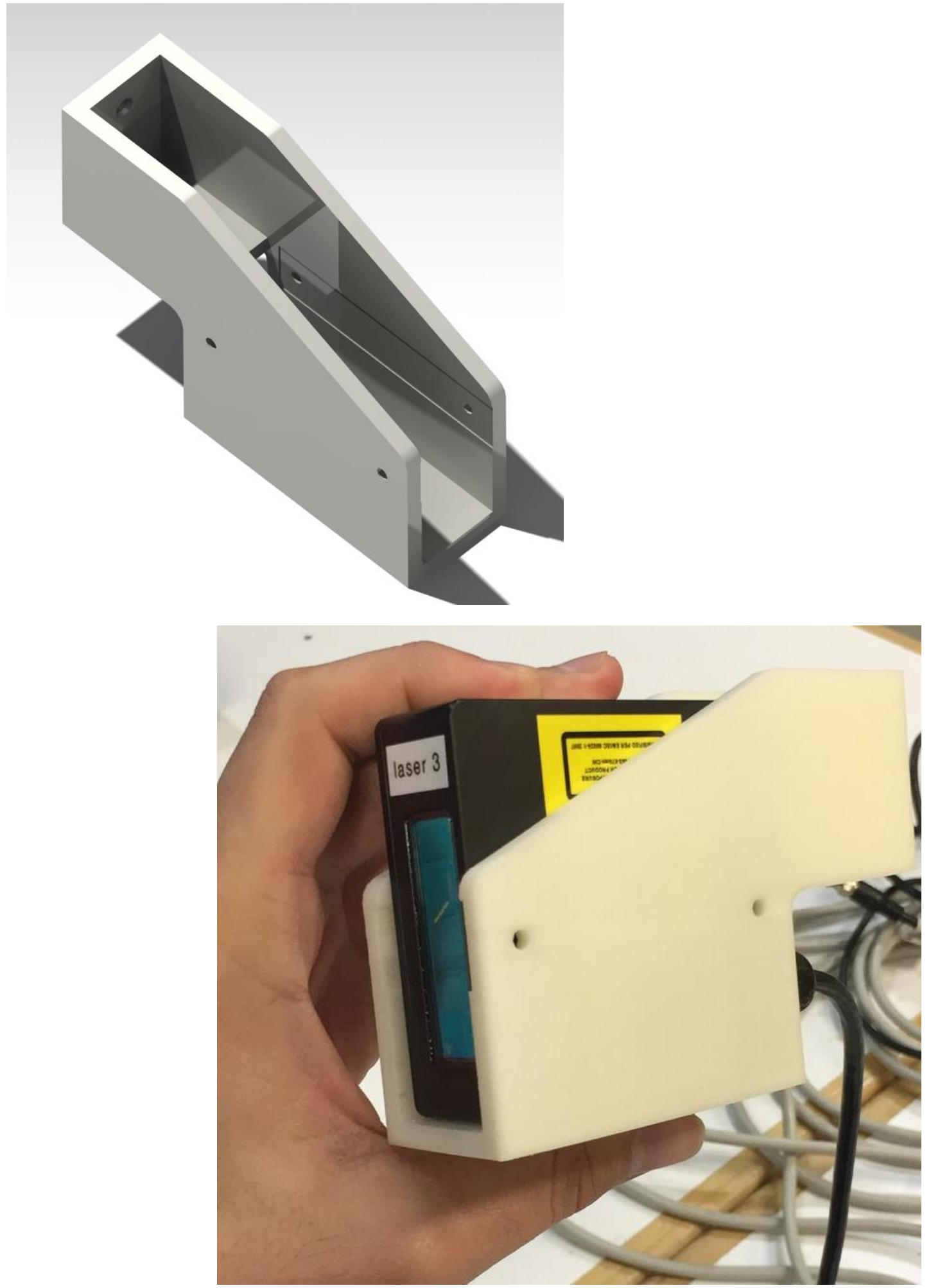


APPENDIX A2 3D CAD EXPERIMENTATION SETUP DESIGN

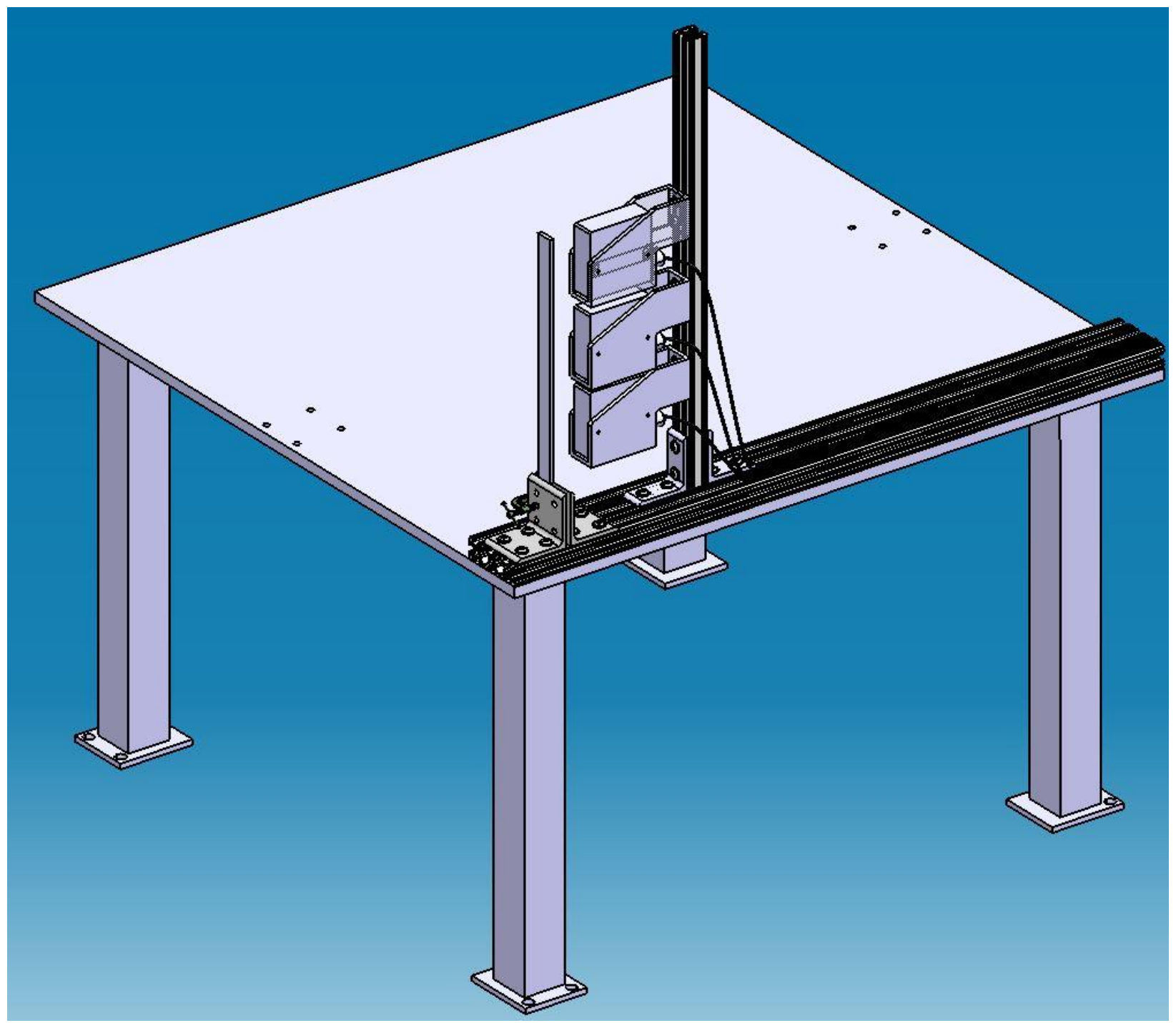


Actual test setup with the specimen clamped in front of the sensors

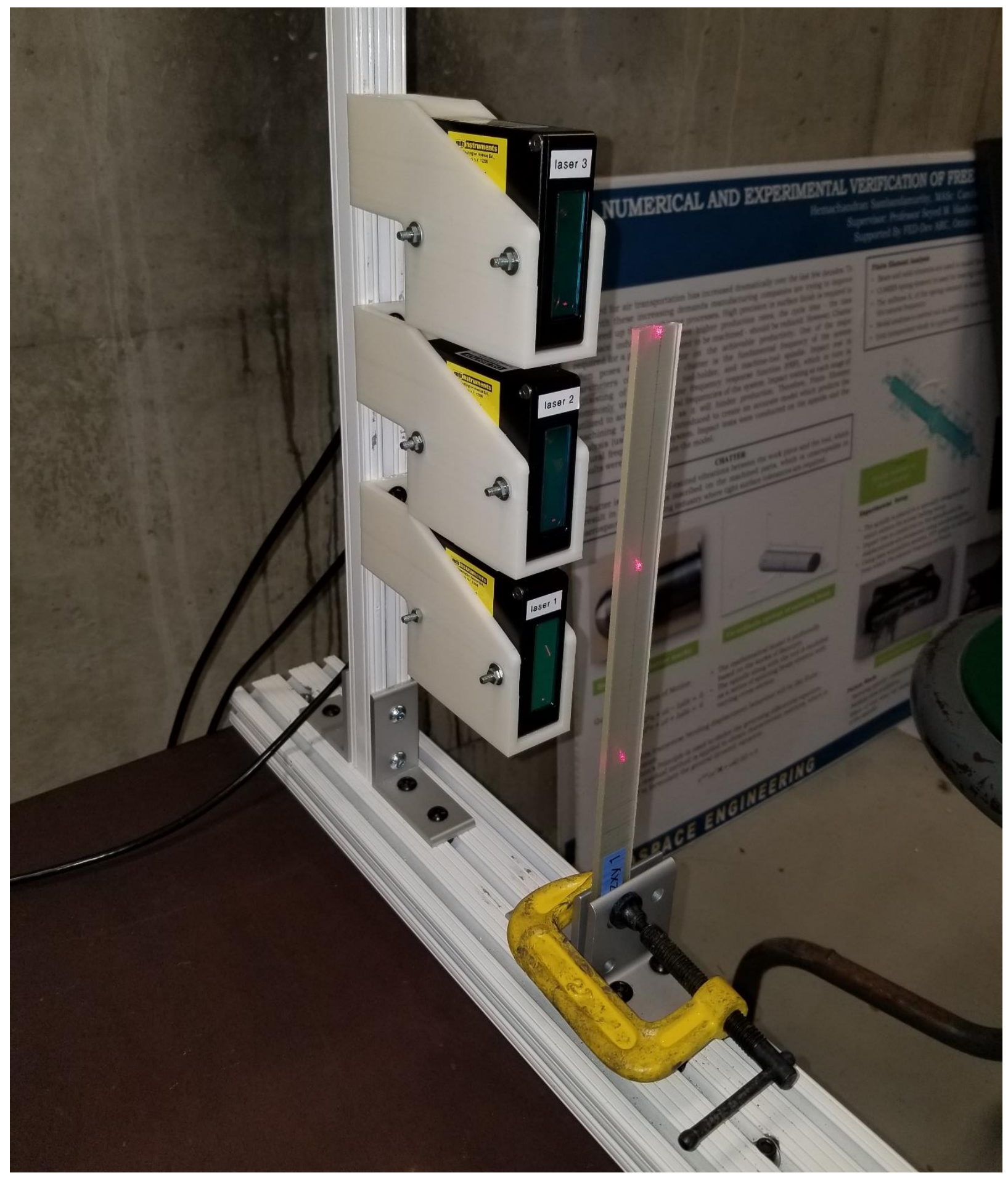


APPENDIX A3 SUMMARY OF REPORTED TEST SPECIMENS

\begin{tabular}{|c|c|c|c|c|c|c|c|c|}
\hline $\begin{array}{c}\mathbf{L} \\
(\mathbf{m m})\end{array}$ & $\begin{array}{c}\mathbf{W} \\
(\mathbf{m m})\end{array}$ & $\begin{array}{c}\mathbf{T} \\
(\mathbf{m m})\end{array}$ & MATERIAL & BC & Env & NAME & YR & $\begin{array}{l}\text { ADDITIONAL } \\
\text { INFO }\end{array}$ \\
\hline $\begin{array}{c}230 \\
\text { or } \\
340\end{array}$ & 50 & $\begin{array}{c}2,2.6 \\
3, \\
3.7,4 \\
5,5\end{array}$ & $\begin{array}{l}\text { wood } \\
\text { comp }\end{array}$ & Clamped & $\begin{array}{c}\text { Relative } \\
\text { Humidity } \\
\text { of 03+- } \\
5 \% \text { and } \\
\text { Temp of } \\
20+-2 \\
\text { degree } \\
\text { Centigra } \\
\text { de }\end{array}$ & $\begin{array}{l}\text { Determining } \\
\text { shear modulus } \\
\text { of thin wood } \\
\text { composite } \\
\text { materials using } \\
\text { a cantilever } \\
\text { beam vibration } \\
\text { method, Cheng } \\
\text { Guan, Houjiang } \\
\text { Zhang, John } \\
\text { F.Hunt, } \\
\text { Haicheng Yan. }\end{array}$ & 2015 & $\begin{array}{c}\text { To minimize } \\
\text { Vibrational } \\
\text { shear effects, } \\
\text { the ratio of free } \\
\text { length to } \\
\text { thickness of } \\
\text { specimen should } \\
\text { be greater than } \\
14.5,\end{array}$ \\
\hline 400 & 40 & 30 & $\begin{array}{l}\text { Carbon } \\
\text { fiber }\end{array}$ & $\begin{array}{c}\text { Clamped } \\
50\end{array}$ & & $\begin{array}{c}\text { Study of free } \\
\text { vibration } \\
\text { charachteristics } \\
\text { of carbon epoxy } \\
\text { based composite } \\
\text { beams, } \\
\text { R.Ramesh } 2015\end{array}$ & & \\
\hline 350 & 25 & 25 & Styrofoam & $\begin{array}{l}\text { Supporte } \\
\mathrm{d} \text { at mid- } \\
\text { lent, } \\
\text { free-free }\end{array}$ & & $\begin{array}{c}\text { 45easurement } \\
\text { young modulus } \\
\text { and shear } \\
\text { modulus of } \\
\text { polystyrene } \\
\text { foam by } \\
\text { longitudinal and } \\
\text { flexural vibratio, } \\
\text { Hiroshi } \\
\text { Yoshihara } 2018\end{array}$ & & \\
\hline 160 & 25 & $2.9-3$ & $\begin{array}{l}\text { Carbon fiber / } \\
\text { liquid MMA } \\
\text { resin, Carbon / } \\
\text { Epoxy }\end{array}$ & $\begin{array}{c}\text { Clamped } \\
30\end{array}$ & & $\begin{array}{c}\text { Enhanced } \\
\text { Vibration } \\
\text { damping and } \\
\text { dynamic } \\
\text { mechanical } \\
\text { charachteristics } \\
\text { of composites } \\
\text { with novel } \\
\text { pseudo- } \\
\text { thermoset } \\
\text { matrix system, } \\
\text { Somen K. } \\
\text { Bhudolia, 2017 }\end{array}$ & & $\begin{array}{l}\text { impact hammer } \\
\text { position at } 15 \% \\
\text { of free beam, } \\
\text { ASTM E756-05 }\end{array}$ \\
\hline
\end{tabular}




\begin{tabular}{|c|c|c|c|c|c|c|c|c|}
\hline $\begin{array}{c}\mathbf{L} \\
(\mathbf{m m})\end{array}$ & $\begin{array}{c}\mathbf{W} \\
(\mathbf{m m})\end{array}$ & $\begin{array}{c}\mathbf{T} \\
(\mathbf{m m})\end{array}$ & MATERIAL & BC & Env & NAME & YR & $\begin{array}{l}\text { ADDITIONAL } \\
\text { INFO }\end{array}$ \\
\hline $\begin{array}{c}210,22 \\
0, \\
280\end{array}$ & 10 & $\begin{array}{l}1.96, \\
2.01, \\
3.86\end{array}$ & $\begin{array}{c}\text { Glare, 2024- } \\
\text { T3 }\end{array}$ & Clamped & & $\begin{array}{l}\text { Charactrization } \\
\text { of the elastic } \\
\text { and damping } \\
\text { propersties of } \\
\text { traditional FML } \\
\text { and FML based } \\
\text { on a self } \\
\text { reinforced } \\
\text { polypropylene, } \\
\text { J. Iriondo, 2015 }\end{array}$ & & $\begin{array}{l}\text { ASTM E756- } \\
05,\end{array}$ \\
\hline 250 & 25 & 4 & Jute / Epoxy & Clamped & & & & $\begin{array}{l}\text { ASTM E756- } \\
05,\end{array}$ \\
\hline 200 & 60 & 3 & Aluminum & $\begin{array}{c}\text { Clamped } \\
\text { to Iron } \\
\text { Mass of } \\
\text { 30kg No } \\
\text { reasonin } \\
\mathrm{g}\end{array}$ & & $\begin{array}{l}\text { Measurement of } \\
\text { vibrational } \\
\text { modal } \\
\text { parameters } \\
\text { using laser pulse } \\
\text { excitation } \\
\text { techniques, P. } \\
\text { Castellini, 2003 }\end{array}$ & 2004 & $\begin{array}{l}\text { Impact Hammer } \\
23 \mathrm{~g}\end{array}$ \\
\hline 300 & 40 & 2 & Steel & Clamped & & $\begin{array}{c}\text { Feasibility } \\
\text { Analysis of } \\
\text { using } \\
\text { piezoceramic } \\
\text { transducers for } \\
\text { cantilever beam } \\
\text { modal testing, } \\
\text { Bor-Tsuen } \\
\text { Wang, } 1996\end{array}$ & 1997 & \\
\hline 550 & 25 & 10 & $\begin{array}{l}\text { Mild Steel \& } \\
\text { Aluminum }\end{array}$ & Clamped & & $\begin{array}{c}\text { Investigation on } \\
\text { modal } \\
\text { parameers of } \\
\text { rectangular } \\
\text { cantilever beam } \\
\text { using } \\
\text { Experimental } \\
\text { modal analysis, } \\
\text { Walunj Prashant } \\
\text { S., 2015 }\end{array}$ & 2015 & \\
\hline
\end{tabular}


APPENDIX B LAB MANUAL 


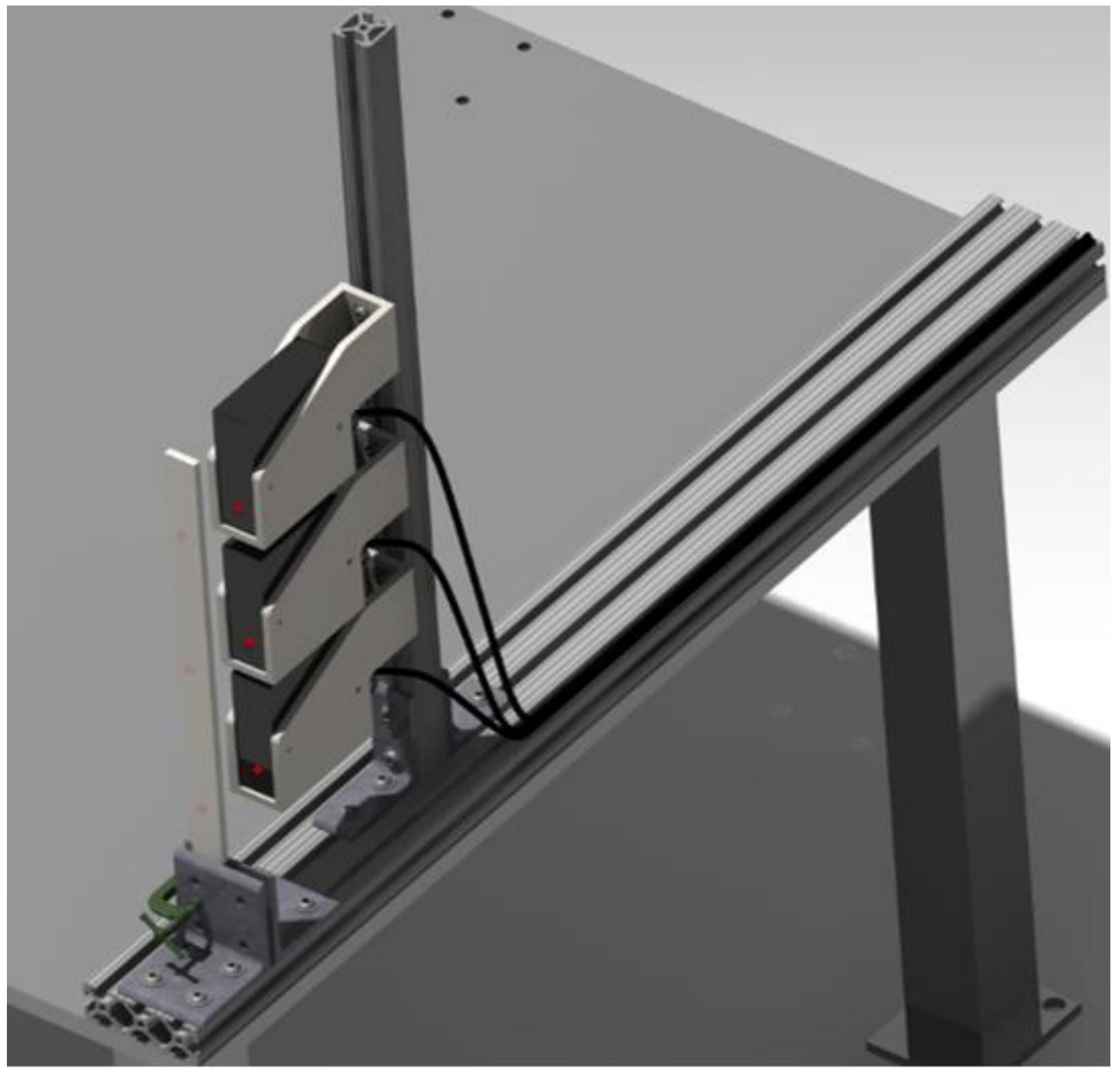

Dynamic Investigation through Laser sensors

LAB MANUAL

Mohsin Afridi | MEng Project | 5-12-18 


\section{Important Information}

The Ryerson University FRAMES Lab is equipped with various structural and material analysis sensors, equipment, hardware and software. The focus of this manual is on Dynamic Investigation through use of Laser sensors.

This how-to document is a complete systematic process of setting up a dynamic Investigation using the available equipment Ryerson FRAMES Lab.

Since the experimental setup involves a number of equipment from different vendors and each vendor provides a setup or functional manual going though each one and them determining issues such as compatibility etc. can be a tedious process.

The setup sequence for ease of setup:

1. Sensor and Hardware setup

2. Software setup

3. Sensor placement and Equipment Integration

\section{Sensor \& hardware setup}

The Hardware equipment involved in the setup include the following:

- $\quad$ Laser sensors (Mti Instruments Microtrak III Laser Sensors)

- Piezoelectric sensor (Dytran Dynapulse 5800B4)

- $\quad$ Laser Sensor Interface (Duram Instruments) 
- $\quad$ Data Amplifier Unit (HBM X400A)

- Bench Power Supply and

- $\quad$ PC/ Laptop

\section{Sensors}

The Laser sensor has the following effective range and proposed orientation for reliable results.

Students should refer to the detailed specification provided by the manufacturer for a better understanding of the limitations and range and other factors affecting the performance of the sensor. Following are specs and setup orientation illustrations from the Manufacturers Brochure:
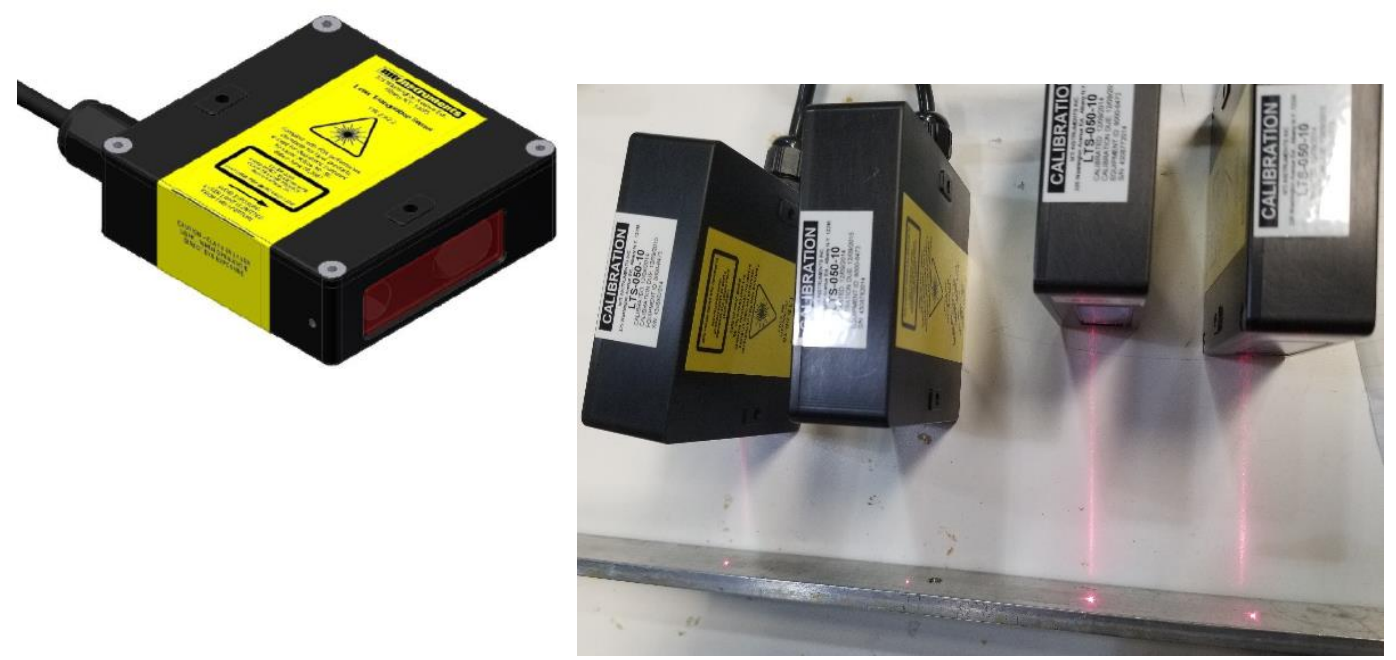

Figure 2: Laser displacement sensor

\begin{tabular}{|c|c|c|c|c|c|c|c|c|c|c|c|c|}
\hline Produ & Info & Technical S & cificatio & & & & & & & & & \\
\hline $\mathrm{P} / \mathrm{N}$ & Model & $\begin{array}{l}\text { Measurement } \\
\text { Range }\end{array}$ & Accuracy & $\begin{array}{l}\text { Min. } \\
\text { Range }\end{array}$ & $\begin{array}{l}\text { Stand- } \\
\text { Off }\end{array}$ & Resolution & Noise & $\begin{array}{l}\text { Spot } \\
\text { Size }\end{array}$ & Interface & Type & $\begin{array}{l}\text { Frequency } \\
\text { Response }\end{array}$ & $\begin{array}{l}\text { Request } \\
\text { Info }\end{array}$ \\
\hline $\begin{array}{l}8000- \\
6473\end{array}$ & $\begin{array}{l}\text { LTS- } \\
050-10\end{array}$ & $\begin{array}{l}10 \mathrm{~mm} \\
(0.39 ")\end{array}$ & $\begin{array}{l}0.03 \% \\
\text { FSO }\end{array}$ & $\begin{array}{l}43.75 \mathrm{~mm} \\
(1.71 ")\end{array}$ & $\begin{array}{l}50 \mathrm{~mm} \\
\left(1.95^{\prime \prime}\right)\end{array}$ & $0.191 \mu \mathrm{m}$ & $\begin{array}{l}1.625 \\
\mu \mathrm{m} \\
\mathrm{RMS}\end{array}$ & $\begin{array}{l}36 \\
\mu \mathrm{m}\end{array}$ & $\begin{array}{l}\text { RS485 } \\
\text { to USB }\end{array}$ & $\begin{array}{l}\text { RED Laser, 3R } \\
\text { Laser Class }\end{array}$ & $20 \mathrm{kHZ}$ & $\begin{array}{l}\text { Request } \\
\text { Info }\end{array}$ \\
\hline
\end{tabular}


Table 1: Laser Sensor Manufacturer's specification
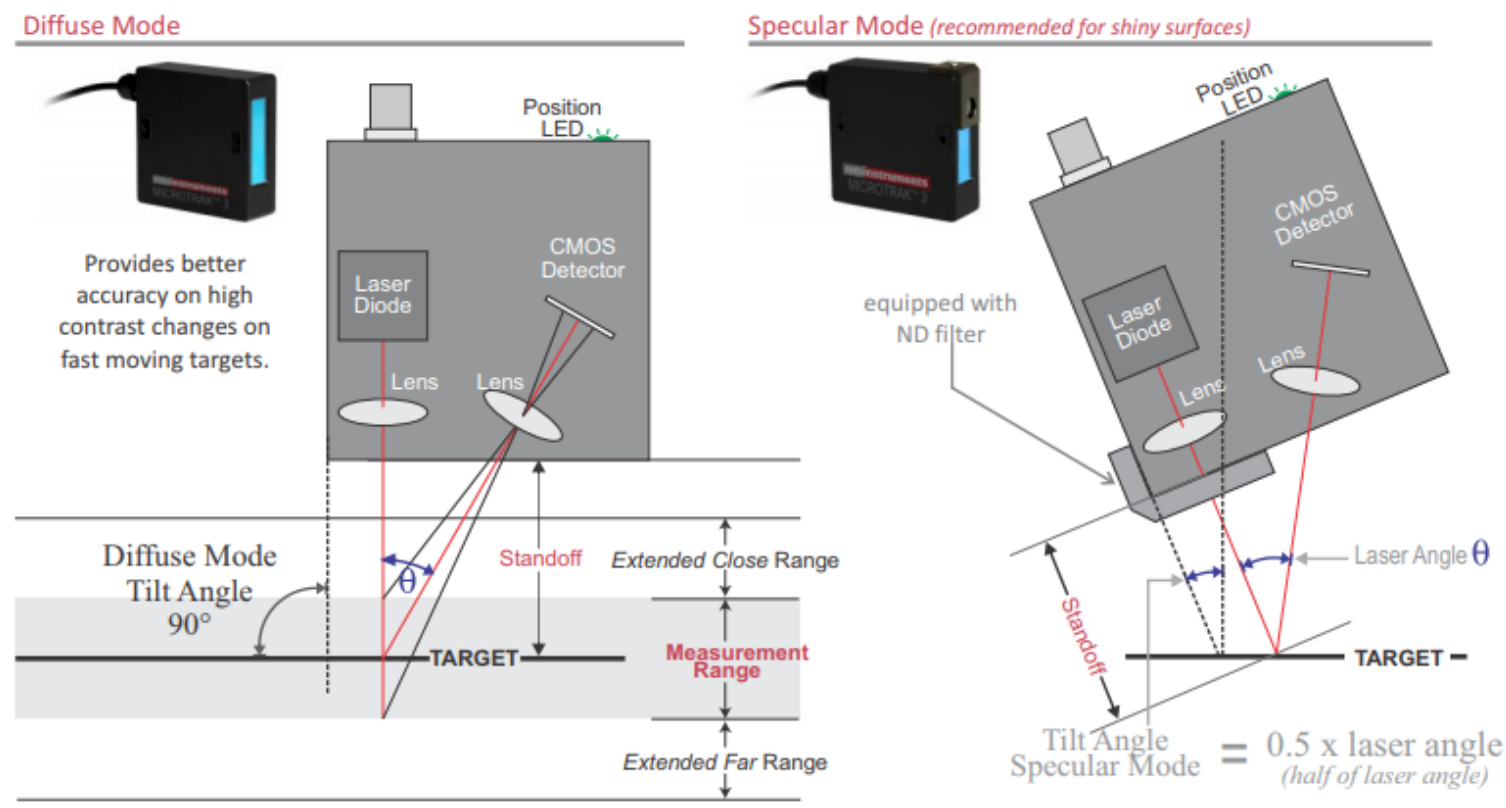

Figure 3: Laser displacement sensor mode of operation and range schematic

\section{Piezoelectric sensor}

The Dytran Dynapulse 5800B4 contains a piezoelectric sensor that can be directly connected to the Amplifier channel for DAQ. Below is an image of the Impulse hammer with integrated sensor.

NOTE: A soft, silicone tip is recommended for elastic impulses at low frequencies.

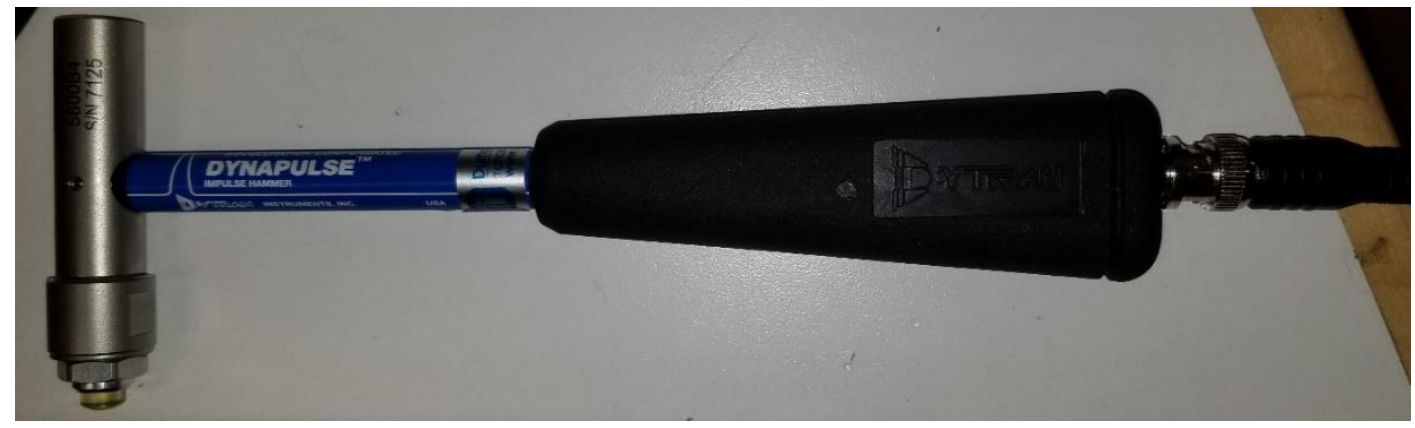




\section{Sensor Interface}

The Laser sensor Interface from Durham Instruments connects directly to the Laser sensors and the Data Acquisition Unit.

As per the illustrations below, the connection for both Laser sensors and the Data Acquisition Unit, have labels on each side with each connector individually labelled for quick tracing of individual sensors.

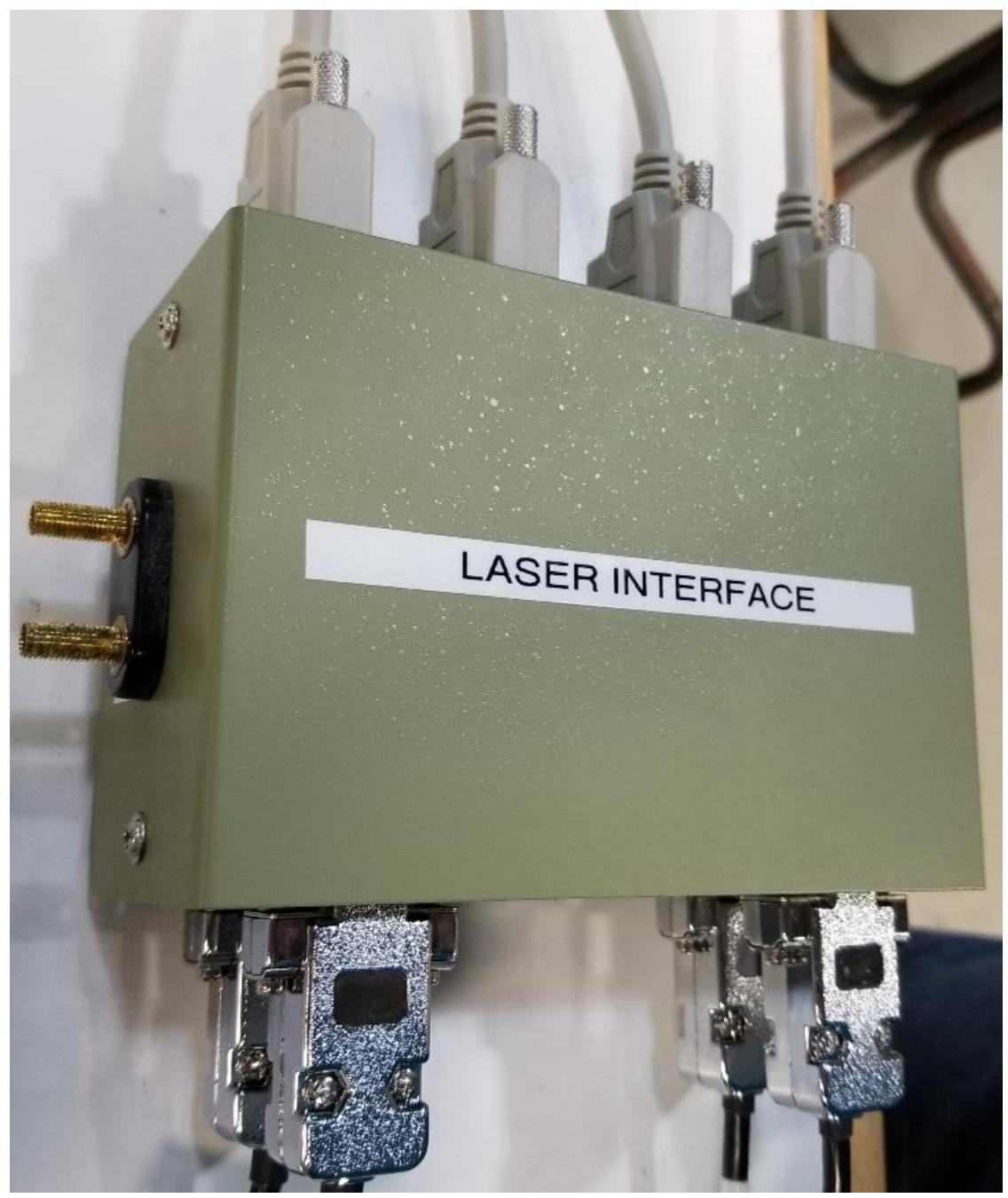

Figure 4: Laser Interface top-iso view illustrating sensor and amplifier connections 


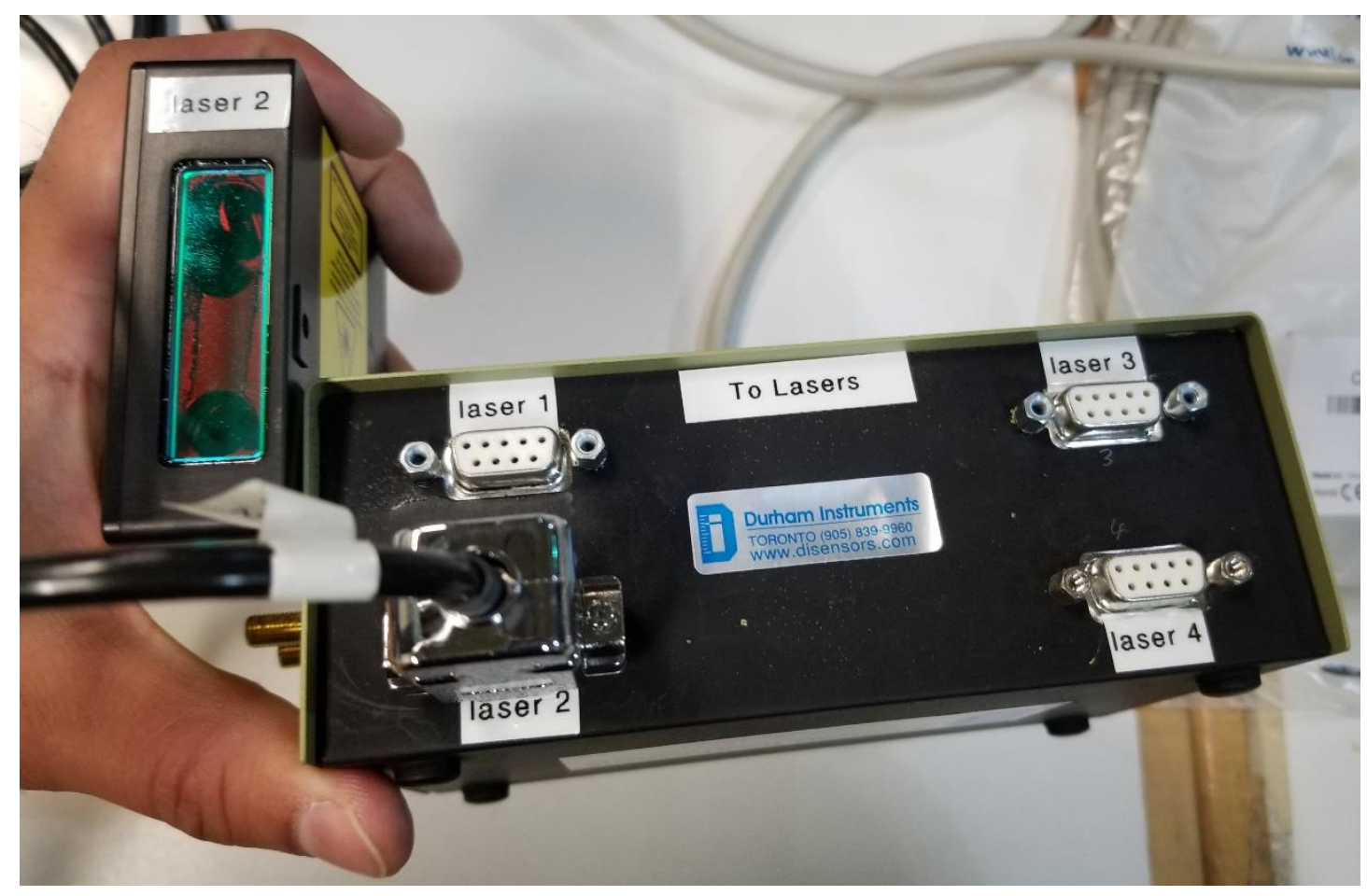

Figure 5: Laser Interface illustrating sensor connections labelled for each sensor 


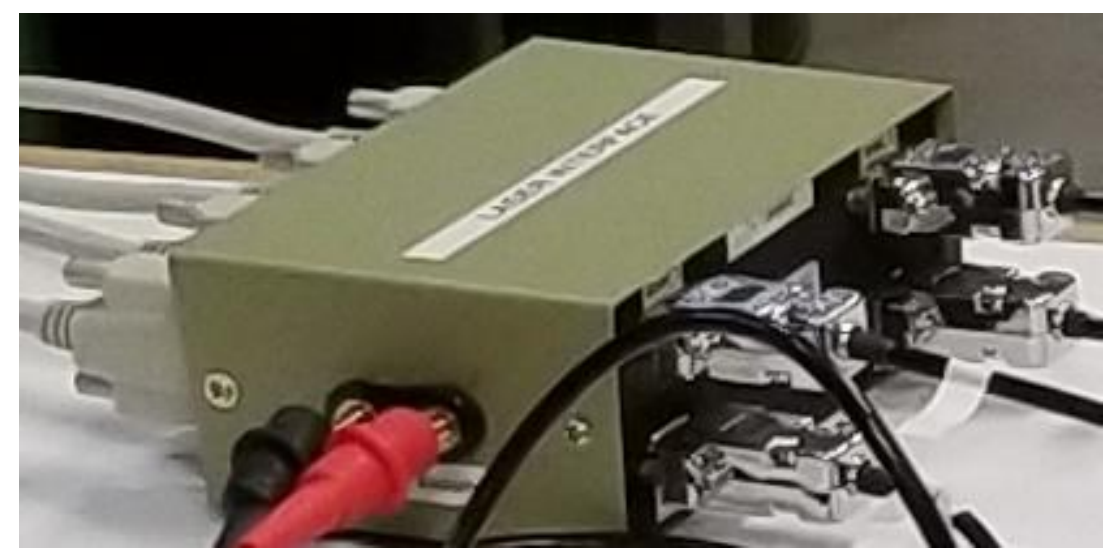

Figure 6: Laser Interface illustrating the power input terminals on the left side

NOTE: Please note the Orientation of the Bench Power Source terminals connected on the side of the Interface unit. Wrong terminals will not power up the laser sensors properly.

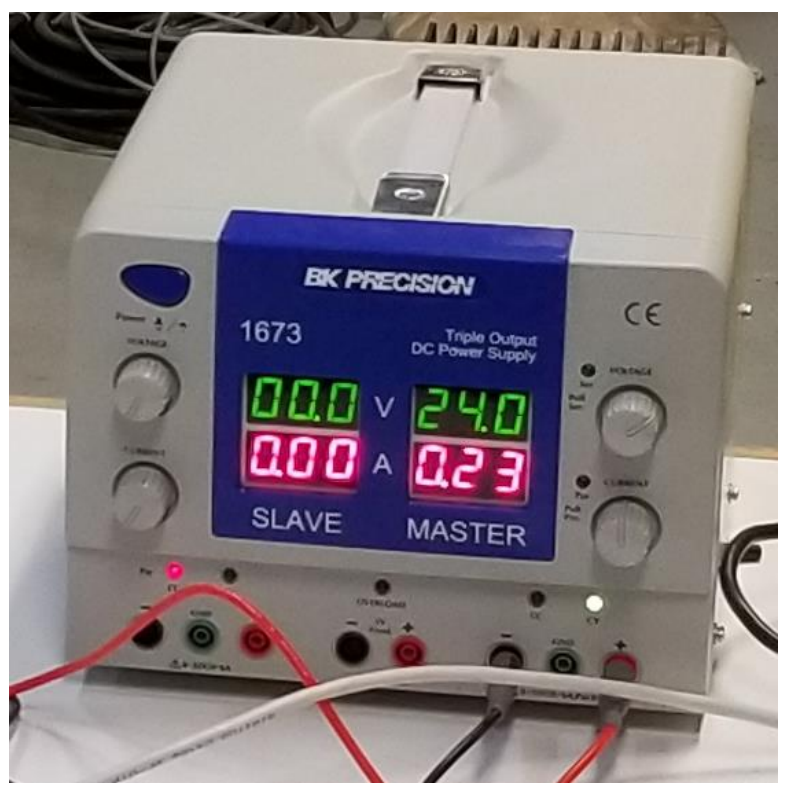

Figure 7: Bench Power Unit

The Laser sensors also derive their power from the Bench power supply connection. As per the laser requirements, the Bench voltage is set to nominal 24 Volt as per manufacturer specs.

Amplifier Unit 
The Amplifier unit is an HBM X400A model that has four input channels for four sensors. The unit has its own separate power connection. Once the HBM DAQ software is installed, the user can control the blinking of these LEDs to test the connection status and location of each sensor connection.

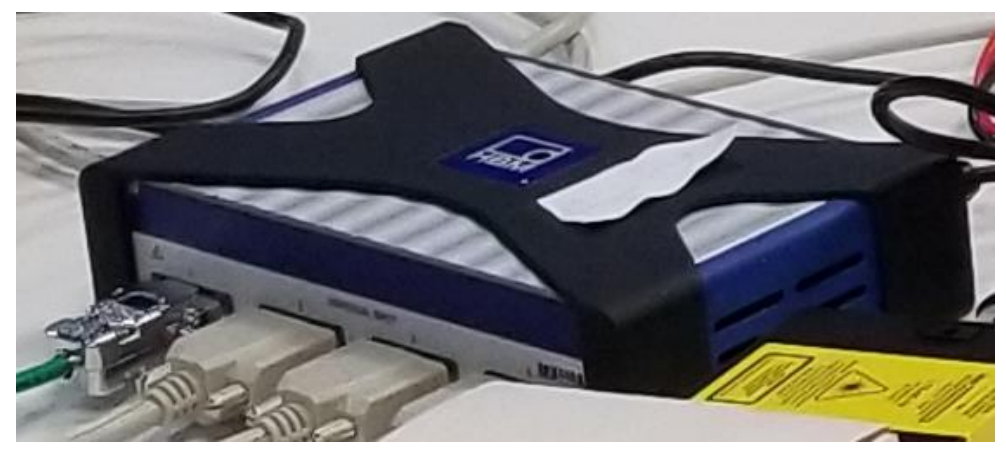

Figure 8: HBM X400A in DAQ setup

The Amplifier Unit is connected to the PC through an Ethernet Cable. For more details the link to manufacturer specification brochure is provided in the hyperlink on image below 


\title{
QUANTUMX MX440A
}

\section{Universal amplifier}

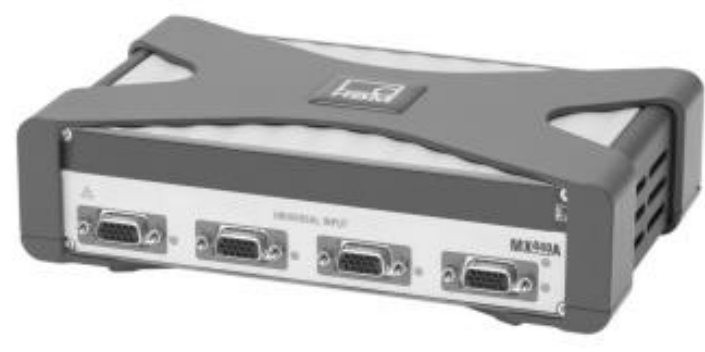

\author{
Special features
}
-4 individually configurable inputs (electrically isolated)
- Connection of more than 12 transducers technologies
- Data rate: up to $19,200 \mathrm{~Hz}$
- 24-bit A/D converter per channel for synchronous, parallel measurements
- Active low pass filter
- TEDS support
- Supply voltage (DC): $10 \mathrm{~V} . . .30 \mathrm{~V}$
- Supply voltage for active transducers (DC): 5 V ... $24 \mathrm{~V}$

Figure 9: HBM X400A four channel amplifier unit. 


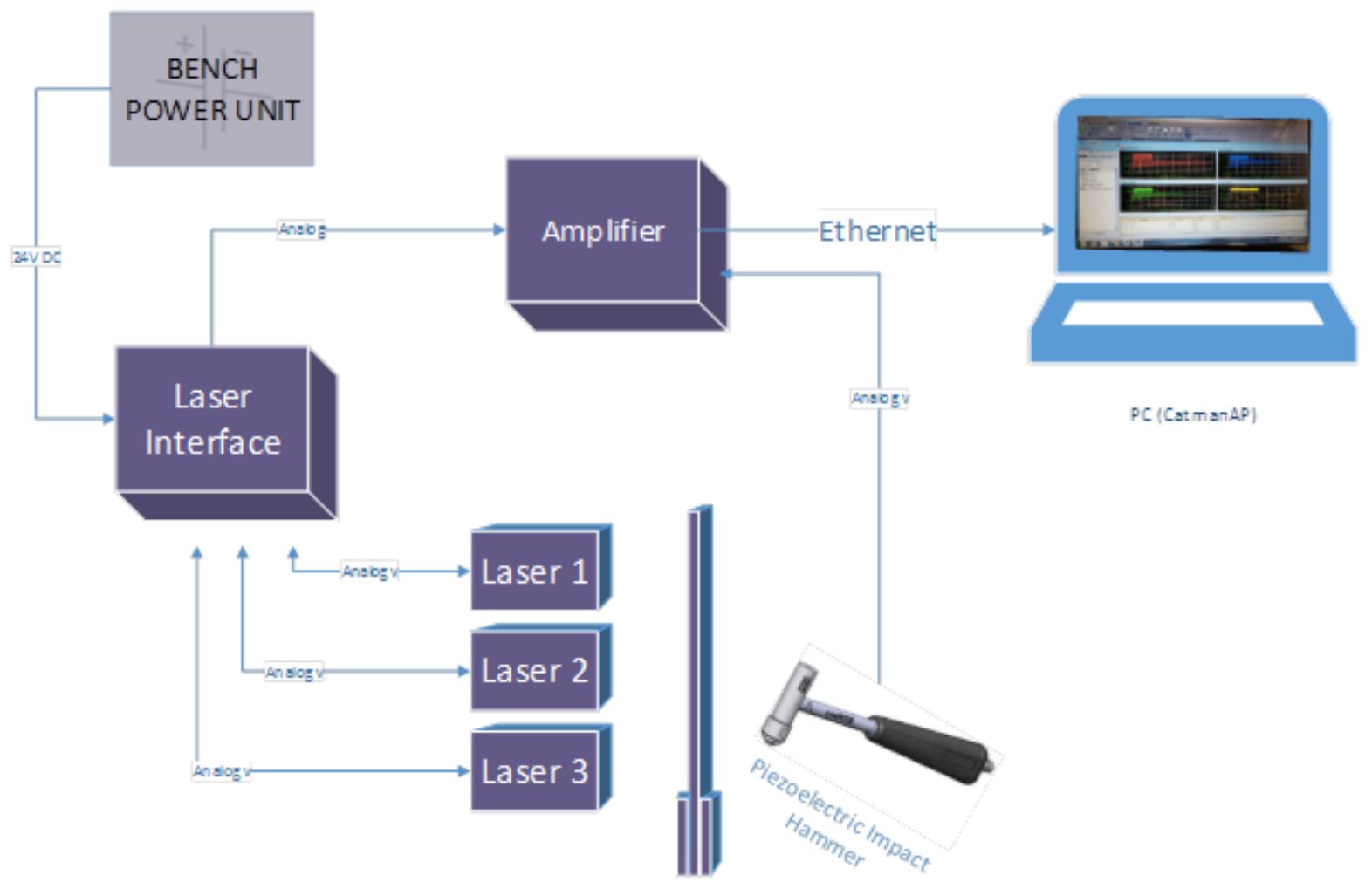

Figure 10: Experimental Layout Schematic

After connecting, the sensors through the interface to the acquisition unit the user shall install the CatmanAP, Data Acquisition software. 


\section{Software setup}

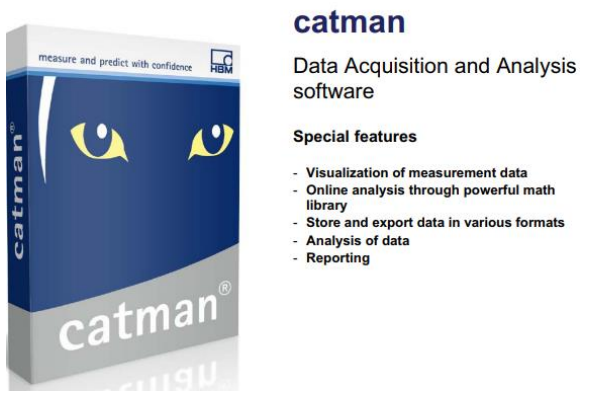

HBM produces the Data Acquisition Unit X400A. It has developed the CatmanAP Software for Data Acquisition and Analysis. The lab carries on CD drive a copy of the software version 3.3 with the required License for use.

NOTE: Higher versions for the same software are available online with added features and functionality but do require a newer License. Therefore, user shall install the same version available in the lab until the newer version is available.

Software installation steps are very straight forward as shown below:

- Insert CD

- Run executable file to install the software

- Once the software has been completely installed, the user shall be prompted for the License.

- The product license is provided with the $\mathrm{CD}$. Enter the License as shown below:

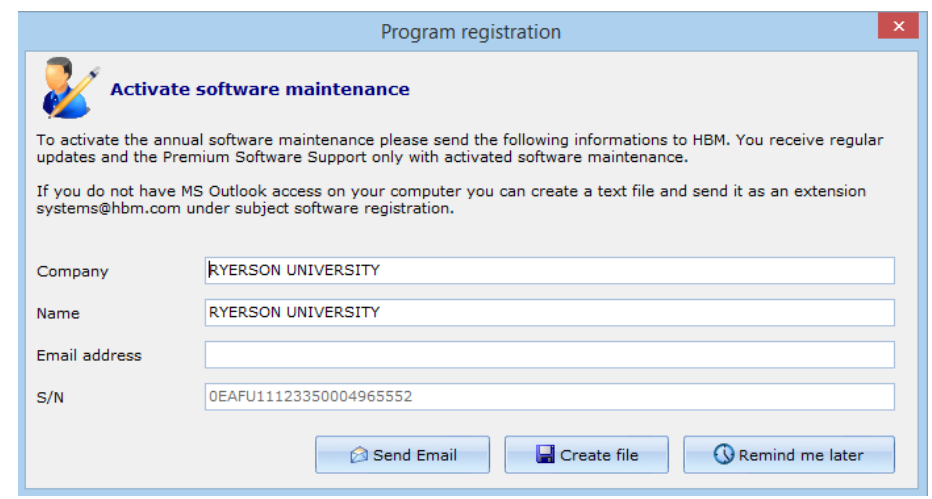

Figure 11: Enter License in the bottom field (Only field required) 
Launching the CatmanAP software opens the following Main User Interface :

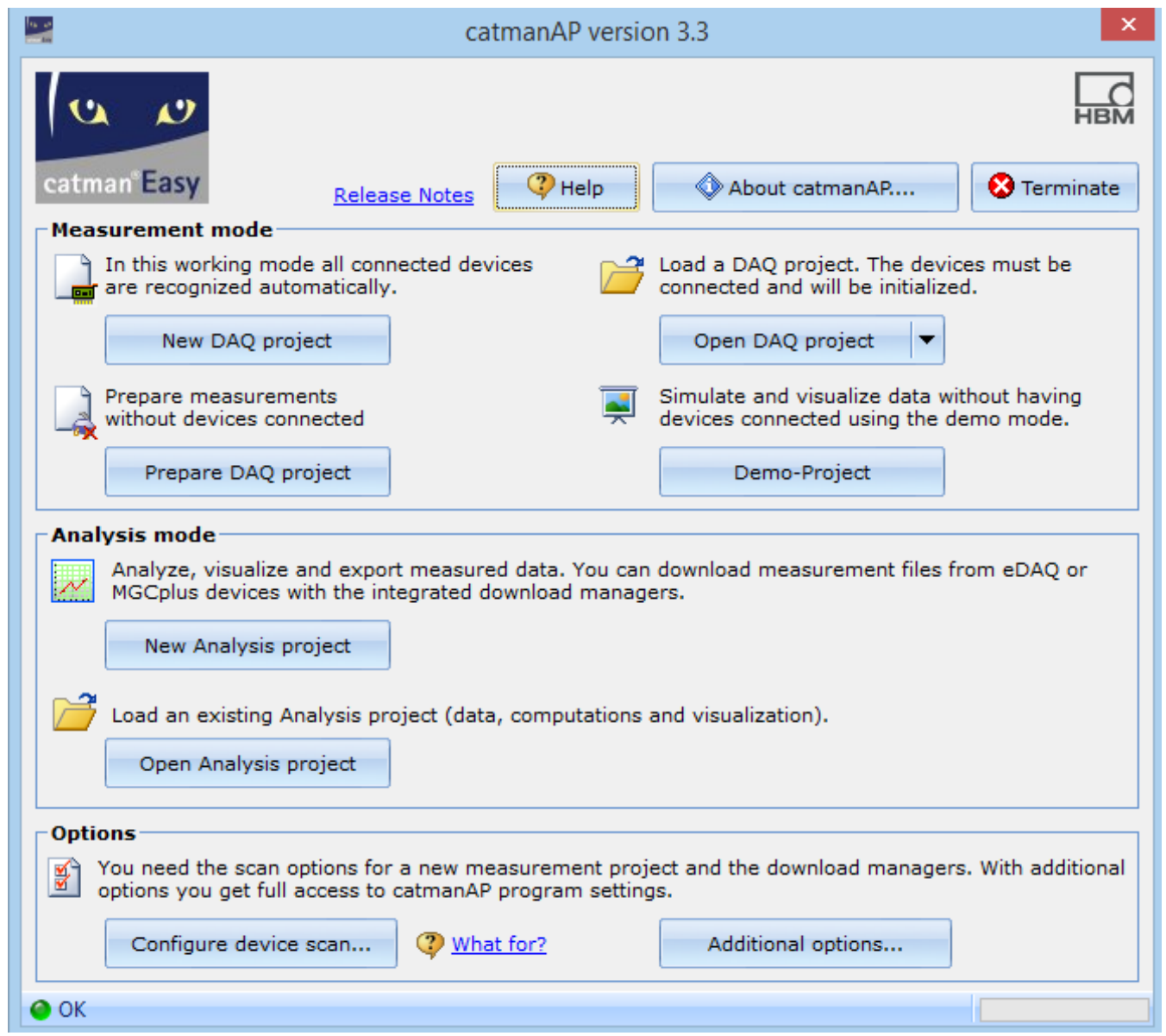

The first important step to configure and ensure connectivity with the X400A DAQ is to select the "Configure device scan" under Options section.

NOTE: User shall enter the PC's IP Address for the Ethernet connection. There are many simple ways to find the address. One such method is to use Ctrl+Alt+Del to enter the Task Manager and select the Ethernet tab on the left as illustrated below 


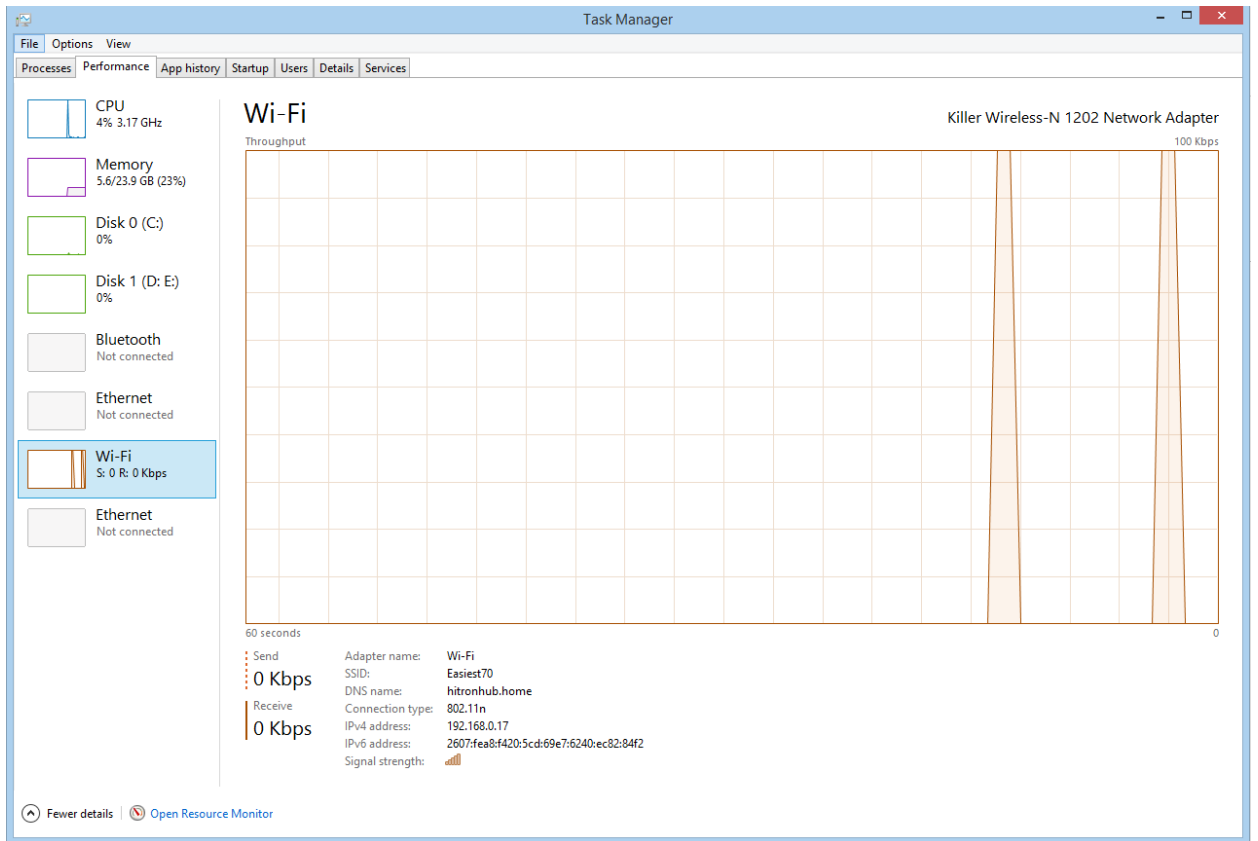

Select the Configure Device scan as shown below:

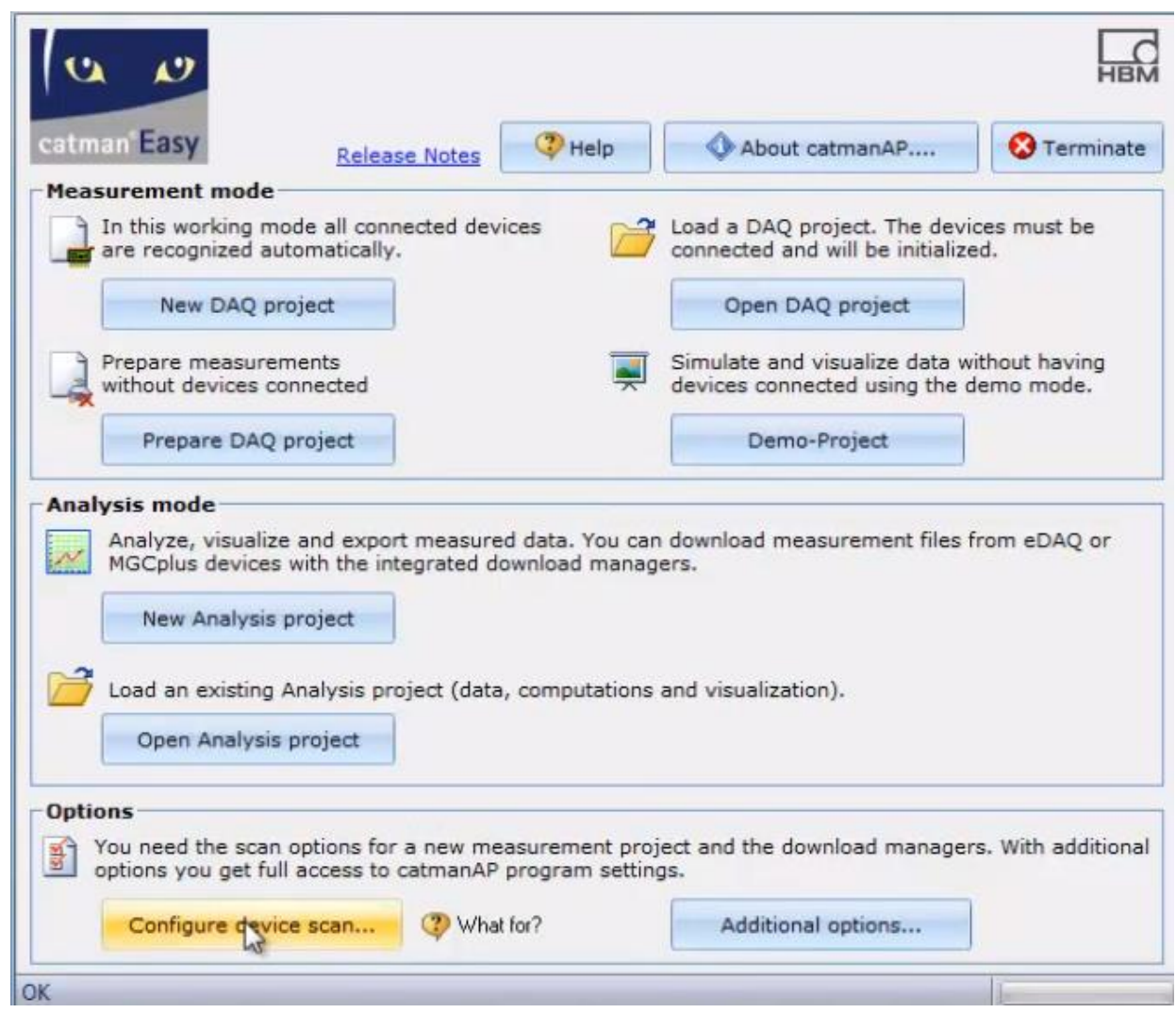


Select the "QuantumX" option under Search devices types and "Use QuantumX device manager" under Search Ports section. Also, check the "Sensor-scan" option under the "General scan options".

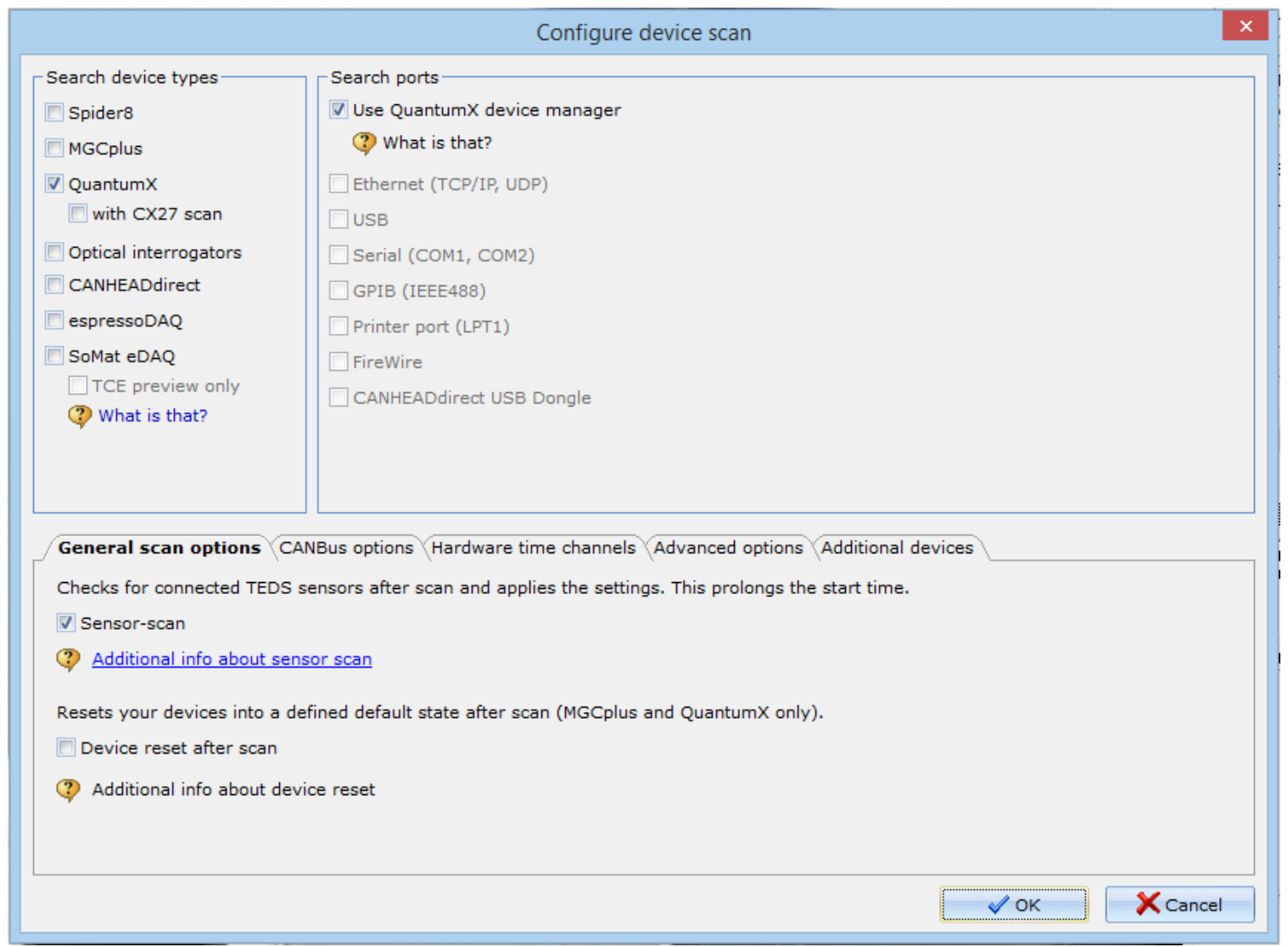

Upon selecting the "New DAQ Project" as shown below, the software shall automatically search for the DAQ unit connection. 


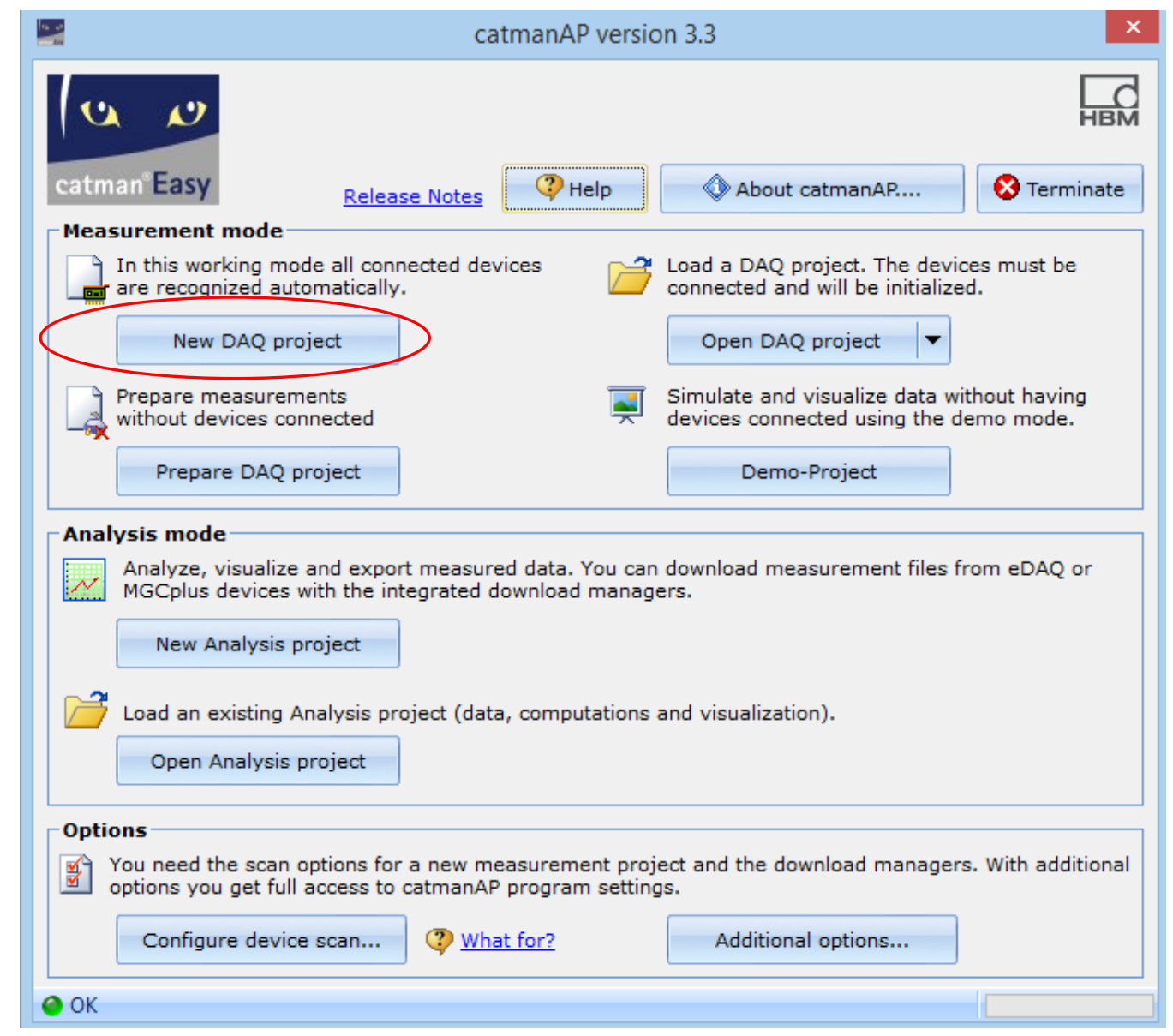

Note: Ethernet connection has to be established between the PC and DAQ.

The Software Searches for the DAQ Module using the network address

The IPv4 address can be readily acquired through the Ctrl+Alt+Del option under

the "Ethernet" Connection 


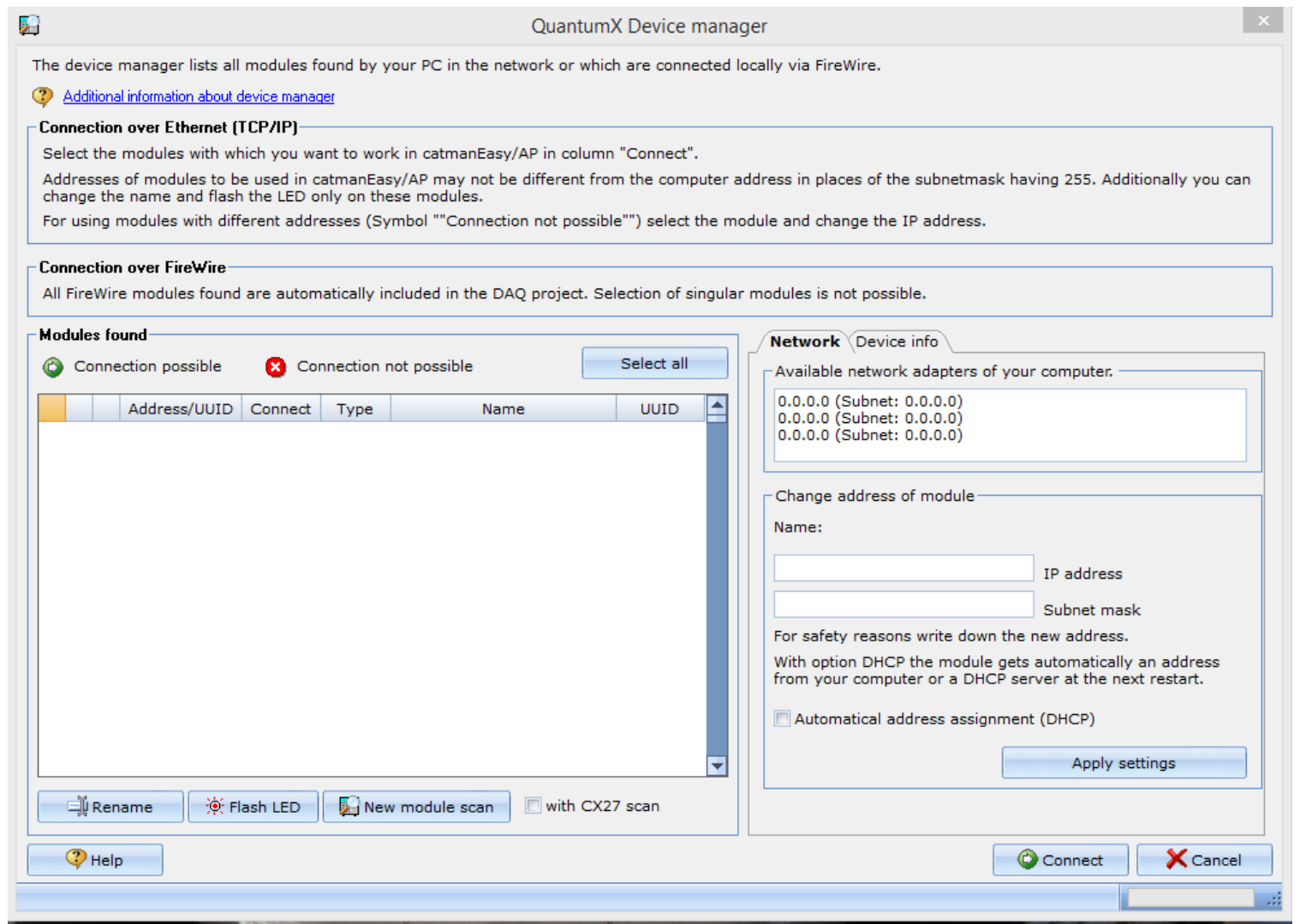

The 'Modules found' field is empty if no available connection is established to the DAQ unit. The user can set the IP address of the module as shown above to enable the connection to DAQ unit. 
Select "Connect" or enter once the Module is automatically detected upon Launch.

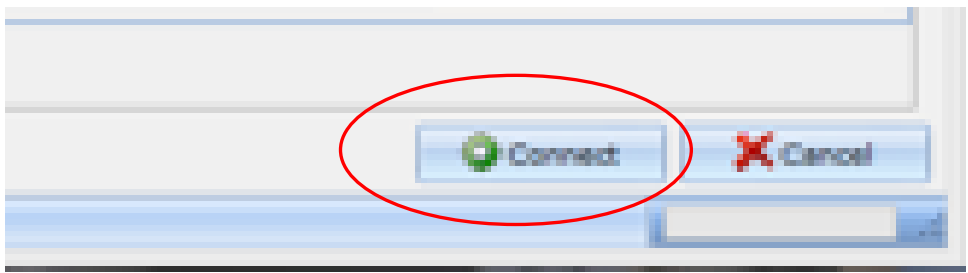

Once module is detected the software home screen appears as follows

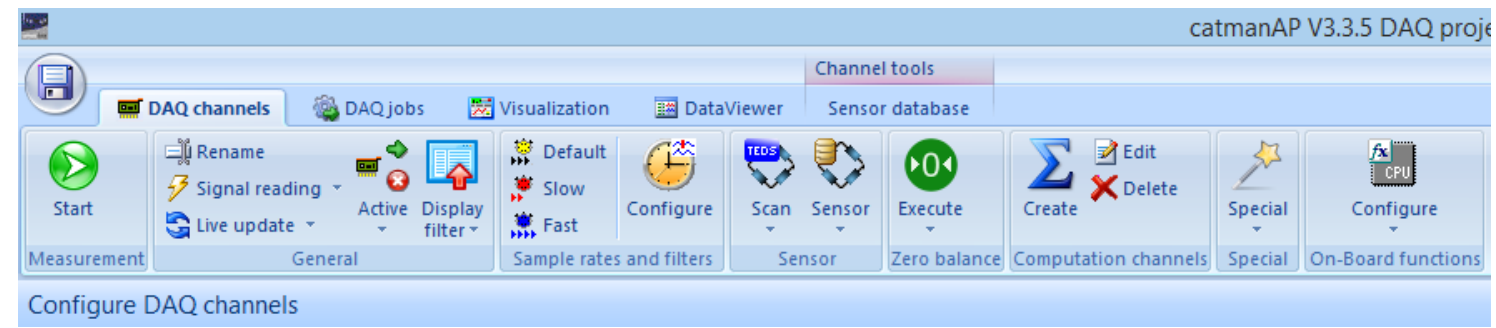

Sensor Selection using software is important. Normal sensors from vendor can be ordered with TED's support that are readily recognized by the software.

In the absence of the TEDS support, the user shall specify the sensor from the list of sensors provided.

A number of tutorials are available online for different ways sensors can be configured using the acquisition software. 
Note: User shall go over the sensor specs in detail to properly configure the software settings for optimal result generation from experiments.

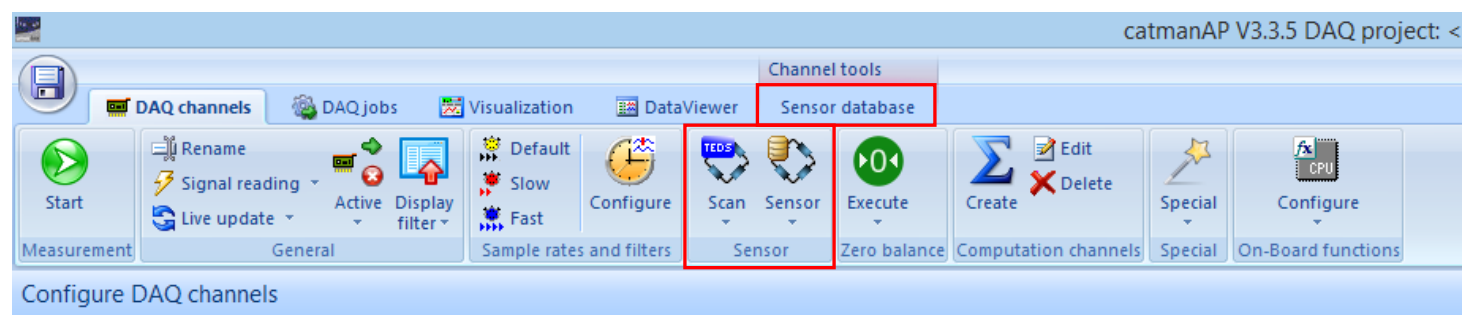

The current sensors on channels from the module are listed and status is shown

Select the "my sensors" tab under the sensors group to select the following customized sensor as per the manufacture specifications: 


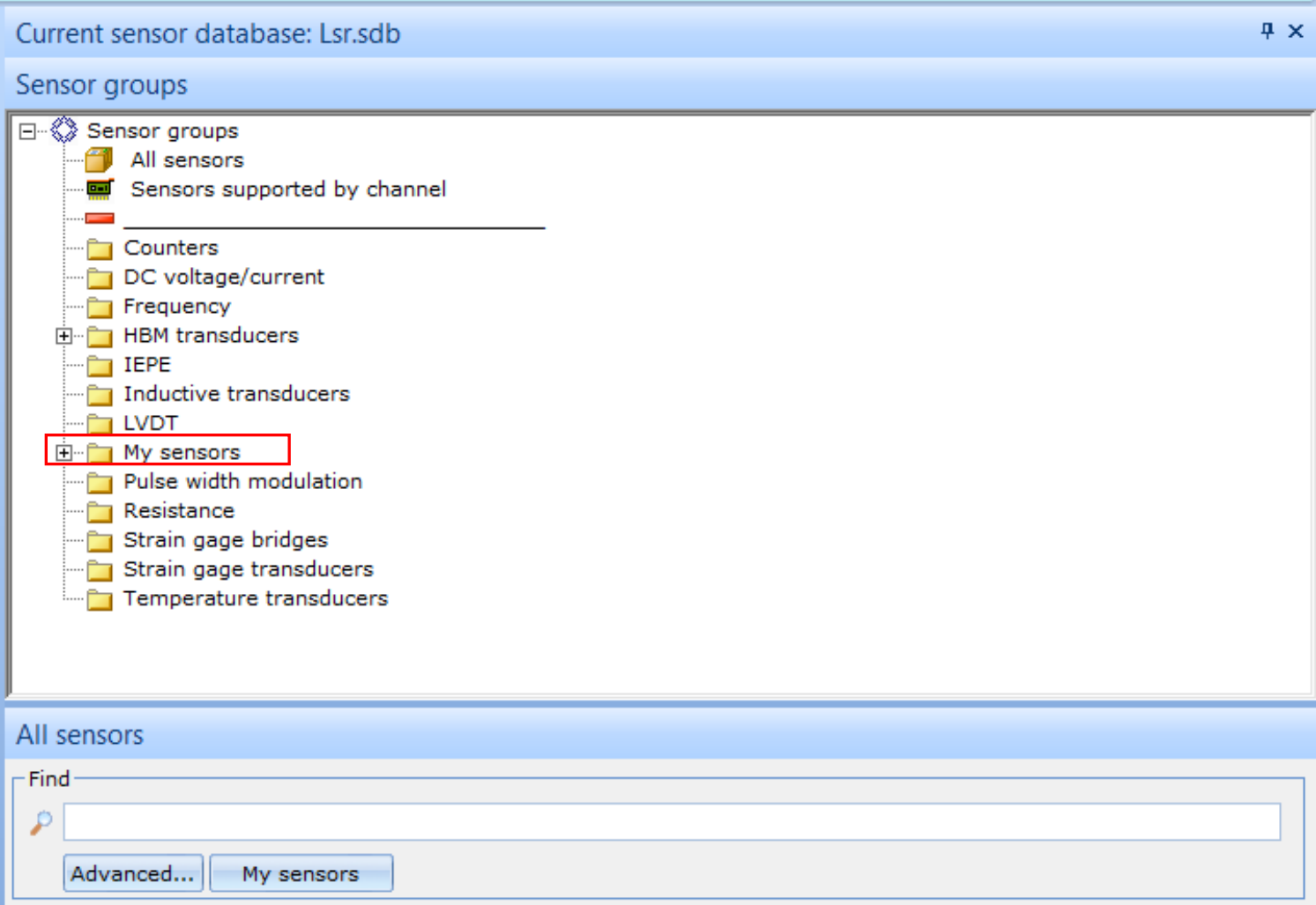

Once sensors are specified, select the "Execute" green button to initialize the sensors for the new set of readings.

CatmanAP V3.3.5 DAQ project: <
Measurement
Configure DAQ channels

To view sensor reading in a graphical interface the "Visualization" tab should be selected. 


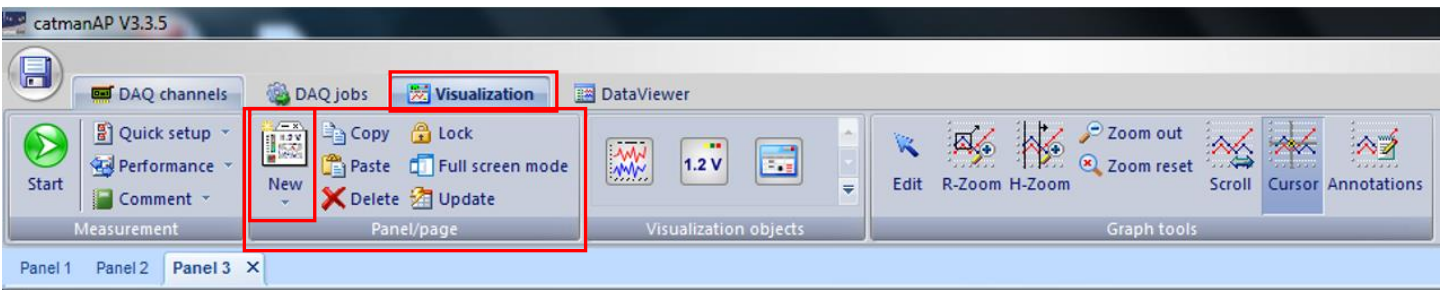

Using the "New" Drop down menu on the Visualization Tab various Panels can be created and each can be customized with the different graph options from the visualization objects

Following real time scope graphs for each sensor Channel can be observed below:

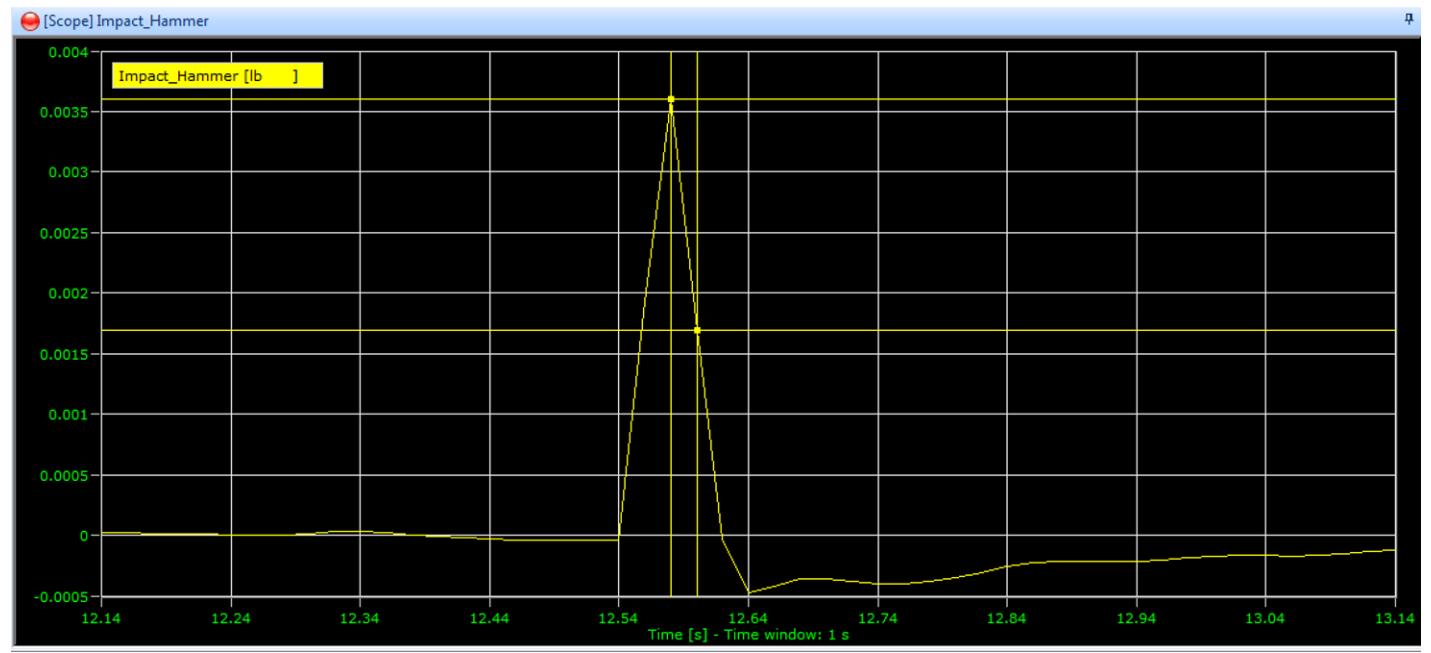

User can select multiple Channel representations on the same scope or create a different one for each. The above screenshot represents an Impulse from a Piezoelectric Impact Hammer sensor. 
As explained earlier the Panels can be customized with various Visualization objects such as different Graphs and Charts and even real time digitial value output fields etc.

Each Tab can be customized for one or many of these objects.

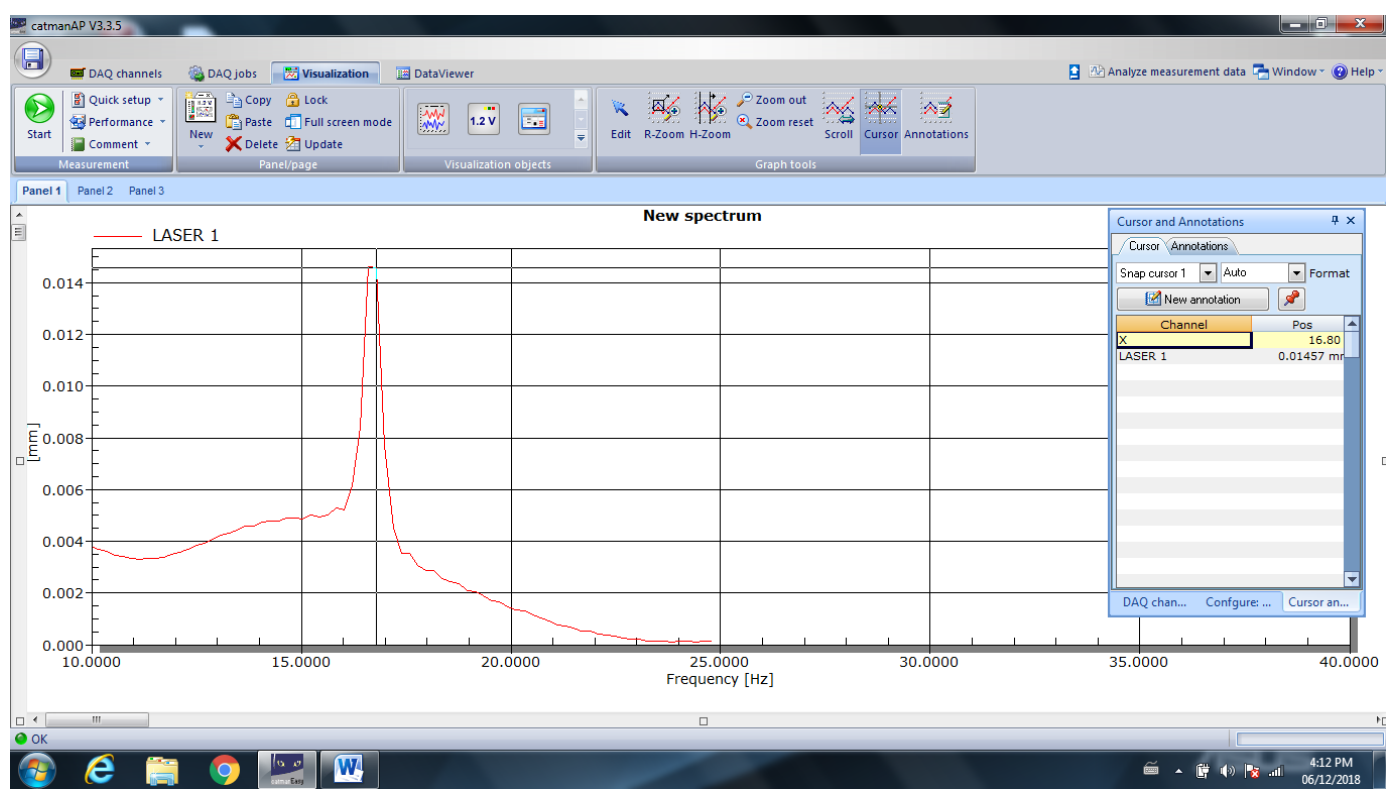

In the screenshots each separate Panel contains one sensor graph as illustrated.

The Zoom options and Cursor can be used to traverse any point on the graph. Normally this is to determine the readings on Peak values or any other point of concern the user deems important. 


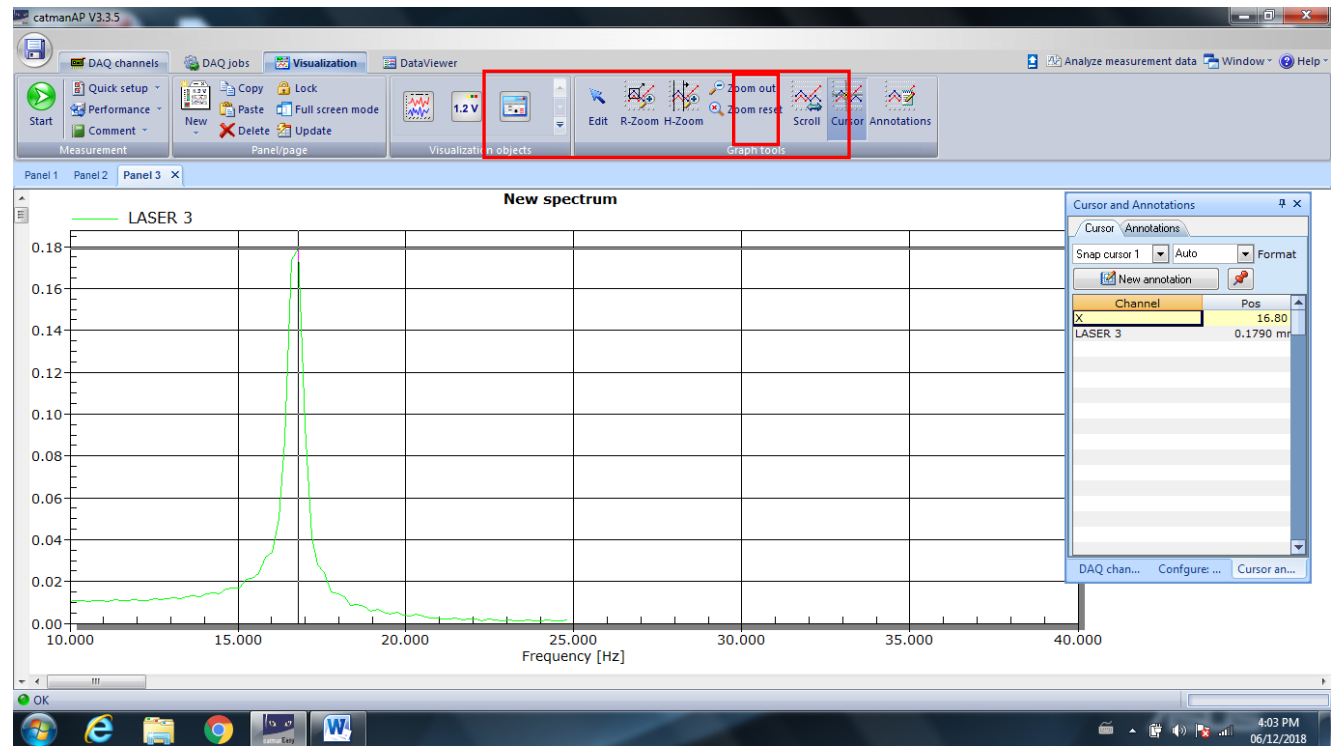

For Analysis at any time after the Project jobs (Test runs) are saved. They can be accessed directly from the startup interface by loading an already saved analysis project or by creating a new one 


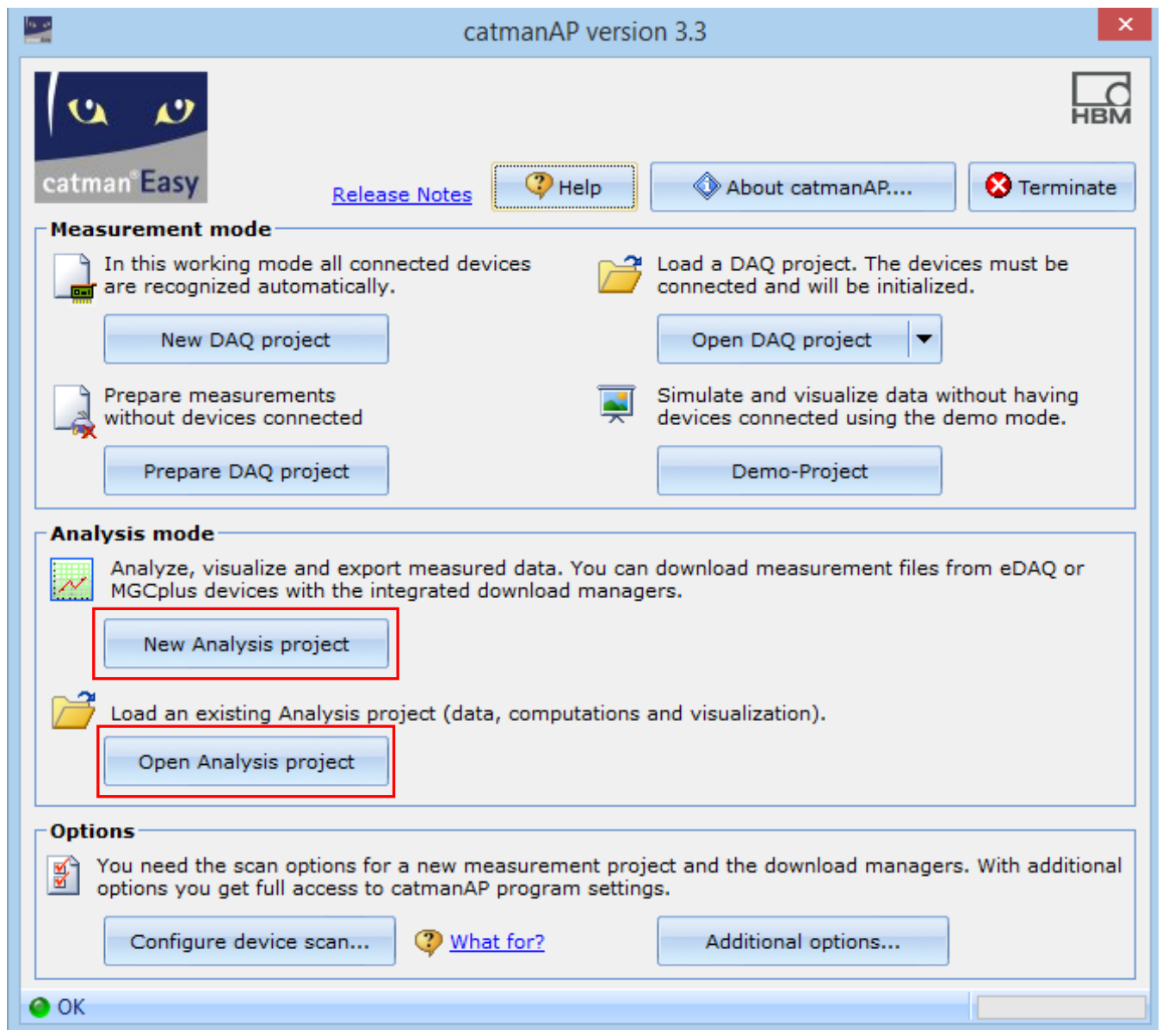


The Analysis Interface is illustrated below.

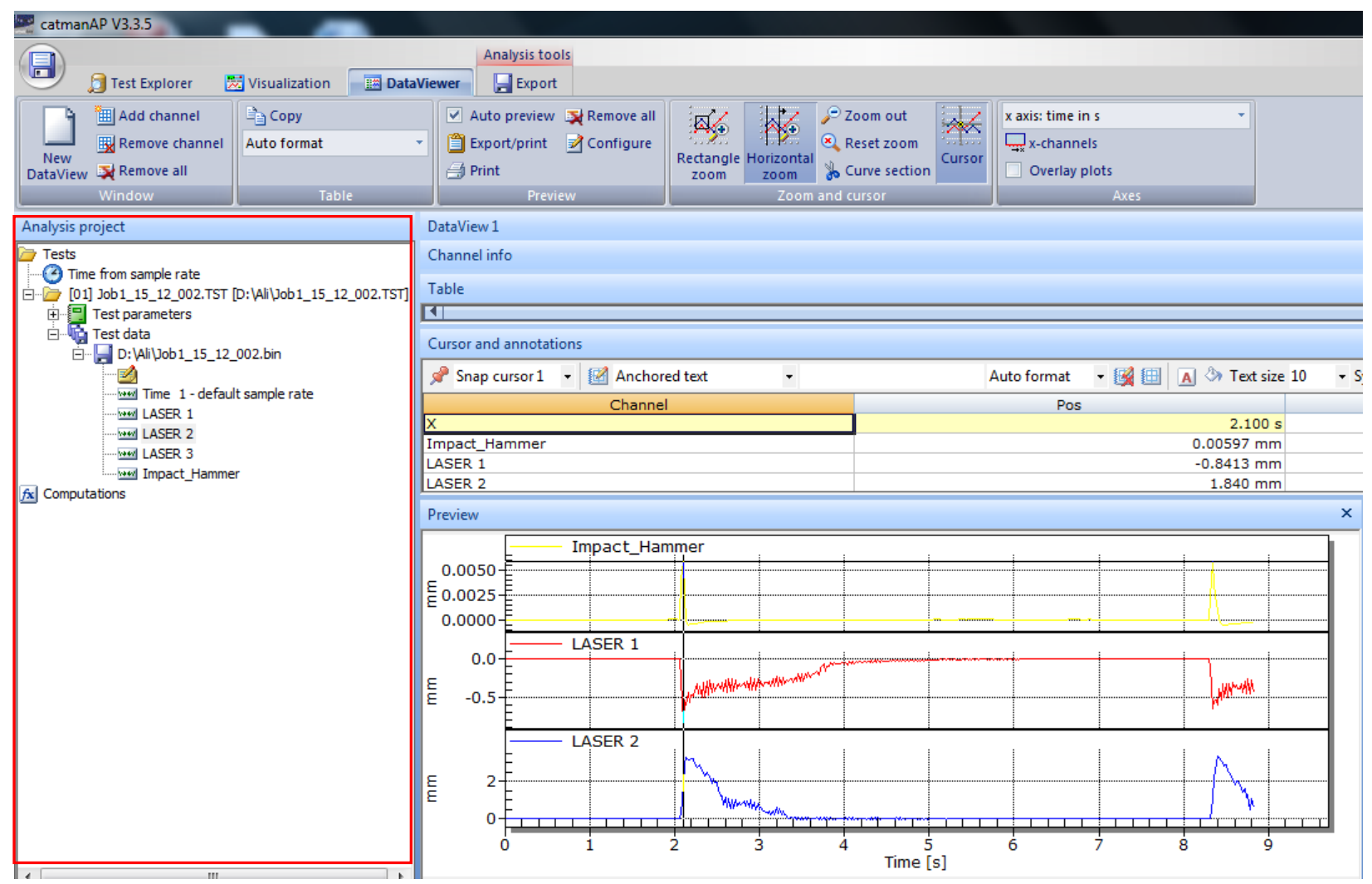

User can add any jobs (Test runs) from the project visible in the Analysis Project window on the left by simple "drag and drop" feature.

Once Analysis or experimentation is completed. The software offers a number of formats to store information including ones used in Excel, Matlab, csv etc. 


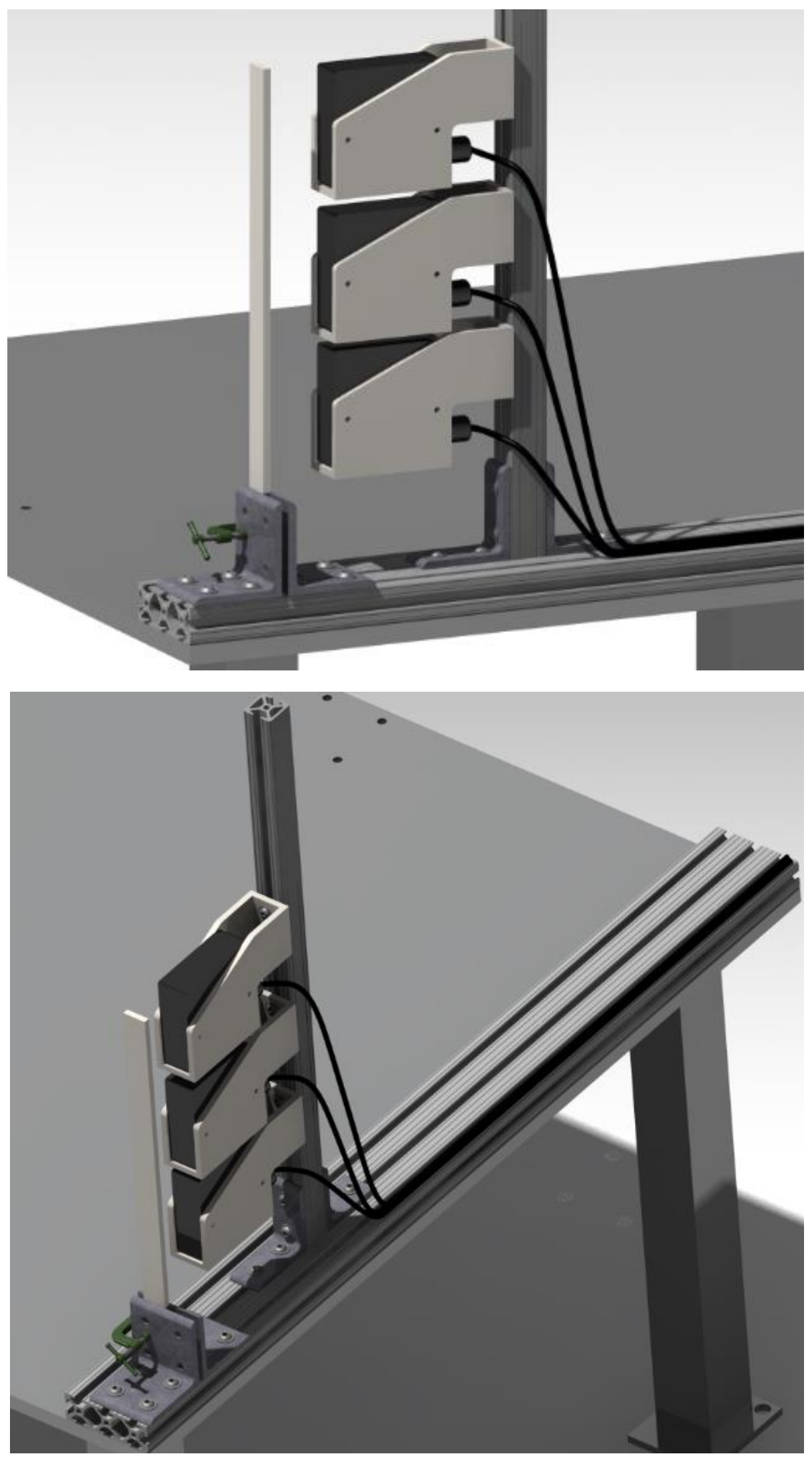




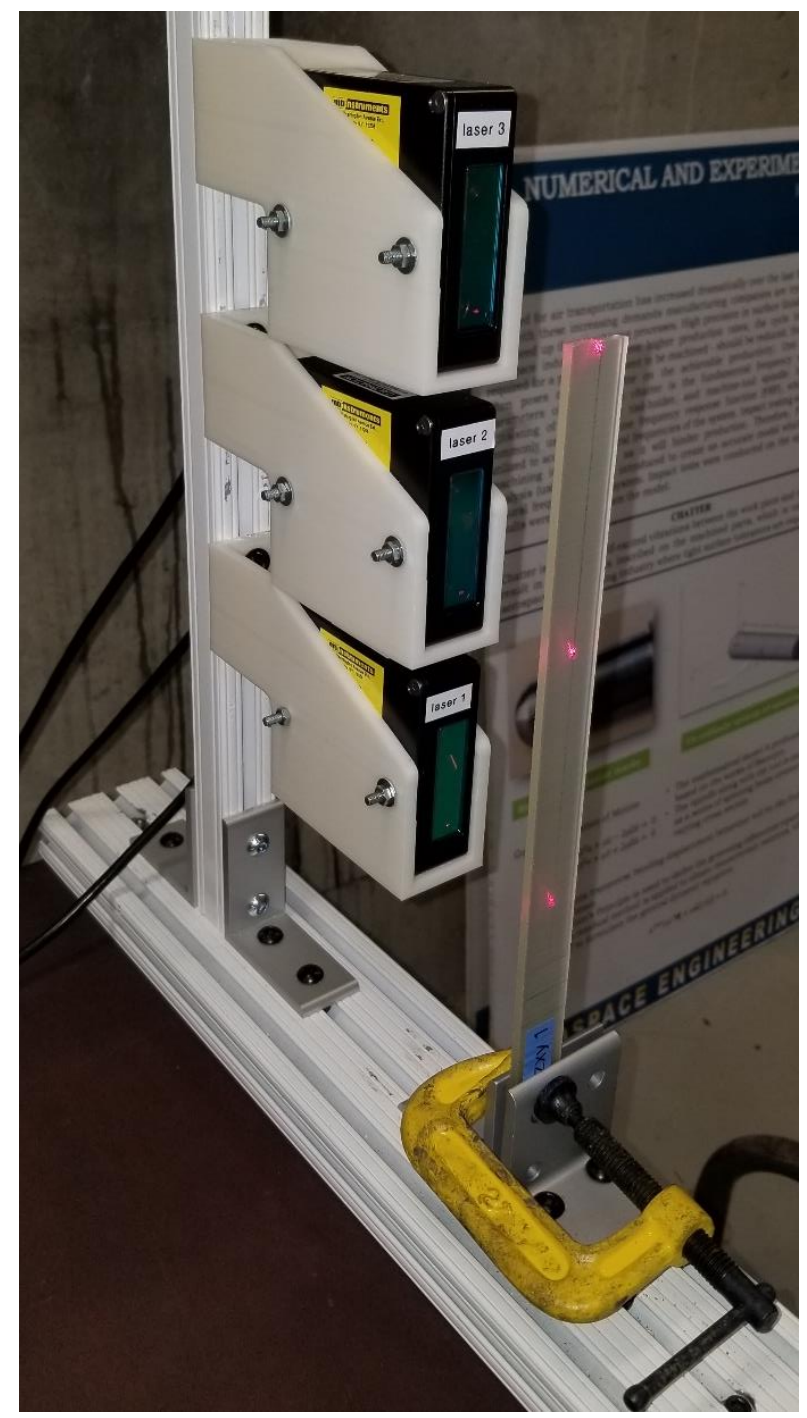

\section{USEFUL LINKS}

\section{$>$ ONLINE TUTORIAL ON HOW TO CONFIGURE SENSORS}

$>$ CatmanAP DAQ Software Brochure

Manufacturer's Specification for the CatmanAP Software 
APPENDIX C EXPERIMENTATION RESULTS 


\section{APPENDIX C1 IET RESULTS}

Results from the IET Experiment and calculated E values based on specimen Parameters

\begin{tabular}{|c|c|c|c|c|c|c|c|}
\hline$\rho$ & $\begin{array}{c}\text { Cross- } \\
\text { sectional } \\
\text { Area }\end{array}$ & $\begin{array}{c}\text { omega - } \\
(\mathrm{rad} / \mathrm{sec}) \\
\wedge_{2}\end{array}$ & Length^4 & $\begin{array}{c}\text { Non- } \\
\text { dimensional } \\
\wedge_{2}\end{array}$ & I & $\begin{array}{c}\mathbf{E} \\
(\mathbf{P a})\end{array}$ & \# \\
\hline 1225.673 & $\begin{array}{c}7.116 \mathrm{E}- \\
05\end{array}$ & $\begin{array}{c}10631.06 \\
8\end{array}$ & 0.0033177 & 12.362 & $\begin{array}{c}\text { 7.314E- } \\
11\end{array}$ & $3.402 \mathrm{E}+09$ & $\begin{array}{c}0-1 \\
\text { XYZ }\end{array}$ \\
\hline 1215.19 & $\begin{array}{c}6.855 \mathrm{E}- \\
05\end{array}$ & $\begin{array}{c}9880.358 \\
2\end{array}$ & 0.0033177 & 12.362 & $\begin{array}{c}\text { 6.464E- } \\
11\end{array}$ & $3.417 \mathrm{E}+09$ & $\begin{array}{c}1-1 \\
X Y Z\end{array}$ \\
\hline 1216.699 & $\begin{array}{c}\text { 7.321E- } \\
05\end{array}$ & $\begin{array}{c}10631.06 \\
8\end{array}$ & 0.0033177 & 12.362 & $\begin{array}{c}8.057 \mathrm{E}- \\
11\end{array}$ & $3.154 \mathrm{E}+09$ & $\begin{array}{c}1-2 \\
X Y Z\end{array}$ \\
\hline 1223.982 & $\begin{array}{l}\text { 7.093E- } \\
05\end{array}$ & $\begin{array}{c}10631.06 \\
8\end{array}$ & 0.0033177 & 12.362 & $\begin{array}{c}\text { 7.324E- } \\
11\end{array}$ & $3.382 \mathrm{E}+09$ & $\begin{array}{c}1-3 \\
X Y Z\end{array}$ \\
\hline 1226.412 & $\begin{array}{c}\text { 7.115E- } \\
05\end{array}$ & $\begin{array}{c}10631.06 \\
8\end{array}$ & 0.0033177 & 12.362 & $\begin{array}{c}\text { 7.330E- } \\
11\end{array}$ & $3.397 \mathrm{E}+09$ & $\begin{array}{c}1-4 \\
X Y Z\end{array}$ \\
\hline 1174.275 & $\begin{array}{c}\text { 7.445E- } \\
05\end{array}$ & $\begin{array}{c}11142.38 \\
8\end{array}$ & 0.0033177 & 12.362 & $\begin{array}{c}8.687 \mathrm{E}- \\
11\end{array}$ & $3.009 \mathrm{E}+09$ & $\begin{array}{c}2- \\
1 \mathrm{XZY}\end{array}$ \\
\hline 1186.286 & $\begin{array}{c}\text { 7.334E- } \\
05\end{array}$ & $\begin{array}{c}10878.67 \\
2\end{array}$ & 0.0033177 & 12.362 & $\begin{array}{c}8.223 \mathrm{E}- \\
11\end{array}$ & $3.089 \mathrm{E}+09$ & $\begin{array}{c}2- \\
2 X Z Y\end{array}$ \\
\hline 1170.223 & $\begin{array}{c}\text { 7.433E- } \\
05\end{array}$ & $\begin{array}{c}11142.38 \\
8\end{array}$ & 0.0033177 & 12.362 & $\begin{array}{c}8.461 \mathrm{E}- \\
11\end{array}$ & $3.074 \mathrm{E}+09$ & $\begin{array}{c}2- \\
3 X Z Y\end{array}$ \\
\hline 1161.99 & $\begin{array}{c}7.881 \mathrm{E}- \\
05\end{array}$ & $\begin{array}{c}16284.69 \\
3\end{array}$ & 0.0021367 & 12.362 & $\begin{array}{c}1.011 \mathrm{E}- \\
10\end{array}$ & $2.549 \mathrm{E}+09$ & $\begin{array}{c}3-1 \\
\text { ZXY }\end{array}$ \\
\hline 1152.801 & $\begin{array}{c}\text { 7.445E- } \\
05\end{array}$ & $\begin{array}{c}16284.69 \\
3\end{array}$ & 0.0021367 & 12.362 & $\begin{array}{c}8.521 \mathrm{E}- \\
11\end{array}$ & $2.835 \mathrm{E}+09$ & $\begin{array}{c}3-2 \\
\text { ZXY }\end{array}$ \\
\hline 1148.842 & $\begin{array}{c}\text { 7.413E- } \\
05\end{array}$ & $\begin{array}{c}17244.56 \\
7\end{array}$ & 0.0021367 & 12.362 & $\begin{array}{c}8.411 \mathrm{E}- \\
11\end{array}$ & $3.018 \mathrm{E}+09$ & $\begin{array}{c}3-3 \\
\text { ZXY }\end{array}$ \\
\hline
\end{tabular}




\section{APPENDIX C2 TENSILE TESTING RESULTS}

Following are the tensile test $\mathrm{E}$ results for the three build orientations:

\begin{tabular}{|c|c|c|c|}
\hline $\begin{array}{l}\text { Max force } \\
\text { (lbf) }\end{array}$ & $\begin{array}{c}\text { Failure stress } \\
\quad(p s i)\end{array}$ & $\begin{array}{l}\text { Strength } \\
\text { (MPa) }\end{array}$ & $\begin{array}{c}\text { Young's Modulus } \\
\text { (GPa) }\end{array}$ \\
\hline 633.5769653 & 8767.719745 & 60.45132339 & 3.1084 \\
\hline 581.2393799 & 8045.87483 & 55.47437595 & 3.026 \\
\hline 543.0488892 & 7584.888821 & 52.29598805 & 3.2958 \\
\hline 596.2262573 & 8354.298192 & 57.600881 & 3.1104 \\
\hline \multirow[t]{4}{*}{615.6503906} & 8613.430871 & 59.38760754 & 3.2124 \\
\hline & Average & 57.0 & 3.15 \\
\hline & $\begin{array}{c}\text { Standard } \\
\text { Deviation }\end{array}$ & 3.26 & 0.10 \\
\hline & $\mathrm{CV}$ & $5.7 \%$ & $3.3 \%$ \\
\hline 512.3497314 & 6831.565139 & 47.10200205 & 2.994 \\
\hline 306.6999817 & 4017.571362 & 27.70019033 & 3.107 \\
\hline 485.7545166 & 6044.210674 & 41.67338199 & 2.8667 \\
\hline 511.0496826 & 6390.210615 & 44.05896854 & 2.8356 \\
\hline \multirow[t]{4}{*}{501.7422485} & 6709.263612 & 46.25876238 & 2.9724 \\
\hline & Average & 44.8 & 2.92 \\
\hline & $\begin{array}{c}\text { Standard } \\
\text { Deviation }\end{array}$ & 2.43 & 0.08 \\
\hline & $\mathrm{CV}$ & $5.4 \%$ & $2.7 \%$ \\
\hline 674.2185669 & 9194.757768 & 63.39564807 & 3.115 \\
\hline 672.5359497 & 9188.890053 & 63.35519158 & 3.1483 \\
\hline 666.5275269 & 9097.895233 & 62.72780414 & 3.0903 \\
\hline 667.800293 & 9047.839964 & 62.38268507 & 3.1451 \\
\hline \multirow[t]{4}{*}{668.0767822} & 9047.41046 & 62.37972374 & 3.091 \\
\hline & Average & 62.8 & 3.12 \\
\hline & $\begin{array}{c}\text { Standard } \\
\text { Deviation }\end{array}$ & 0.50 & 0.03 \\
\hline & $\mathrm{CV}$ & $0.8 \%$ & $0.9 \%$ \\
\hline
\end{tabular}

NOTE: The value in pink is off due to specimen defect that was discovered and was not considered in comparison with the IET result values. 
APPENDIX D FEM ANALYSIS REPORTS 


\section{MNSYS}

Appendix D1 Build orientation XYZ

\begin{tabular}{|c|c|}
\hline First Saved & Monday, December 24, 2018 \\
\hline Last Saved & Monday, December 24, 2018 \\
\hline Product Version & 19.2 Release \\
\hline Save Project Before Solution & No \\
\hline Save Project After Solution & No \\
\hline
\end{tabular}




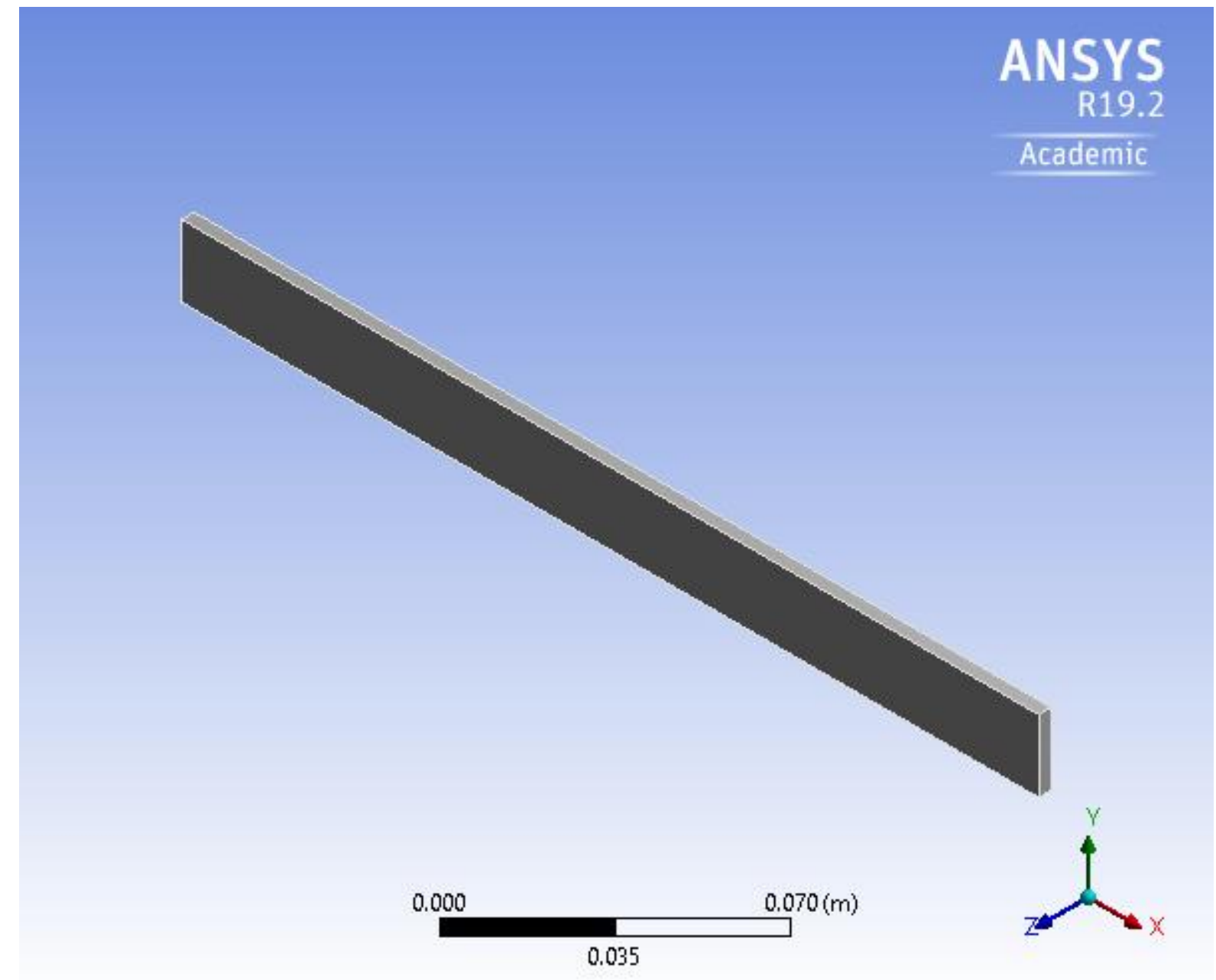

Contents

- $\quad \underline{\text { Units }}$

- Model (C4)

- Geometry

- SYSISolid

- Materials

- XZY PLA

- ZXY PLA

- PLA

- New Folder 
- Coordinate Systems

$\circ \underline{\text { Mesh }}$

$\circ \quad \underline{\text { Modal (C5) }}$

- $\quad$ Pre-Stress (None)

- Analysis Settings

- $\quad$ Fixed Support

- Solution (C6)

- Solution Information

- Results

- Material Data

- XYZ PLA

Units

TABLE 1

\begin{tabular}{|l|l|}
\hline Unit System & Metric (m, kg, N, s, V, A) Degrees rad/s Celsius \\
\hline Angle & Degrees \\
\hline Rotational Velocity & $\mathrm{rad} / \mathrm{s}$ \\
\hline Temperature & Celsius \\
\hline
\end{tabular}

Model (C4)

Geometry 
TABLE 2

Model (C4) > Geometry

\begin{tabular}{|c|c|}
\hline $\begin{array}{l}\text { Object } \\
\text { Name }\end{array}$ & Geometry \\
\hline State & Fully Defined \\
\hline \multicolumn{2}{|l|}{ Definition } \\
\hline Source & $\begin{array}{l}\text { C:IUserslasus\AppDatalLocallTemplWB_DESKTOP- } \\
\text { N3USIQU_asus_7184_2lunsaved_project_filesldp0ISYS\DM } \backslash S Y S . s c d o c\end{array}$ \\
\hline Type & SpaceClaim \\
\hline Length Unit & Meters \\
\hline $\begin{array}{l}\text { Element } \\
\text { Control }\end{array}$ & Program Controlled \\
\hline $\begin{array}{ll}\text { Display } \\
\text { Style }\end{array}$ & Body Color \\
\hline \multicolumn{2}{|c|}{ Bounding Box } \\
\hline Length X & $0.241 \mathrm{~m}$ \\
\hline Length Y & $2.0148 \mathrm{e}-002 \mathrm{~m}$ \\
\hline
\end{tabular}




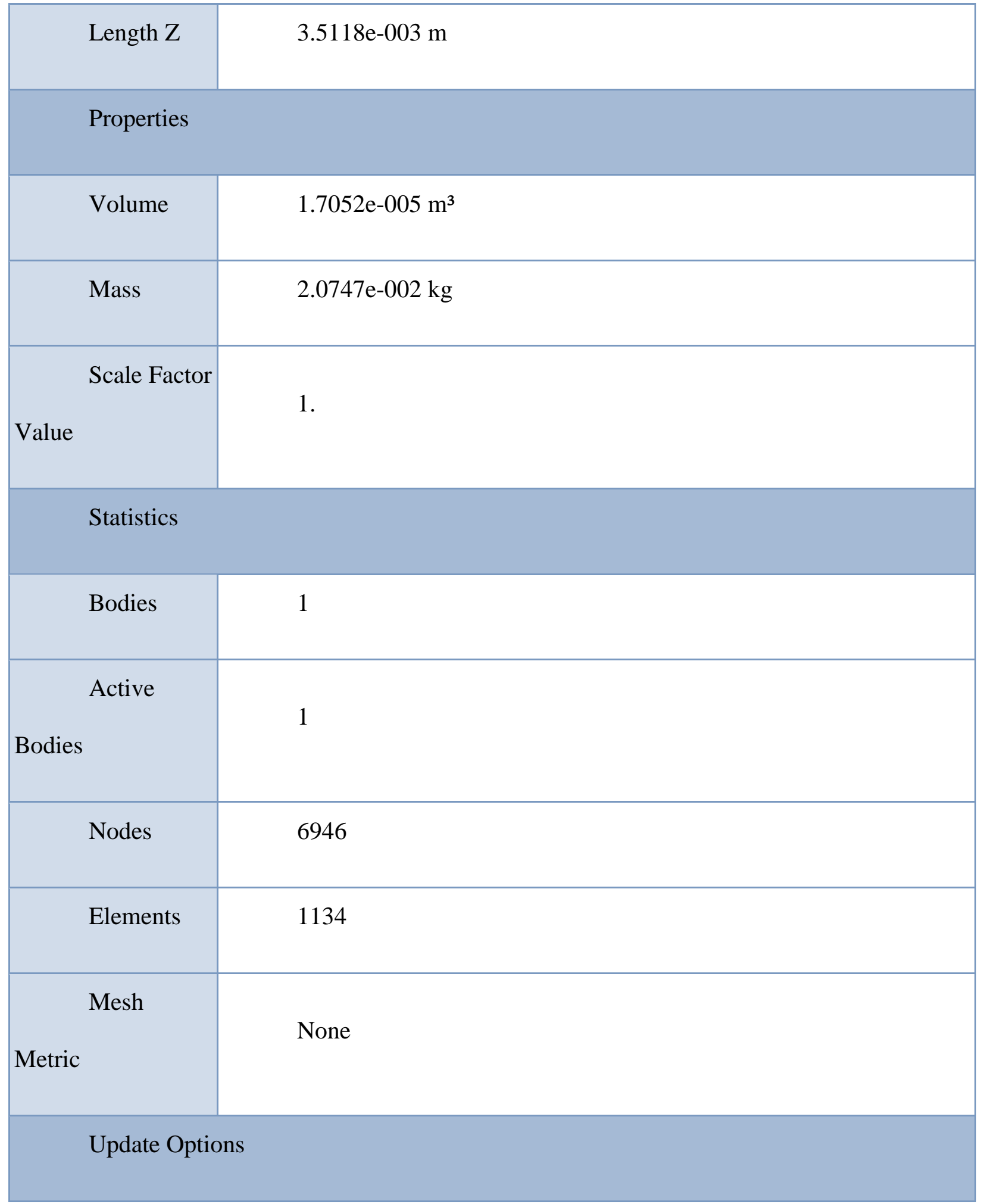




\begin{tabular}{|c|c|}
\hline $\begin{array}{c}\text { Assign } \\
\text { Default Material }\end{array}$ & No \\
\hline \multicolumn{2}{|c|}{ Basic Geometry Options } \\
\hline $\begin{array}{l}\text { Solid } \\
\text { Bodies }\end{array}$ & Yes \\
\hline $\begin{array}{l}\text { Surface } \\
\text { Bodies }\end{array}$ & Yes \\
\hline Line Bodies & Yes \\
\hline Parameters & Independent \\
\hline $\begin{array}{l}\text { Parameter } \\
\text { Key }\end{array}$ & \\
\hline Attributes & Yes \\
\hline $\begin{array}{l}\text { Attribute } \\
\text { Key }\end{array}$ & \\
\hline $\begin{array}{l}\text { Named } \\
\text { Selections }\end{array}$ & Yes \\
\hline
\end{tabular}




\begin{tabular}{|c|c|}
\hline Named & \\
Selection Key & \\
\hline Material & Yes \\
\hline Properties & \\
\hline Advanced Geometry Options \\
\hline Use & Yes \\
\hline Associativity & Yes \\
\hline Coordinate & Yes \\
\hline Systems \\
\hline Undate \\
\hline Coordinate & \\
\hline System Key & \\
\hline Rodated File & \\
\hline
\end{tabular}




\begin{tabular}{|c|c|}
\hline Compare & No \\
Parts On Update & \\
\hline Analysis & 3-D \\
\hline Mype & \\
\hline Mixport Resolution & None \\
\hline Clean & No \\
\hline Bodies On Import & \\
\hline Stitch & No \\
\hline Surfaces On Import & \\
\hline Processing & \\
\hline Decompose & Yes \\
\hline Disjoint Geometry & \\
\hline
\end{tabular}

TABLE 3

Model (C4) > Geometry > Parts

\begin{tabular}{|l|l|}
\hline Object Name & SYSISolid \\
\hline
\end{tabular}




\begin{tabular}{|c|c|}
\hline State & Meshed \\
\hline \multicolumn{2}{|l|}{ Graphics Properties } \\
\hline Visible & Yes \\
\hline Transparency & 1 \\
\hline \multicolumn{2}{|l|}{ Definition } \\
\hline Suppressed & No \\
\hline Stiffness Behavior & Flexible \\
\hline Coordinate System & Default Coordinate System \\
\hline Reference Temperature & By Environment \\
\hline Behavior & None \\
\hline \multicolumn{2}{|l|}{ Material } \\
\hline Assignment & XYZ PLA \\
\hline Nonlinear Effects & Yes \\
\hline Thermal Strain Effects & Yes \\
\hline Bounding Box & \\
\hline
\end{tabular}




\begin{tabular}{|c|c|}
\hline Length X & $0.241 \mathrm{~m}$ \\
\hline Length Y & $2.0148 \mathrm{e}-002 \mathrm{~m}$ \\
\hline Length Z & $3.5118 \mathrm{e}-003 \mathrm{~m}$ \\
\hline \multicolumn{2}{|l|}{ Properties } \\
\hline Volume & $1.7052 \mathrm{e}-005 \mathrm{~m}^{3}$ \\
\hline Mass & $2.0747 \mathrm{e}-002 \mathrm{~kg}$ \\
\hline Centroid X & $0.1205 \mathrm{~m}$ \\
\hline Centroid Y & $-2.074 \mathrm{e}-003 \mathrm{~m}$ \\
\hline Centroid Z & $2.2441 \mathrm{e}-003 \mathrm{~m}$ \\
\hline Moment of Inertia Ip1 & $7.2317 \mathrm{e}-007 \mathrm{~kg} \cdot \mathrm{m}^{2}$ \\
\hline Moment of Inertia Ip2 & $1.0044 \mathrm{e}-004 \mathrm{~kg} \cdot \mathrm{m}^{2}$ \\
\hline Moment of Inertia Ip3 & $1.0112 \mathrm{e}-004 \mathrm{~kg} \cdot \mathrm{m}^{2}$ \\
\hline \multicolumn{2}{|l|}{ Statistics } \\
\hline Nodes & 6946 \\
\hline Elements & 1134 \\
\hline
\end{tabular}




\begin{tabular}{|l|l|}
\hline Mesh Metric & None \\
\hline CAD Attributes & \\
\hline PartTolerance: & 0.00000001 \\
\hline Color:143.175.143 & \\
\hline
\end{tabular}

New Folder

Coordinate Systems

TABLE 4

Model (C4) > Coordinate Systems > Coordinate System

\begin{tabular}{|l|l|}
\hline Object Name & Global Coordinate System \\
\hline State & Fully Defined \\
\hline Definition & \\
\hline Type & Cartesian \\
\hline Coordinate System ID & 0. \\
\hline Origin & \\
\hline Origin X & $0 . \mathrm{m}$ \\
\hline Origin Y & $0 . \mathrm{m}$ \\
\hline
\end{tabular}




\begin{tabular}{|l|l|}
\hline Origin Z & $0 . \mathrm{m}$ \\
\hline Directional Vectors \\
\hline X Axis Data & {$\left[\begin{array}{l} \\
\hline \text { Y Axis Data }\end{array}\right]$} \\
\hline Z Axis Data & {$[0.1 .0]$.} \\
\hline
\end{tabular}

Mesh

TABLE 5

Model (C4) > Mesh

\begin{tabular}{|l|l|}
\hline Object Name & Mesh \\
\hline State & Solved \\
\hline Display & \\
\hline Display Style & Maximum Corner Angle \\
\hline Defaults & \\
\hline Physics Preference & Mechanical \\
\hline
\end{tabular}




\begin{tabular}{|c|c|}
\hline Element Order & Program Controlled \\
\hline Element Size & 3.e-003 m \\
\hline \multicolumn{2}{|l|}{ Sizing } \\
\hline Use Adaptive Sizing & Yes \\
\hline Resolution & Default (2) \\
\hline Mesh Defeaturing & Yes \\
\hline Defeature Size & Default \\
\hline Transition & Fast \\
\hline Span Angle Center & Coarse \\
\hline Initial Size Seed & Assembly \\
\hline Bounding Box Diagonal & $0.24187 \mathrm{~m}$ \\
\hline Average Surface Area & $1.9243 \mathrm{e}-003 \mathrm{~m}^{2}$ \\
\hline Minimum Edge Length & $3.5118 \mathrm{e}-003 \mathrm{~m}$ \\
\hline \multicolumn{2}{|l|}{ Quality } \\
\hline Check Mesh Quality & Yes, Errors \\
\hline
\end{tabular}




\begin{tabular}{|l|l|}
\hline Error Limits & Standard Mechanical \\
\hline Target Quality & Default (0.050000) \\
\hline Smoothing & Medium \\
\hline Mesh Metric & None \\
\hline Inflation & \\
\hline Use Automatic Inflation & None \\
\hline Inflation Option & Smooth Transition \\
\hline Transition Ratio & Pre \\
\hline Maximum Layers & 0.272 \\
\hline Straight Sided Elements & \\
\hline Growth Rate & \\
\hline Inflation Algorithm & \\
\hline & \\
\hline Niew Advanced Options & \\
\hline & \\
\hline & \\
\hline & \\
\hline
\end{tabular}




\begin{tabular}{|l|l|}
\hline Number of Retries & Default (4) \\
\hline Rigid Body Behavior & Dimensionally Reduced \\
\hline Triangle Surface Mesher & Program Controlled \\
\hline Topology Checking & Yes \\
\hline Pinch Tolerance & Please Define \\
\hline Generate Pinch on Refresh & No \\
\hline Statistics & \\
\hline Nodes & 6946 \\
\hline Elements & 1134 \\
\hline
\end{tabular}

Modal (C5)

TABLE 6

Model (C4) > Analysis 


\begin{tabular}{|l|l|}
\hline Object Name & Modal (C5) \\
\hline State & Solved \\
\hline Definition & Structural \\
\hline Physics Type & Modal \\
\hline Analysis Type & Mechanical APDL \\
\hline Solver Target & \\
\hline Options & \\
\hline Environment Temperature & $22 .{ }^{\circ} \mathrm{C}$ \\
\hline Generate Input Only & No \\
\hline
\end{tabular}

TABLE 7

Model (C4) $>$ Modal (C5) $>$ Initial Condition

\begin{tabular}{|l|l|}
\hline Object Name & Pre-Stress (None) \\
\hline State & Fully Defined \\
\hline Definition & \\
\hline Pre-Stress Environment & None Available \\
\hline
\end{tabular}

TABLE 8

Model (C4) $>$ Modal (C5) $>$ Analysis Settings 


\begin{tabular}{|c|c|}
\hline Object Name & Analysis Settings \\
\hline State & Fully Defined \\
\hline \multicolumn{2}{|l|}{ Options } \\
\hline $\begin{array}{l}\text { Max Modes } \\
\text { to Find }\end{array}$ & 6 \\
\hline $\begin{array}{l}\text { Limit Search } \\
\text { to Range }\end{array}$ & No \\
\hline \multicolumn{2}{|c|}{ Solver Controls } \\
\hline Damped & No \\
\hline Solver Type & Program Controlled \\
\hline \multicolumn{2}{|c|}{ Rotordynamics Controls } \\
\hline $\begin{array}{l}\text { Coriolis } \\
\text { Effect }\end{array}$ & Off \\
\hline $\begin{array}{l}\text { Campbell } \\
\text { Diagram }\end{array}$ & Off \\
\hline Output Contrc & \\
\hline
\end{tabular}




\begin{tabular}{|c|c|}
\hline Stress & No \\
\hline Strain & No \\
\hline Nodal Forces & No \\
\hline $\begin{array}{l}\text { Calculate } \\
\text { Reactions }\end{array}$ & No \\
\hline $\begin{array}{r}\text { General } \\
\text { Miscellaneous }\end{array}$ & No \\
\hline \multicolumn{2}{|c|}{ Analysis Data Management } \\
\hline $\begin{array}{l}\text { Solver Files } \\
\text { Directory }\end{array}$ & $\begin{array}{l}\text { C:IUserslasus\AppDatalLocal\TemplWB_DESKTOP- } \\
\text { N3USIQU_asus_7184_2lunsaved_project_filesldp0\SYS-1\MECH। }\end{array}$ \\
\hline $\begin{array}{l}\text { Future } \\
\text { Analysis }\end{array}$ & None \\
\hline Scratch & \\
\hline $\begin{array}{ll}\text { Solver } & \text { Files } \\
\text { Directory } & \end{array}$ & \\
\hline $\begin{array}{r}\text { Save } \\
\text { MAPDL db }\end{array}$ & No \\
\hline
\end{tabular}




\begin{tabular}{|c|l|}
\hline Contact & Program Controlled \\
\hline Dummary & \\
\hline Delete & Yes \\
\hline Solver Units & Active System \\
\hline Solver Unit & mks \\
\hline System & \\
\hline
\end{tabular}

TABLE 9

Model (C4) $>$ Modal (C5) $>$ Loads

\begin{tabular}{|l|l|}
\hline Object Name & Fixed Support \\
\hline State & Fully Defined \\
\hline
\end{tabular}

Scope

\begin{tabular}{|l|l|}
\hline Scope \\
\hline Scoping Method & Geometry Selection \\
\hline Geometry & 1 Face \\
\hline
\end{tabular}

\section{Definition}

\begin{tabular}{|l|l|}
\hline \multicolumn{2}{|l|}{ Definition } \\
\hline Type & Fixed Support \\
\hline Suppressed & No \\
\hline
\end{tabular}


Solution (C6)

\begin{tabular}{|l|l|}
\multicolumn{2}{|c|}{ TABLE 10 } \\
Model (C4) > Modal (C5) $>$ Solution \\
\hline Object Name & Solution (C6) \\
\hline State & Solved \\
\hline Adaptive Mesh Refinement \\
\hline Max Refinement Loops \\
\hline Refinement Depth \\
\hline Information \\
\hline Peam Section Results \\
\hline Status \\
\hline MAPDL Elapsed Time \\
\hline
\end{tabular}

The following bar chart indicates the frequency at each calculated mode.

FIGURE 1

Model (C4) $>$ Modal (C5) > Solution (C6) 
6.

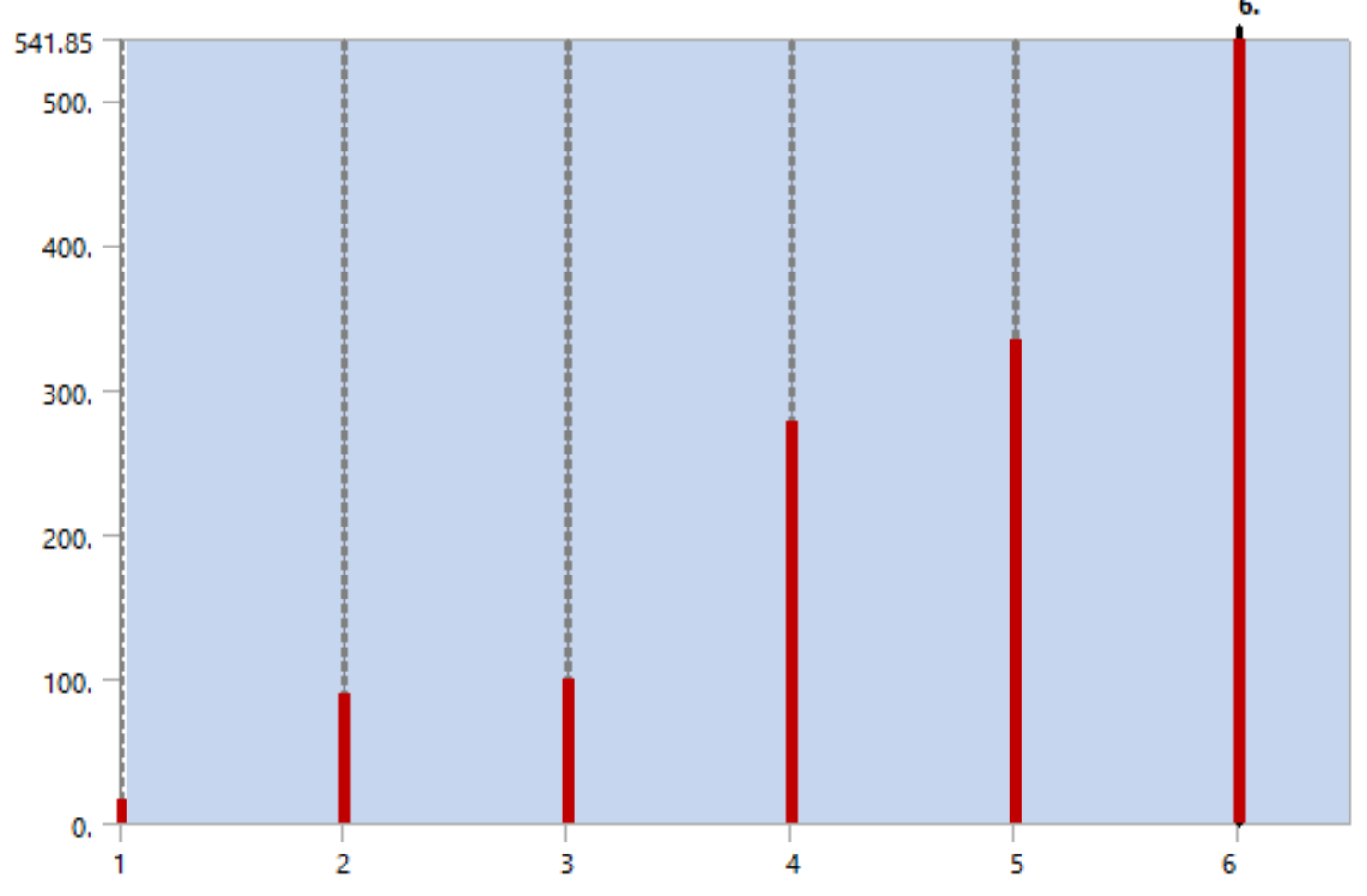

TABLE 11

Model (C4) > Modal (C5) > Solution (C6)

\begin{tabular}{|c|c|}
\hline Mode & Frequency $[\mathrm{Hz}]$ \\
\hline 1. & 15.82 \\
\hline 2. & 89.862 \\
\hline 3. & 99.021 \\
\hline 4. & 276.92 \\
\hline 5. & 333.45 \\
\hline 6. & 541.85 \\
\hline
\end{tabular}


TABLE 12

Model (C4) $>$ Modal (C5) $>$ Solution (C6) $>$ Solution Information

\begin{tabular}{|l|l|}
\hline Object Name & Solution Information \\
\hline State & Solved \\
\hline Solution Information & \\
\hline Solution Output & Solver Output \\
\hline Newton-Raphson Residuals & 0 \\
\hline Identify Element Violations & 0 \\
\hline Update Interval & All s \\
\hline Display Points & All Nodes \\
\hline FE Connection Visibility & \\
\hline Activate Visibility & Yes \\
\hline Display & \\
\hline Draw Connections Attached To & \\
\hline & \\
\hline & \\
\hline & \\
\hline & \\
\hline & \\
\hline & \\
\hline
\end{tabular}




\begin{tabular}{|l|l|}
\hline Line Thickness & Single \\
\hline Display Type & Lines \\
\hline
\end{tabular}

TABLE 13

Model (C4) $>$ Modal (C5) $>$ Solution (C6) $>$ Results

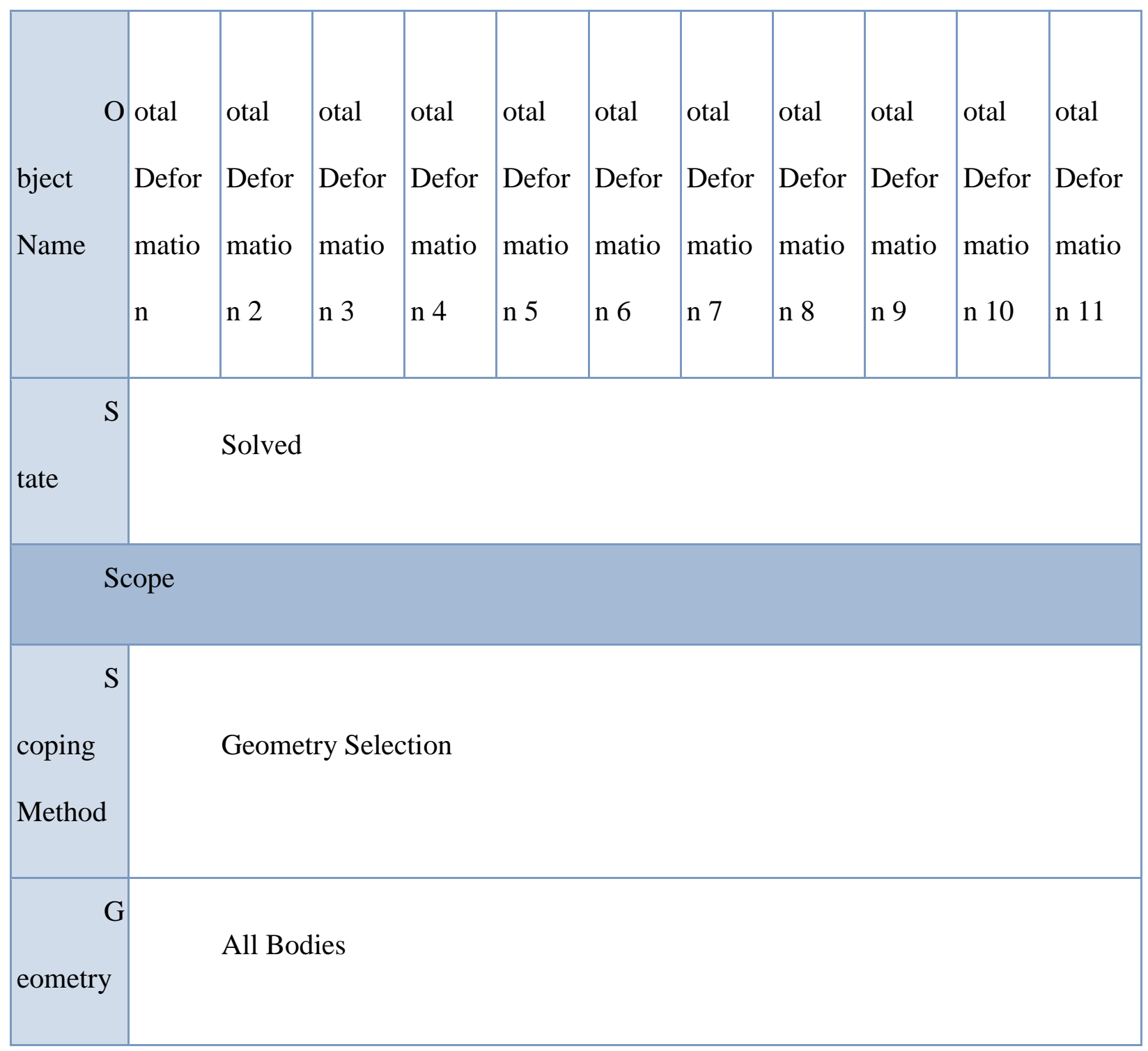




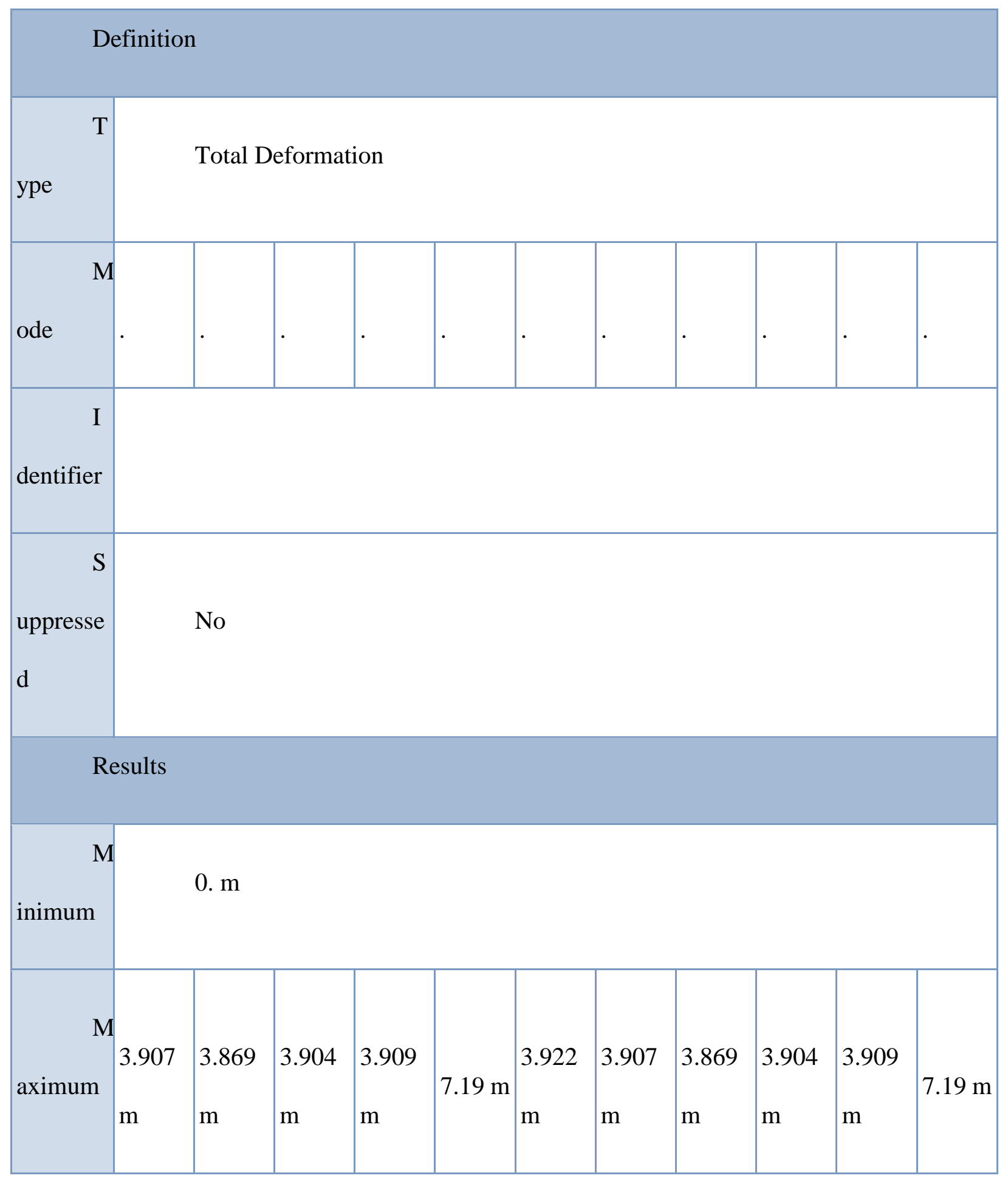




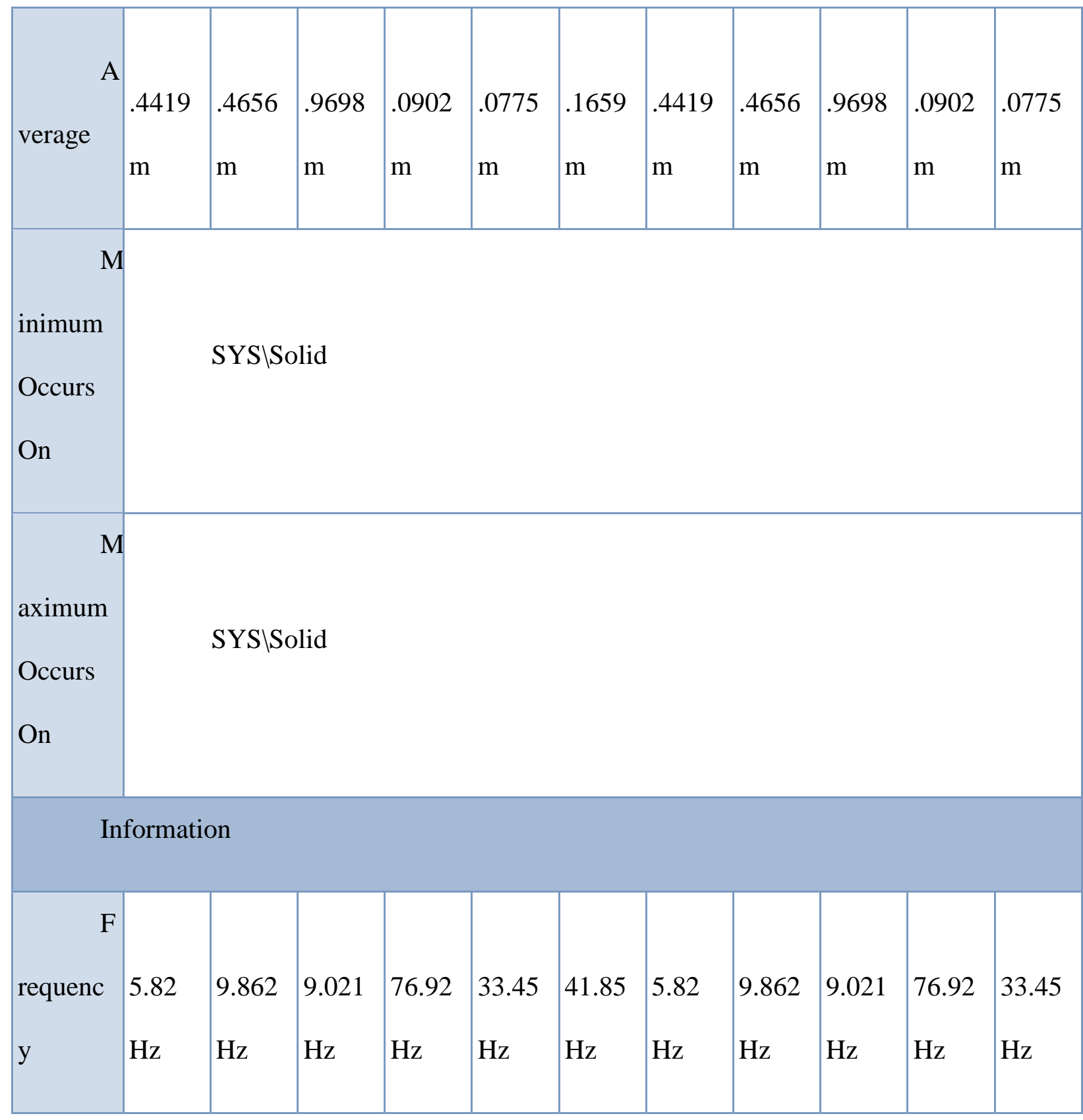

TABLE 14

Model (C4) > Modal (C5) > Solution (C6) > Total Deformation

\begin{tabular}{|l|l|}
\hline Mode & Frequency $[\mathrm{Hz}]$ \\
\hline 1. & 15.82 \\
\hline
\end{tabular}




\begin{tabular}{|c|c|}
\hline 2. & 89.862 \\
\hline 3. & 99.021 \\
\hline 4. & 276.92 \\
\hline 5. & 333.45 \\
\hline 6. & 541.85 \\
\hline
\end{tabular}

TABLE 15

Model (C4) $>$ Modal (C5) $>$ Solution (C6) $>$ Total Deformation 2

\begin{tabular}{|c|c|}
\hline Mode & Frequency $[\mathrm{Hz}]$ \\
\hline 1. & 15.82 \\
\hline 2. & 89.862 \\
\hline 3. & 99.021 \\
\hline 4. & 276.92 \\
\hline 5. & 333.45 \\
\hline 6. & 541.85 \\
\hline
\end{tabular}

TABLE 16

Model (C4) > Modal (C5) > Solution (C6) > Total Deformation 3

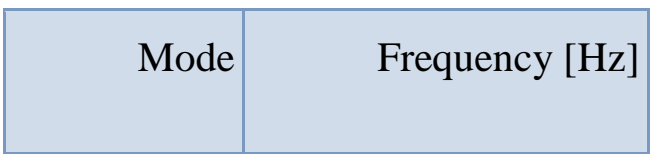




\begin{tabular}{|c|c|}
\hline 1. & 15.82 \\
\hline 2. & 89.862 \\
\hline 3. & 99.021 \\
\hline 4. & 276.92 \\
\hline 5. & 333.45 \\
\hline 6. & 541.85 \\
\hline
\end{tabular}

TABLE 17

Model (C4) > Modal (C5) > Solution (C6) > Total Deformation 4

\begin{tabular}{|c|c|}
\hline Mode & Frequency $[\mathrm{Hz}]$ \\
\hline 1. & 15.82 \\
\hline 2. & 89.862 \\
\hline 3. & 99.021 \\
\hline 4. & 276.92 \\
\hline 5. & 333.45 \\
\hline 6. & 541.85 \\
\hline
\end{tabular}

TABLE 18

Model (C4) > Modal (C5) > Solution (C6) > Total Deformation 5 


\begin{tabular}{|c|c|}
\hline Mode & Frequency $[\mathrm{Hz}]$ \\
\hline 1. & 15.82 \\
\hline 2. & 89.862 \\
\hline 3. & 99.021 \\
\hline 4. & 276.92 \\
\hline 5. & 333.45 \\
\hline 6. & 541.85 \\
\hline
\end{tabular}

TABLE 19

Model (C4) > Modal (C5) > Solution (C6) > Total Deformation 6

\begin{tabular}{|c|c|}
\hline Mode & Frequency $[\mathrm{Hz}]$ \\
\hline 1. & 15.82 \\
\hline 2. & 89.862 \\
\hline 3. & 99.021 \\
\hline 4. & 276.92 \\
\hline 5. & 333.45 \\
\hline 6. & 541.85 \\
\hline
\end{tabular}


TABLE 20

Model (C4) $>$ Modal (C5) $>$ Solution (C6) $>$ Total Deformation 7

\begin{tabular}{|c|c|}
\hline Mode & Frequency $[\mathrm{Hz}]$ \\
\hline 1. & 15.82 \\
\hline 2. & 89.862 \\
\hline 3. & 99.021 \\
\hline 4. & 276.92 \\
\hline 5. & 333.45 \\
\hline 6. & 541.85 \\
\hline
\end{tabular}

TABLE 21

Model (C4) > Modal (C5) > Solution (C6) > Total Deformation 8

\begin{tabular}{|c|c|}
\hline Mode & Frequency $[\mathrm{Hz}]$ \\
\hline 1. & 15.82 \\
\hline 2. & 89.862 \\
\hline 3. & 99.021 \\
\hline
\end{tabular}




\begin{tabular}{|c|c|}
\hline 4. & 276.92 \\
\hline 5. & 333.45 \\
\hline 6. & 541.85 \\
\hline
\end{tabular}

TABLE 22

Model (C4) $>$ Modal (C5) $>$ Solution (C6) $>$ Total Deformation 9

\begin{tabular}{|c|c|}
\hline Mode & Frequency $[\mathrm{Hz}]$ \\
\hline 1. & 15.82 \\
\hline 2. & 89.862 \\
\hline 3. & 99.021 \\
\hline 4. & 276.92 \\
\hline 5. & 333.45 \\
\hline 6. & 541.85 \\
\hline
\end{tabular}

TABLE 23

Model (C4) $>$ Modal (C5) > Solution (C6) > Total Deformation 10

\begin{tabular}{|l|l|}
\hline Mode & Frequency [Hz] \\
\hline 1. & 15.82 \\
\hline 2. & 89.862 \\
\hline
\end{tabular}




\begin{tabular}{|c|c|}
\hline 3. & 99.021 \\
\hline 4. & 276.92 \\
\hline 5. & 333.45 \\
\hline 6. & 541.85 \\
\hline
\end{tabular}

TABLE 24

Model (C4) > Modal (C5) > Solution (C6) > Total Deformation 11

\begin{tabular}{|c|c|}
\hline Mode & Frequency $[\mathrm{Hz}]$ \\
\hline 1. & 15.82 \\
\hline 2. & 89.862 \\
\hline 3. & 99.021 \\
\hline 4. & 276.92 \\
\hline 5. & 333.45 \\
\hline 6. & 541.85 \\
\hline
\end{tabular}

TABLE 25

Model (C4) $>$ Modal (C5) $>$ Solution (C6) $>$ Results

\begin{tabular}{|l|l|}
\hline Object Name & Total Deformation 12 \\
\hline State & Solved \\
\hline
\end{tabular}




\begin{tabular}{|l|l|}
\hline \multicolumn{2}{|l|}{ Scope } \\
\hline Scoping Method & Geometry Selection \\
\hline Geometry & All Bodies \\
\hline Definition & \\
\hline Type & Total Deformation \\
\hline Mode & 6. \\
\hline Identifier & \\
\hline Suppressed & No \\
\hline Results & \\
\hline Mnformation & \\
\hline Minimum & \\
\hline Maximum & \\
\hline
\end{tabular}




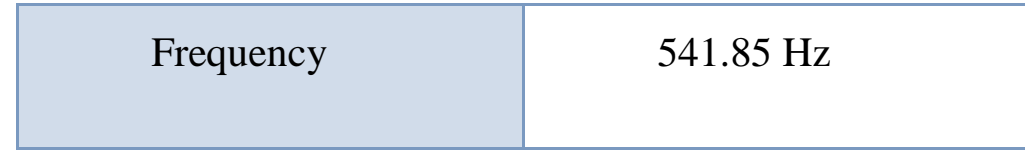

TABLE 26

Model (C4) > Modal (C5) > Solution (C6) > Total Deformation 12

\begin{tabular}{|c|c|}
\hline Mode & Frequency $[\mathrm{Hz}]$ \\
\hline 1. & 15.82 \\
\hline 2. & 89.862 \\
\hline 3. & 99.021 \\
\hline 4. & 276.92 \\
\hline 5. & 333.45 \\
\hline 6. & 541.85 \\
\hline
\end{tabular}

Material Data

XYZ PLA

TABLE 27

XYZ PLA > Constants

\begin{tabular}{|l|l|}
\hline Density & $1216.7 \mathrm{~kg} \mathrm{~m}^{\wedge}-3$ \\
\hline
\end{tabular}


TABLE 28

XYZ PLA > Color

\begin{tabular}{|r|r|r|}
\hline Red & Green & Blue \\
\hline 181 & 194 & 156 \\
\hline
\end{tabular}

TABLE 29

XYZ PLA > Orthotropic Elasticity

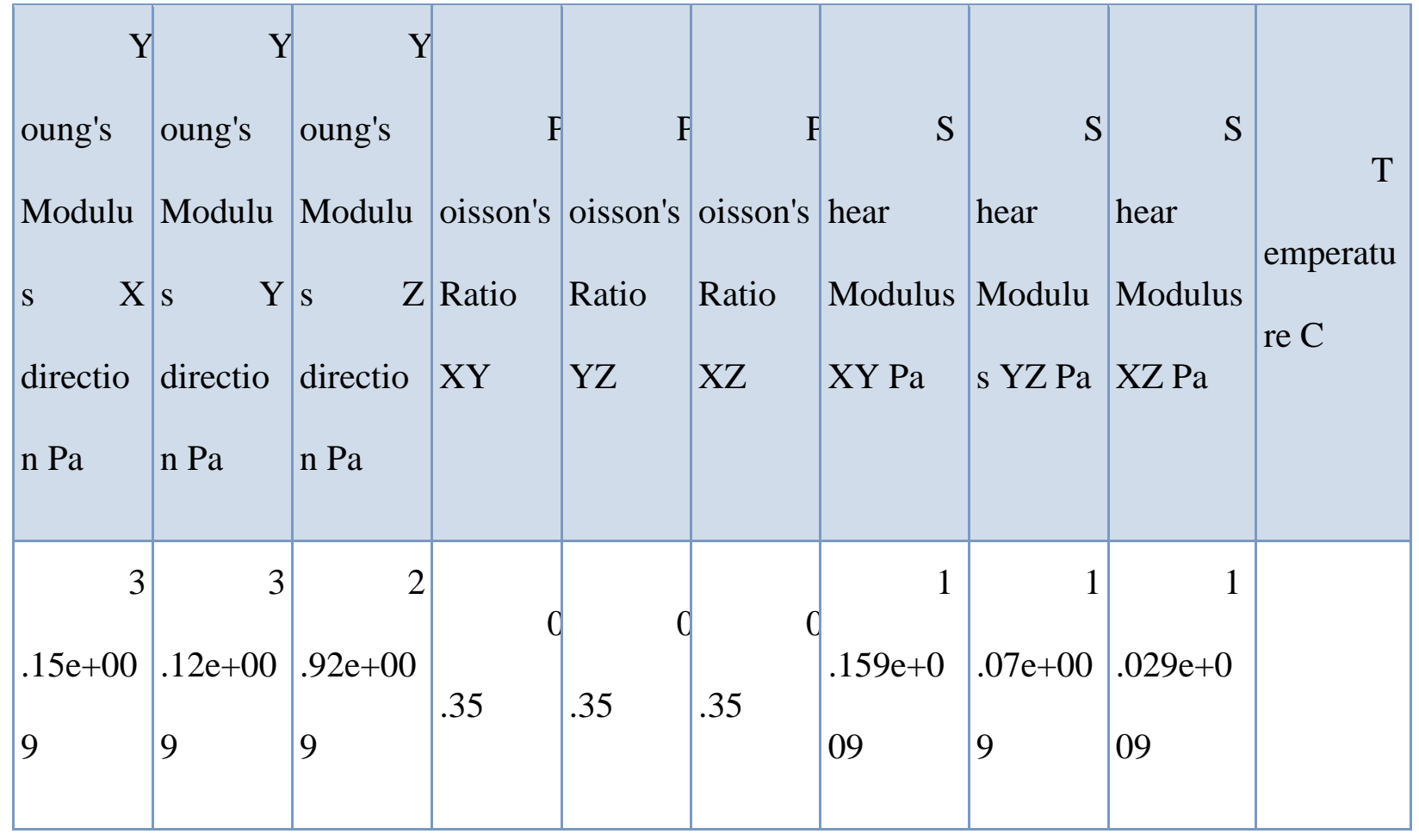



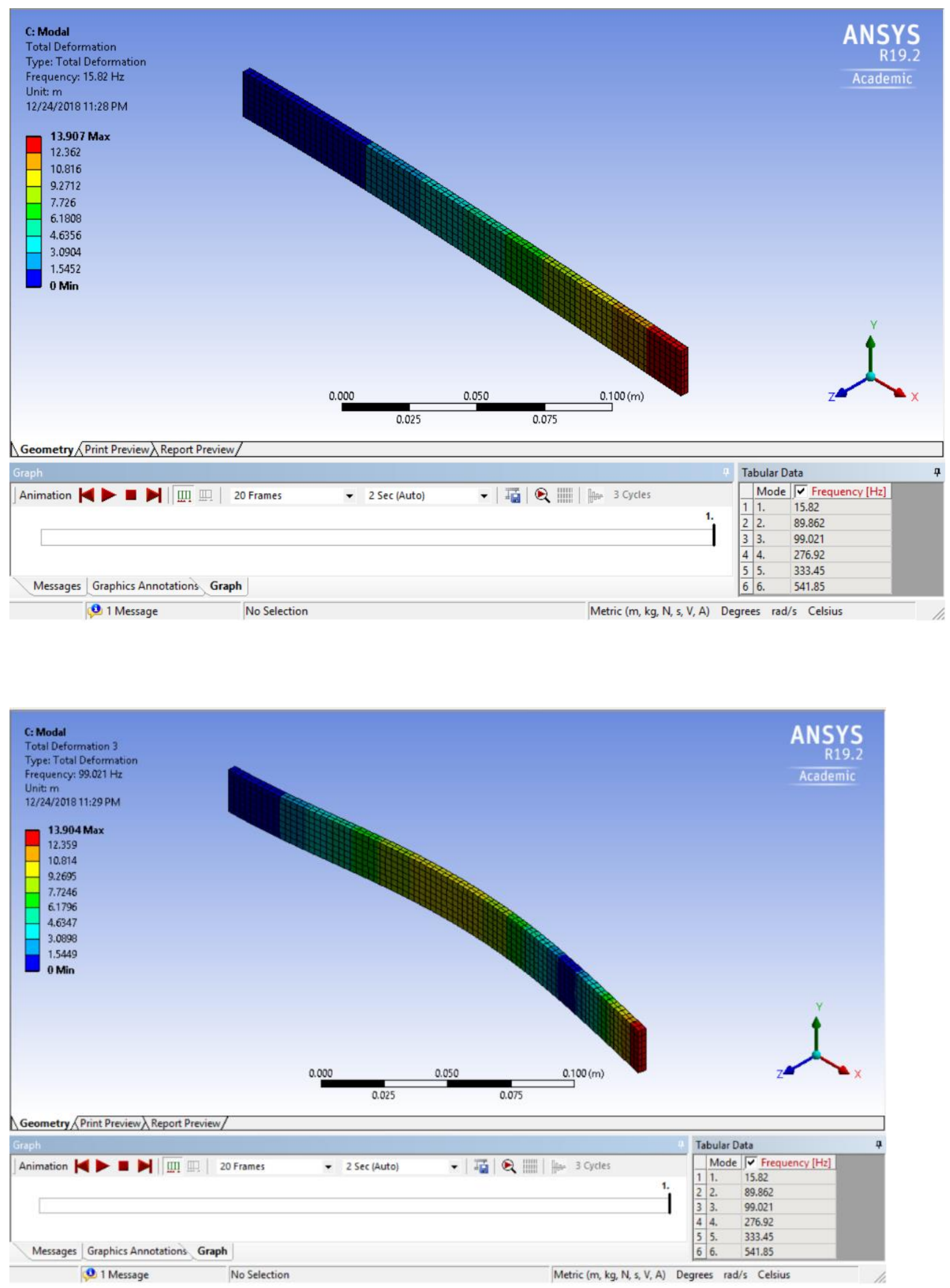


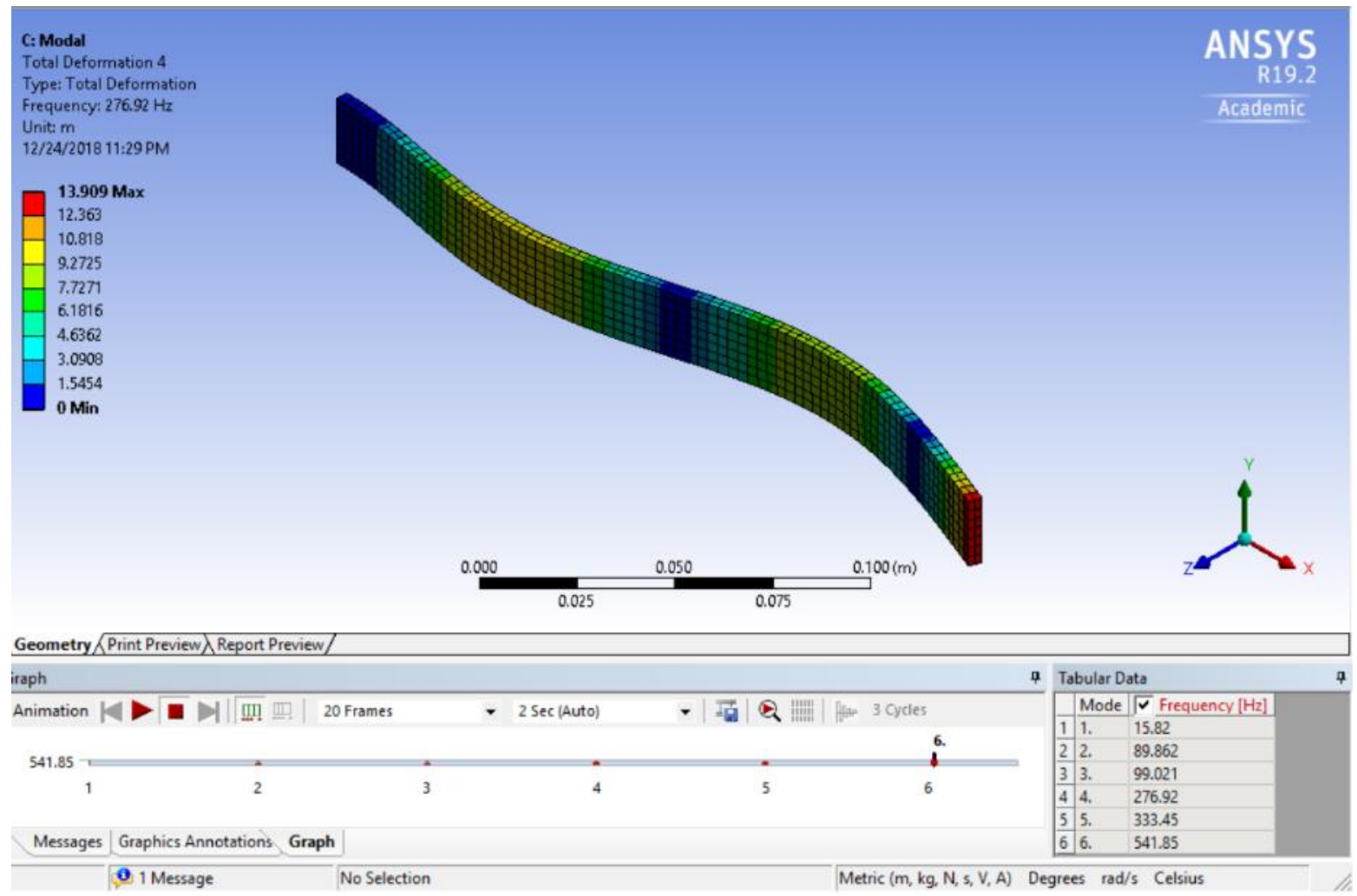




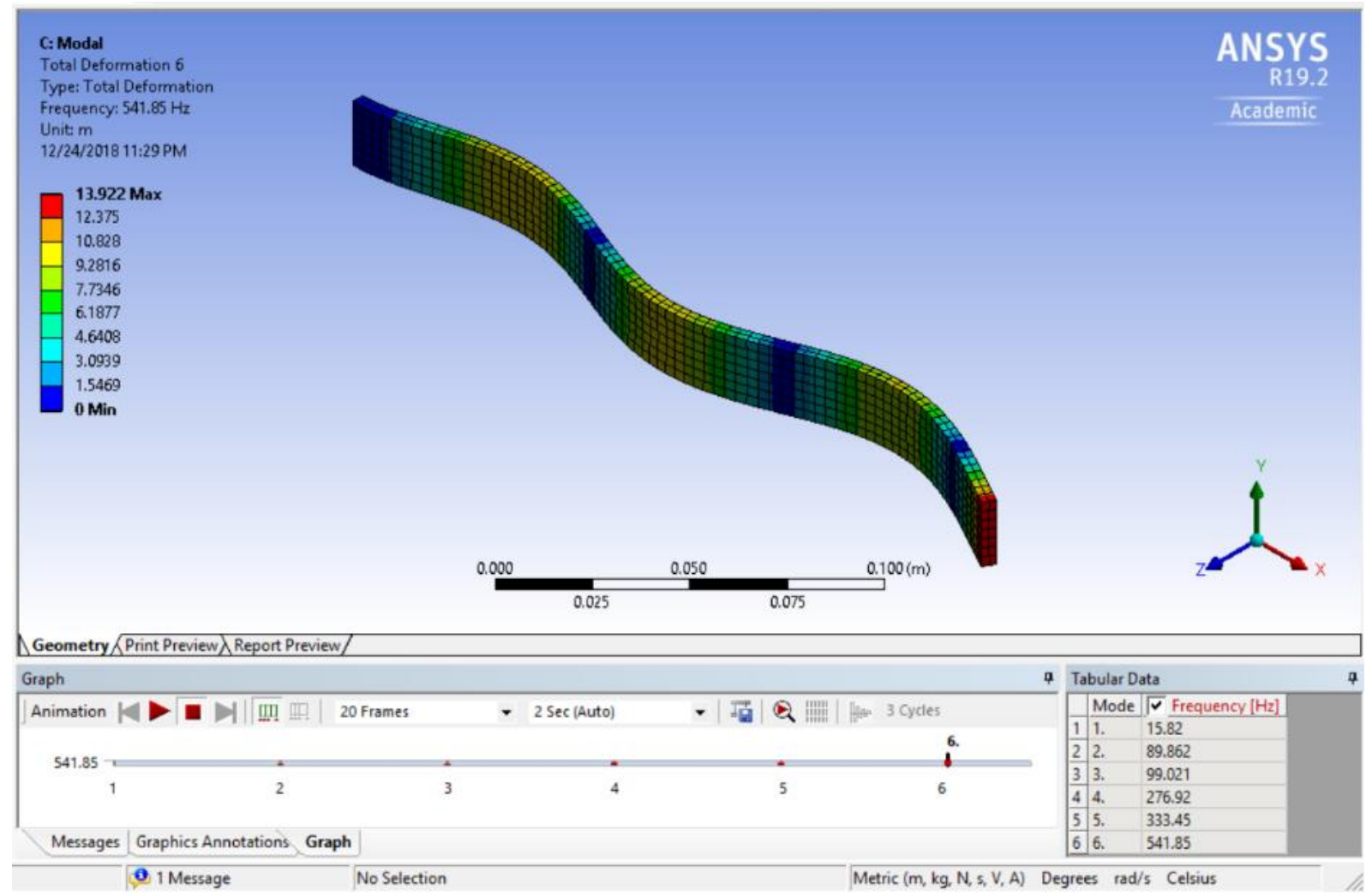

\section{ANSYS}

Appendix D2 Build orientation XZY

\begin{tabular}{|l|l|}
\hline First Saved & Monday, December 24, 2018 \\
\hline Last Saved & Monday, December 24, 2018 \\
\hline Product Version & 19.2 Release \\
\hline Save Project Before Solution & No \\
\hline
\end{tabular}




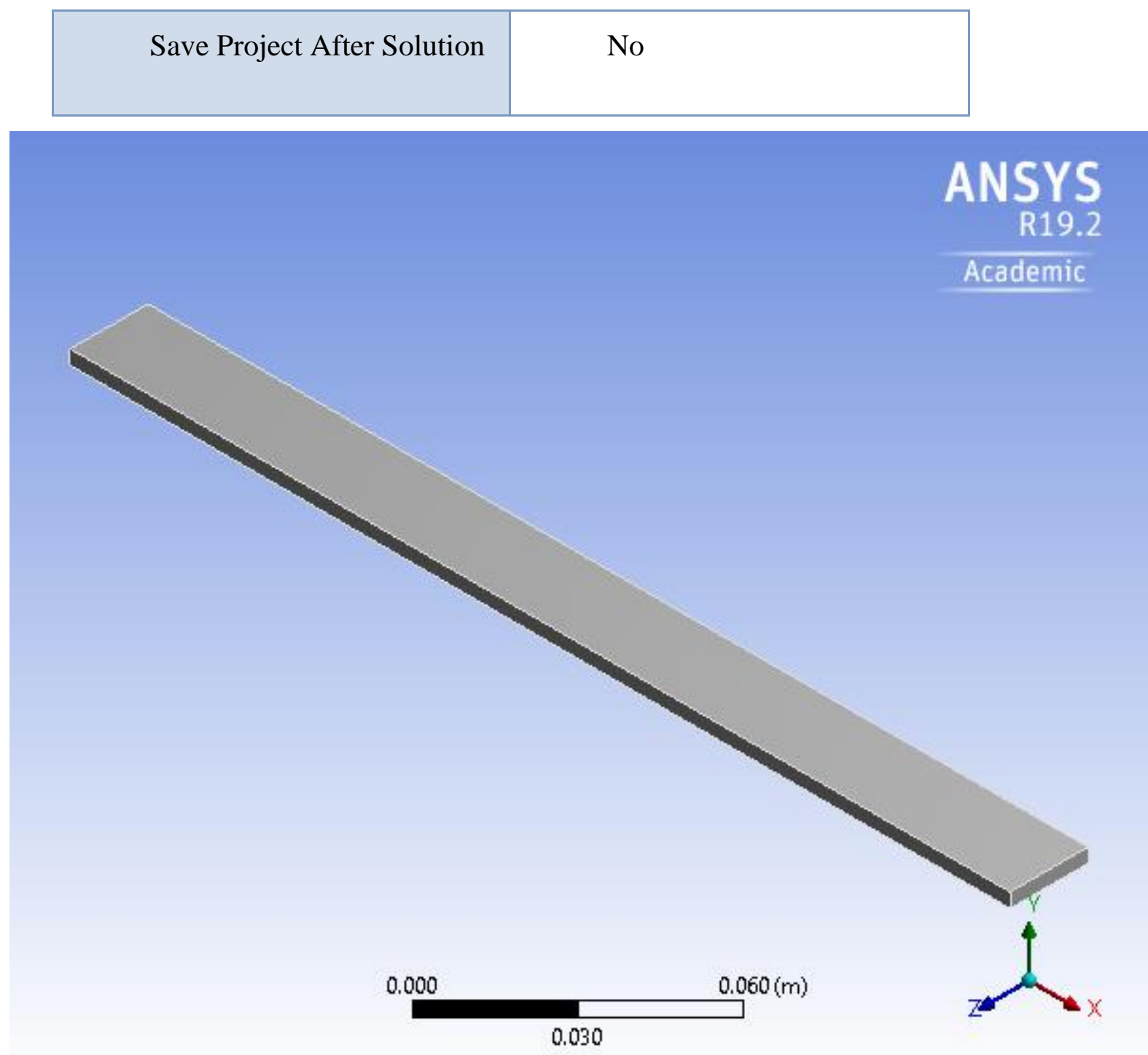

Contents

- $\quad \underline{\text { Units }}$

- Model (C4)

- Geometry

- SYS-2ISolid 
○ Materials

- PLA

- XZY PLA

- Coordinate Systems

○ Mesh

○ Modal (C5)

- $\quad$ Pre-Stress (None)

- Analysis Settings

- $\quad$ Fixed Support

- $\quad$ Solution (C6)

- Solution Information

- $\underline{\text { Results }}$

- Material Data

- $\underline{\text { XZY PLA }}$

Units

TABLE 1

\begin{tabular}{|l|l|}
\hline Unit System & Metric (m, kg, N, s, V, A) Degrees rad/s Celsius \\
\hline Angle & Degrees \\
\hline Rotational Velocity & $\mathrm{rad} / \mathrm{s}$ \\
\hline Temperature & Celsius \\
\hline
\end{tabular}

Model (C4)

Geometry 
TABLE

Model (C4) > Geometry

\begin{tabular}{|c|c|}
\hline Object Name & Geometry \\
\hline State & Fully Defined \\
\hline \multicolumn{2}{|l|}{ Definition } \\
\hline Source & 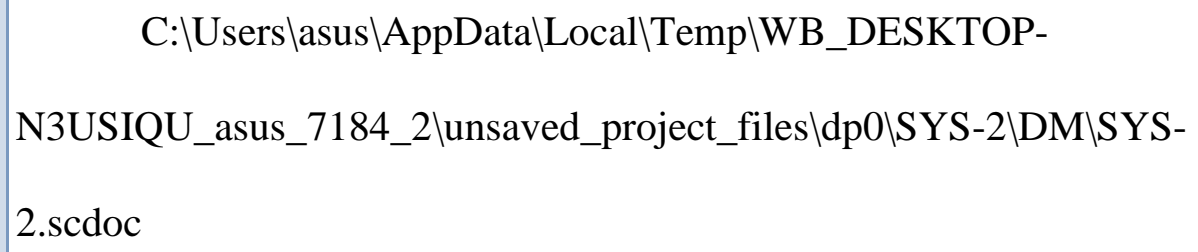 \\
\hline Type & SpaceClaim \\
\hline Length Unit & Meters \\
\hline $\begin{array}{l}\text { Element } \\
\text { Control }\end{array}$ & Program Controlled \\
\hline Display Style & Body Color \\
\hline \multicolumn{2}{|l|}{ Bounding Box } \\
\hline Length $X$ & $0.241 \mathrm{~m}$ \\
\hline Length Y & $3.65 \mathrm{e}-003 \mathrm{~m}$ \\
\hline
\end{tabular}




\begin{tabular}{|c|c|}
\hline Length Z & $1.996 \mathrm{e}-002 \mathrm{~m}$ \\
\hline Properties & \\
\hline Volume & $1.7558 \mathrm{e}-005 \mathrm{~m}^{3}$ \\
\hline Mass & $2.0829 \mathrm{e}-002 \mathrm{~kg}$ \\
\hline Scale Factor & 1. \\
\hline Value & \\
\hline Statistics & 1 \\
\hline Bodies & No \\
\hline Active Bodies & 1 \\
\hline Nodes & 1640 \\
\hline Elements & \\
\hline Material & \\
\hline
\end{tabular}




\begin{tabular}{|c|c|}
\hline \multicolumn{2}{|c|}{ Basic Geometry Options } \\
\hline Solid Bodies & Yes \\
\hline Surface Bodies & Yes \\
\hline Line Bodies & Yes \\
\hline Parameters & Independent \\
\hline Parameter Key & \\
\hline Attributes & Yes \\
\hline Attribute Key & \\
\hline Properties & \\
\hline Named & Yes \\
\hline Selections & \\
\hline Named & \\
\hline
\end{tabular}




\begin{tabular}{|c|c|}
\hline Use & Yes \\
\hline Associativity & \\
\hline Coordinate & Yes \\
\hline Coordinate & \\
\hline System Key & \\
\hline Reader Mode & No \\
\hline Saves Updated File & \\
\hline Use Instances & Yes \\
\hline Smart CAD & Yes \\
\hline Update & \\
\hline Analysis Type & 3 -D \\
\hline Compare Parts & No \\
\hline Opdate & \\
\hline
\end{tabular}




\begin{tabular}{|c|c|}
\hline Clean Bodies & No \\
On Import & \\
\hline Stitch Surfaces & No \\
\hline On Import & \\
\hline Decompose & Yes \\
\hline Disjoint Geometry & \\
\hline Enclosure and & Yes \\
\hline Symmetry Processing & \\
\hline
\end{tabular}

Model (C4) > Geometry > Parts

\begin{tabular}{|l|l|}
\hline Object Name & SYS-2lSolid \\
\hline State & Meshed \\
\hline Graphics Properties & \\
\hline Visible & Yes \\
\hline Transparency & 1 \\
\hline Definition & \\
\hline Suppressed & No \\
\hline
\end{tabular}




\begin{tabular}{|l|l|}
\hline Stiffness Behavior & Flexible \\
\hline Coordinate System & Default Coordinate System \\
\hline Reference Temperature & By Environment \\
\hline Behavior & None \\
\hline Material & \\
\hline Assignment & XZY PLA \\
\hline Nonlinear Effects & Yes \\
\hline Thermal Strain Effects & Yes \\
\hline Bounding Box & \\
\hline Length Z & \\
\hline Length X & \\
\hline
\end{tabular}




\begin{tabular}{|c|c|}
\hline Centroid X & $0.1205 \mathrm{~m}$ \\
\hline Centroid Y & $1.75 \mathrm{e}-004 \mathrm{~m}$ \\
\hline Centroid Z & $1.98 \mathrm{e}-003 \mathrm{~m}$ \\
\hline Moment of Inertia Ip1 & $7.1464 \mathrm{e}-007 \mathrm{~kg} \cdot \mathrm{m}^{2}$ \\
\hline Moment of Inertia Ip2 & $1.015 \mathrm{e}-004 \mathrm{~kg} \cdot \mathrm{m}^{2}$ \\
\hline Moment of Inertia Ip3 & $1.0084 \mathrm{e}-004 \mathrm{~kg} \cdot \mathrm{m}^{2}$ \\
\hline \multicolumn{2}{|l|}{ Statistics } \\
\hline Nodes & 1640 \\
\hline Elements & 196 \\
\hline Mesh Metric & None \\
\hline \multicolumn{2}{|l|}{ CAD Attributes } \\
\hline PartTolerance: & 0.00000001 \\
\hline Color: 143.175 .143 & \\
\hline
\end{tabular}

Coordinate Systems 
Model (C4) $>$ Coordinate Systems > Coordinate System

\begin{tabular}{|c|c|}
\hline Object Name & Global Coordinate System \\
\hline State & Fully Defined \\
\hline \multicolumn{2}{|l|}{ Definition } \\
\hline Type & Cartesian \\
\hline Coordinate System ID & 0. \\
\hline \multicolumn{2}{|l|}{ Origin } \\
\hline Origin $\mathrm{X}$ & $0 . \mathrm{m}$ \\
\hline Origin $\mathrm{Y}$ & $0 . \mathrm{m}$ \\
\hline Origin $\mathrm{Z}$ & $0 . \mathrm{m}$ \\
\hline \multicolumn{2}{|l|}{ Directional Vectors } \\
\hline X Axis Data & {$\left[\begin{array}{lll}1.0 .0 . & 0 .\end{array}\right.$} \\
\hline Y Axis Data & {$[0.1 .0]$.} \\
\hline Z Axis Data & {$\left[\begin{array}{lll}0.0 .1 . & 0 .\end{array}\right.$} \\
\hline
\end{tabular}

Mesh 
TABLE

Model (C4) > Mesh

\begin{tabular}{|c|c|}
\hline Object Name & Mesh \\
\hline State & Solved \\
\hline \multicolumn{2}{|l|}{ Display } \\
\hline Display Style & Maximum Corner Angle \\
\hline \multicolumn{2}{|l|}{ Defaults } \\
\hline Physics Preference & Mechanical \\
\hline Element Order & Program Controlled \\
\hline Element Size & 5.e-003 m \\
\hline \multicolumn{2}{|l|}{ Sizing } \\
\hline Use Adaptive Sizing & Yes \\
\hline Resolution & Default (2) \\
\hline Mesh Defeaturing & Yes \\
\hline Defeature Size & Default \\
\hline
\end{tabular}




\begin{tabular}{|l|l|}
\hline Transition & Fast \\
\hline Span Angle Center & Coarse \\
\hline Initial Size Seed & Assembly \\
\hline Bounding Box Diagonal & $0.24185 \mathrm{~m}$ \\
\hline Average Surface Area & $1.921 \mathrm{e}-003 \mathrm{~m}^{2}$ \\
\hline Minimum Edge Length & $3.65 \mathrm{e}-003 \mathrm{~m}$ \\
\hline Quality & \\
\hline Check Mesh Quality & Yes, Errors \\
\hline Error Limits & Standard Mechanical \\
\hline Inflation Option & Noneth Transition \\
\hline Target Quality & \\
\hline Smoothing & \\
\hline & \\
\hline & \\
\hline & \\
\hline & \\
\hline & \\
\hline & \\
\hline
\end{tabular}




\begin{tabular}{|l|l|}
\hline Transition Ratio & 0.272 \\
\hline Maximum Layers & 5 \\
\hline Growth Rate & 1.2 \\
\hline Inflation Algorithm & Pre \\
\hline View Advanced Options & No \\
\hline Advanced & \\
\hline Number of CPUs for Parallel Part Meshing & Program Controlled \\
\hline Straight Sided Elements & No \\
\hline Number of Retries & Program Controlled \\
\hline Statistics & Default (4) \\
\hline Trigid Body Behavior & Dimensionally Reduced \\
\hline & \\
\hline Tinch Tolerance & \\
\hline & \\
\hline & \\
\hline & \\
\hline & \\
\hline
\end{tabular}




\begin{tabular}{|l|c|}
\hline Nodes & 1640 \\
\hline Elements & 196 \\
\hline
\end{tabular}

Modal (C5)

TABLE

Model (C4) > Analysis

\begin{tabular}{|l|l|}
\hline Object Name & Modal (C5) \\
\hline State & Solved \\
\hline Definition & Structural \\
\hline Physics Type & Modal \\
\hline Analysis Type & Mechanical APDL \\
\hline Solver Target & \\
\hline Options & \\
\hline Environment Temperature & $22 .{ }^{\circ} \mathrm{C}$ \\
\hline Generate Input Only & No \\
\hline
\end{tabular}

TABLE

Model (C4) > Modal (C5) > Initial Condition 


\begin{tabular}{|l|l|}
\hline Object Name & Pre-Stress (None) \\
\hline State & Fully Defined \\
\hline Definition & \\
\hline Pre-Stress Environment & None Available \\
\hline
\end{tabular}

TABLE

Model (C4) > Modal (C5) > Analysis Settings

\begin{tabular}{|c|l|}
\hline Object Name & Analysis Settings \\
\hline State & Fully Defined \\
\hline Options & \\
\hline Max Modes & 6 \\
to Find & \\
\hline Limit Search & No \\
to Range & \\
\hline Solver Controls & \\
\hline Damped & No \\
\hline
\end{tabular}




\begin{tabular}{|c|c|}
\hline Solver Type & Program Controlled \\
\hline \multicolumn{2}{|c|}{ Rotordynamics Controls } \\
\hline $\begin{array}{l}\text { Coriolis } \\
\text { Effect }\end{array}$ & Off \\
\hline $\begin{array}{l}\text { Campbell } \\
\text { Diagram }\end{array}$ & Off \\
\hline \multicolumn{2}{|c|}{ Output Controls } \\
\hline Stress & No \\
\hline Strain & No \\
\hline Nodal Forces & No \\
\hline $\begin{array}{l}\text { Calculate } \\
\text { Reactions }\end{array}$ & No \\
\hline $\begin{array}{r}\text { General } \\
\text { Miscellaneous }\end{array}$ & No \\
\hline Analysis Data & gement \\
\hline
\end{tabular}




\begin{tabular}{|c|c|}
\hline $\begin{array}{l}\text { Solver Files } \\
\text { Directory }\end{array}$ & 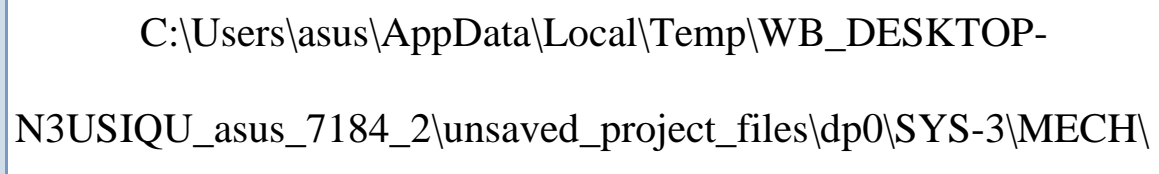 \\
\hline $\begin{array}{l}\text { Future } \\
\text { Analysis }\end{array}$ & None \\
\hline Scratch & \\
\hline $\begin{array}{ll}\text { Solver } & \text { Files } \\
\text { Directory } & \end{array}$ & \\
\hline $\begin{array}{r}\text { Save } \\
\text { MAPDL db }\end{array}$ & No \\
\hline $\begin{array}{l}\text { Contact } \\
\text { Summary }\end{array}$ & Program Controlled \\
\hline $\begin{array}{c}\text { Delete } \\
\text { Unneeded Files }\end{array}$ & Yes \\
\hline Solver Units & Active System \\
\hline $\begin{array}{l}\text { Solver Unit } \\
\text { System }\end{array}$ & mks \\
\hline
\end{tabular}

TABLE

Model (C4) > Modal (C5) > Loads 


\begin{tabular}{|l|l|}
\hline Object Name & Fixed Support \\
\hline State & Fully Defined \\
\hline Scope & \\
\hline Scoping Method & Geometry Selection \\
\hline Geometry & 1 Face \\
\hline Definition & \\
\hline Type & Fixed Support \\
\hline Suppressed & No \\
\hline
\end{tabular}

Solution (C6)

TABLE

Model (C4) > Modal (C5) > Solution

\begin{tabular}{|l|l|}
\hline Object Name & Solution (C6) \\
\hline State & Solved \\
\hline \multicolumn{2}{|l|}{ Adaptive Mesh Refinement } \\
\hline Max Refinement Loops & 1. \\
\hline
\end{tabular}




\begin{tabular}{|l|l|}
\hline Refinement Depth & 2. \\
\hline Information & Done \\
\hline Status & $3 . \mathrm{s}$ \\
\hline MAPDL Elapsed Time & $94 . \mathrm{MB}$ \\
\hline MAPDL Memory Used & \\
\hline MAPDL Result File Size & $768 . \mathrm{KB}$ \\
\hline Post Processing & \\
\hline Beam Section Results & No \\
\hline
\end{tabular}

The following bar chart indicates the frequency at each calculated mode.

FIGURE

Model (C4) > Modal (C5) > Solution (C6) 
6.

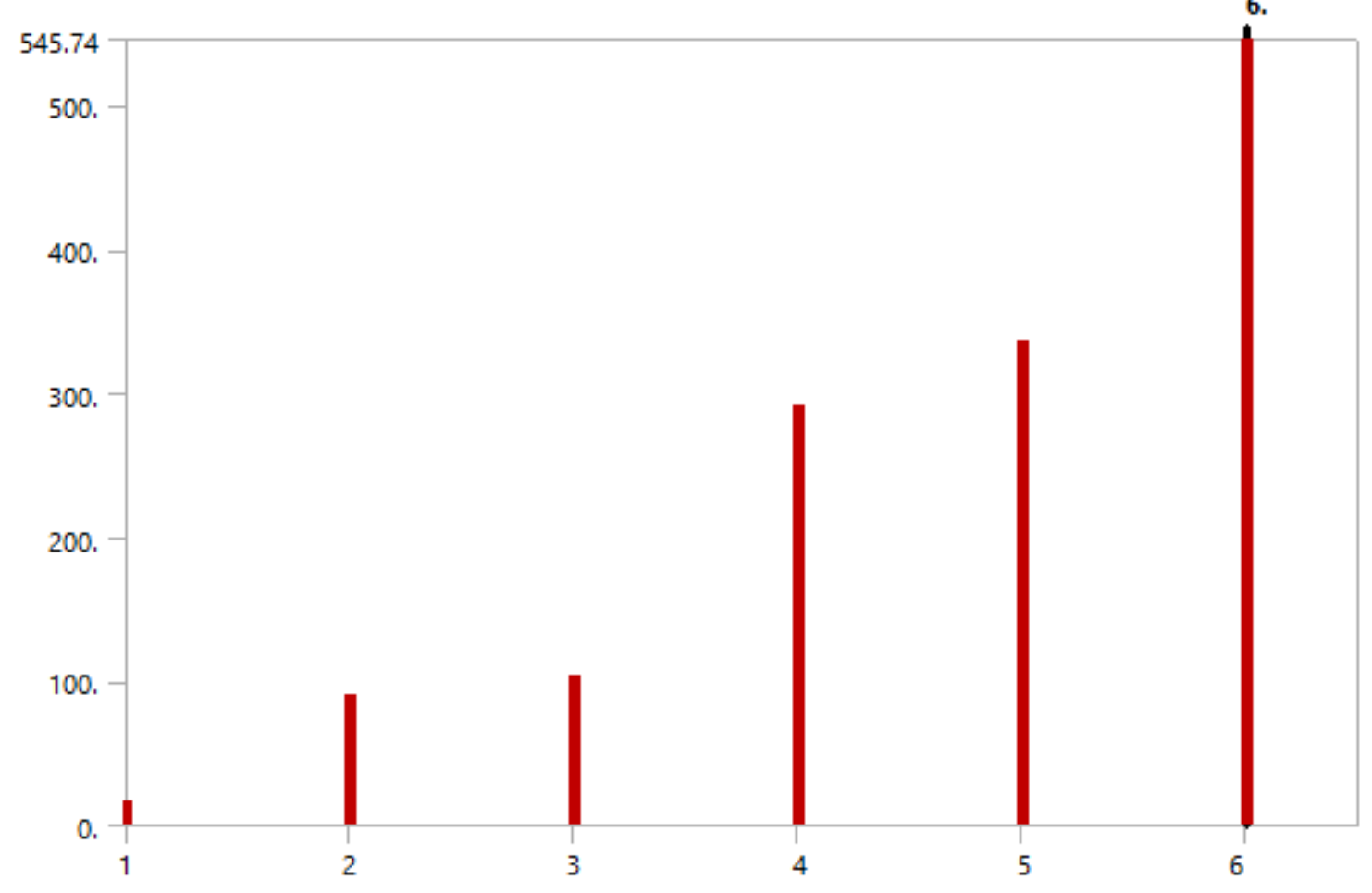

TABLE

Model (C4) > Modal (C5) > Solution (C6)

\begin{tabular}{|c|c|}
\hline Mode & Frequency $[\mathrm{Hz}]$ \\
\hline 1. & 16.68 \\
\hline 2. & 90.136 \\
\hline 3. & 104.42 \\
\hline 4. & 292.07 \\
\hline 5. & 337.24 \\
\hline
\end{tabular}




\begin{tabular}{|l|l|}
\hline 6. & 545.74 \\
\hline
\end{tabular}

TABLE

Model (C4) > Modal (C5) > Solution (C6) > Solution Information

\begin{tabular}{|l|l|}
\hline Object Name & Solution Information \\
\hline State & Solved \\
\hline Solution Information & \\
\hline Solution Output & Solver Output \\
\hline Newton-Raphson Residuals & 0 \\
\hline Identify Element Violations & All Nodes \\
\hline Update Interval & Yes \\
\hline Draw Connections Attached To & \\
\hline Display Points & All \\
\hline
\end{tabular}




\begin{tabular}{|l|l|}
\hline Line Color & Connection Type \\
\hline Visible on Results & No \\
\hline Line Thickness & Single \\
\hline Display Type & Lines \\
\hline
\end{tabular}

TABLE

Model (C4) > Modal (C5) > Solution (C6) > Results

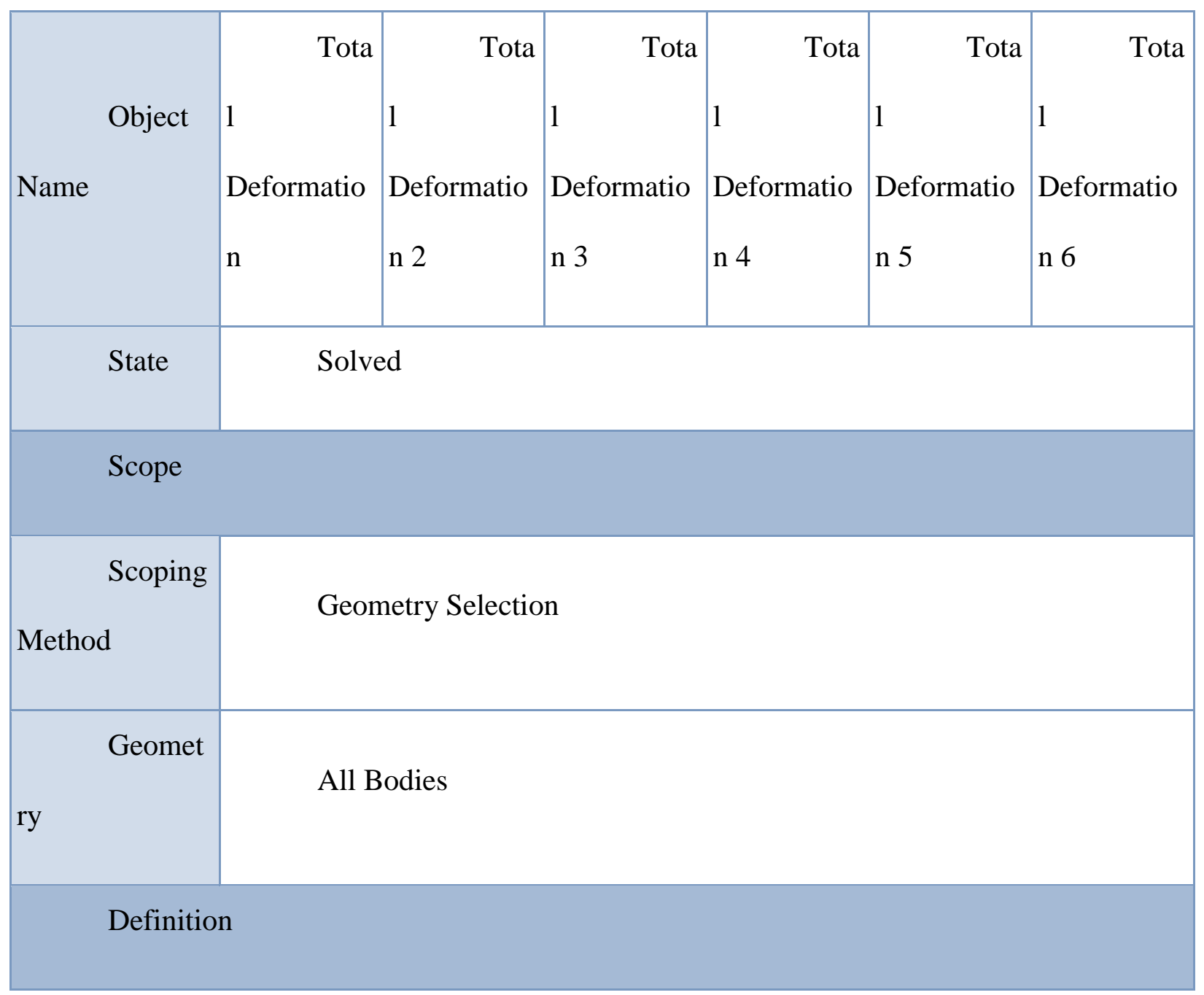




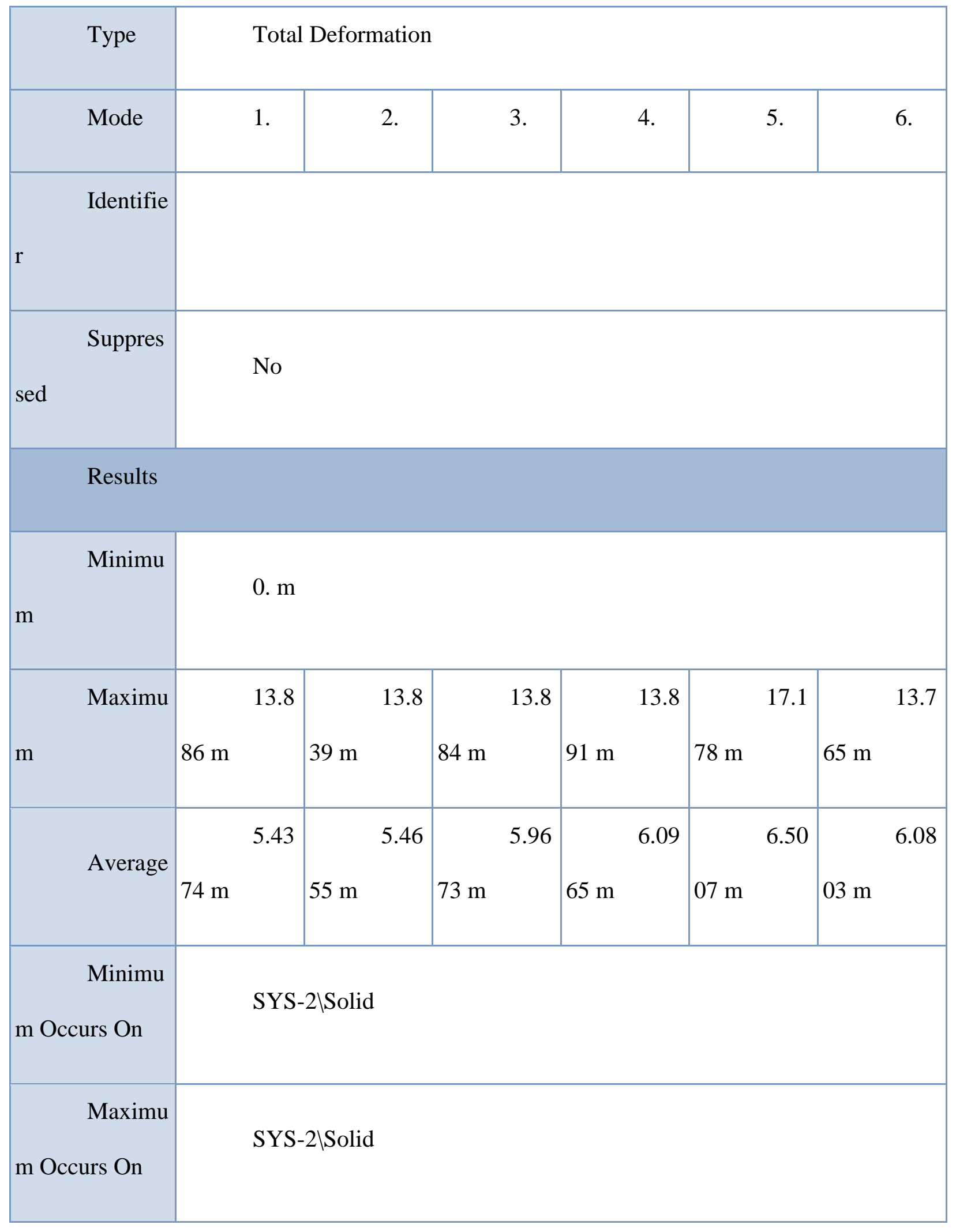




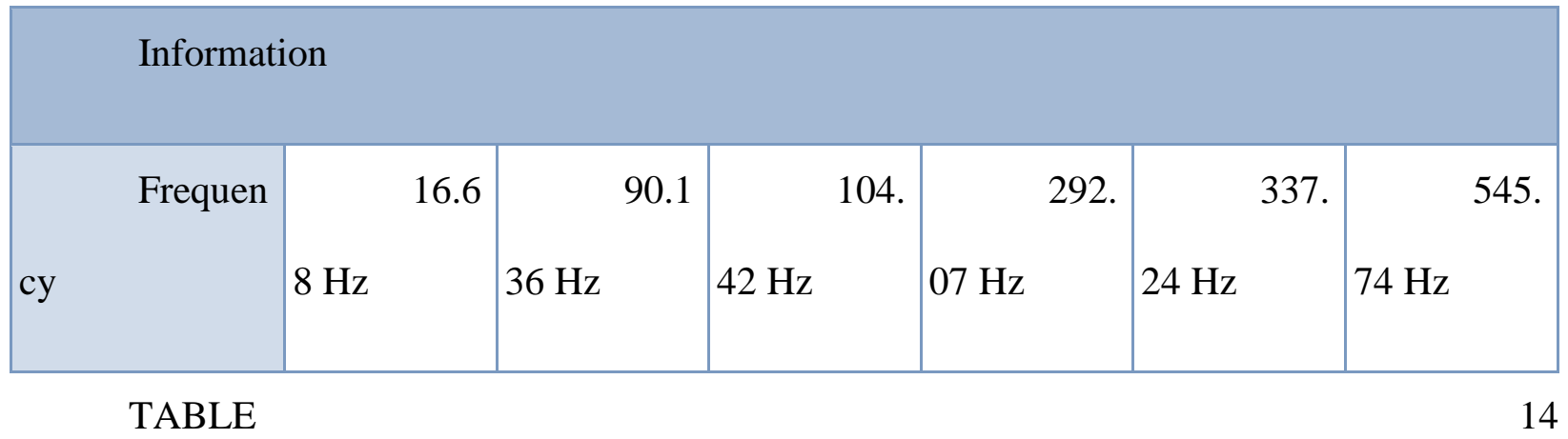

Model (C4) > Modal (C5) > Solution (C6) > Total Deformation

\begin{tabular}{|c|c|}
\hline Mode & Frequency $[\mathrm{Hz}]$ \\
\hline 1. & 16.68 \\
\hline 2. & 90.136 \\
\hline 3. & 104.42 \\
\hline 4. & 292.07 \\
\hline 5. & 337.24 \\
\hline 6. & 545.74 \\
\hline
\end{tabular}

TABLE

Model (C4) > Modal (C5) > Solution (C6) > Total Deformation 2

\begin{tabular}{|c|c|}
\hline Mode & Frequency $[\mathrm{Hz}]$ \\
\hline 1. & 16.68 \\
\hline
\end{tabular}




\begin{tabular}{|c|c|}
\hline 2. & 90.136 \\
\hline 3. & 104.42 \\
\hline 4. & 292.07 \\
\hline 5. & 337.24 \\
\hline 6. & 545.74 \\
\hline
\end{tabular}

TABLE

Model (C4) $>$ Modal (C5) > Solution (C6) $>$ Total Deformation 3

\begin{tabular}{|c|c|}
\hline Mode & Frequency $[\mathrm{Hz}]$ \\
\hline 1. & 16.68 \\
\hline 2. & 90.136 \\
\hline 3. & 104.42 \\
\hline 4. & 292.07 \\
\hline 5. & 337.24 \\
\hline 6. & 545.74 \\
\hline
\end{tabular}

TABLE

Model (C4) $>$ Modal (C5) $>$ Solution (C6) $>$ Total Deformation 4 


\begin{tabular}{|c|c|}
\hline Mode & Frequency $[\mathrm{Hz}]$ \\
\hline 1. & 16.68 \\
\hline 2. & 90.136 \\
\hline 3. & 104.42 \\
\hline 4. & 292.07 \\
\hline 5. & 337.24 \\
\hline 6. & 545.74 \\
\hline
\end{tabular}

TABLE

Model (C4) > Modal (C5) > Solution (C6) > Total Deformation 5

\begin{tabular}{|c|c|}
\hline Mode & Frequency $[\mathrm{Hz}]$ \\
\hline 1. & 16.68 \\
\hline 2. & 90.136 \\
\hline 3. & 104.42 \\
\hline 4. & 292.07 \\
\hline 5. & 337.24 \\
\hline
\end{tabular}




\begin{tabular}{|l|l|}
\hline 6. & 545.74 \\
\hline
\end{tabular}

TABLE

Model (C4) > Modal (C5) > Solution (C6) > Total Deformation 6

\begin{tabular}{|c|c|}
\hline Mode & Frequency $[\mathrm{Hz}]$ \\
\hline 1. & 16.68 \\
\hline 2. & 90.136 \\
\hline 3. & 104.42 \\
\hline 4. & 292.07 \\
\hline 5. & 337.24 \\
\hline 6. & 545.74 \\
\hline
\end{tabular}

Material Data

XZY PLA

TABLE

XZY PLA > Constants

\begin{tabular}{|l|l|}
\hline Density & $1186.3 \mathrm{~kg} \mathrm{~m}^{\wedge} \mathrm{-3}$ \\
\hline
\end{tabular}

TABLE

XZY PLA > Color 


\begin{tabular}{|r|r|r|}
\hline Red & Green & Blue \\
\hline 161 & 209 & 255 \\
\hline
\end{tabular}

TABLE

XZY PLA > Orthotropic Elasticity

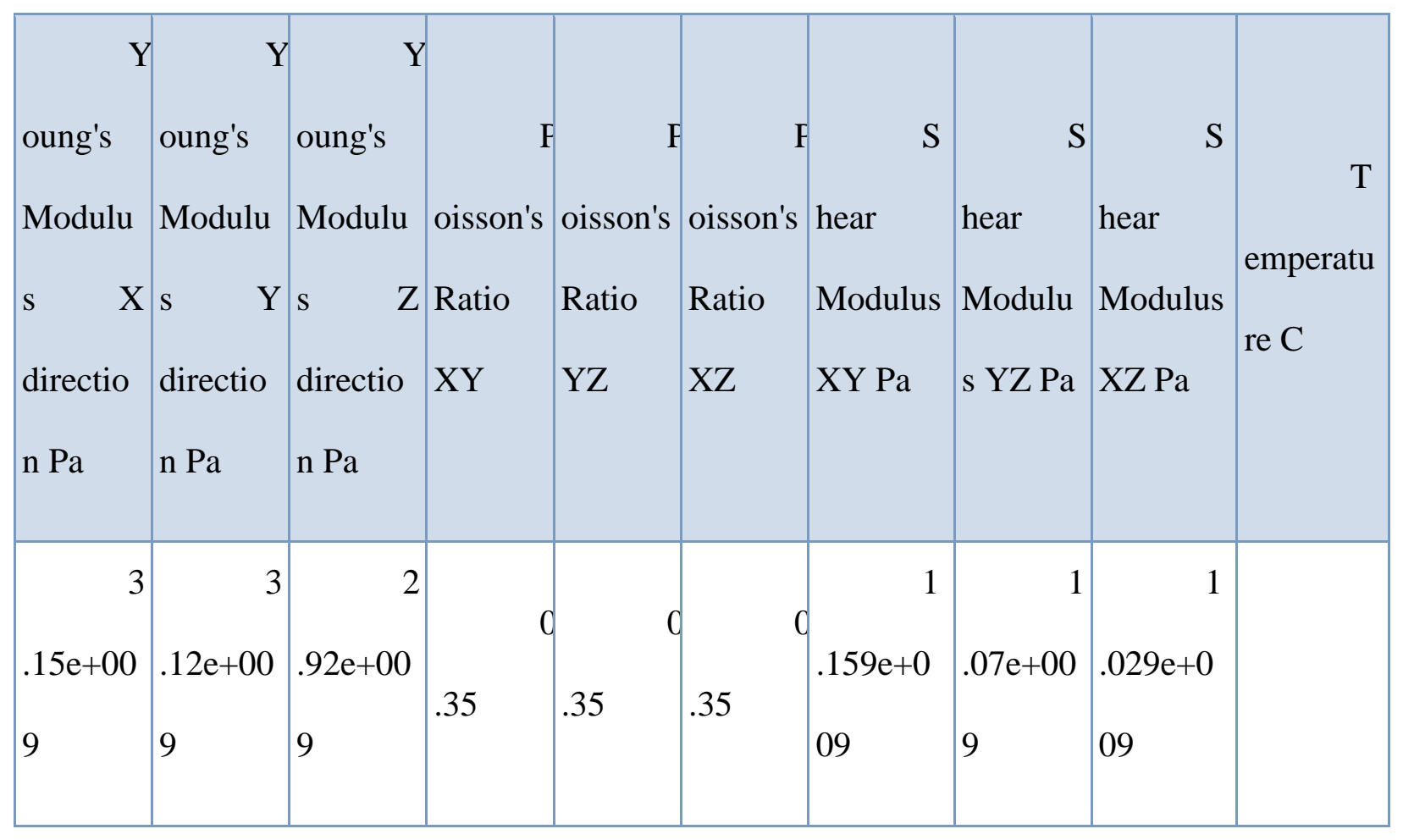




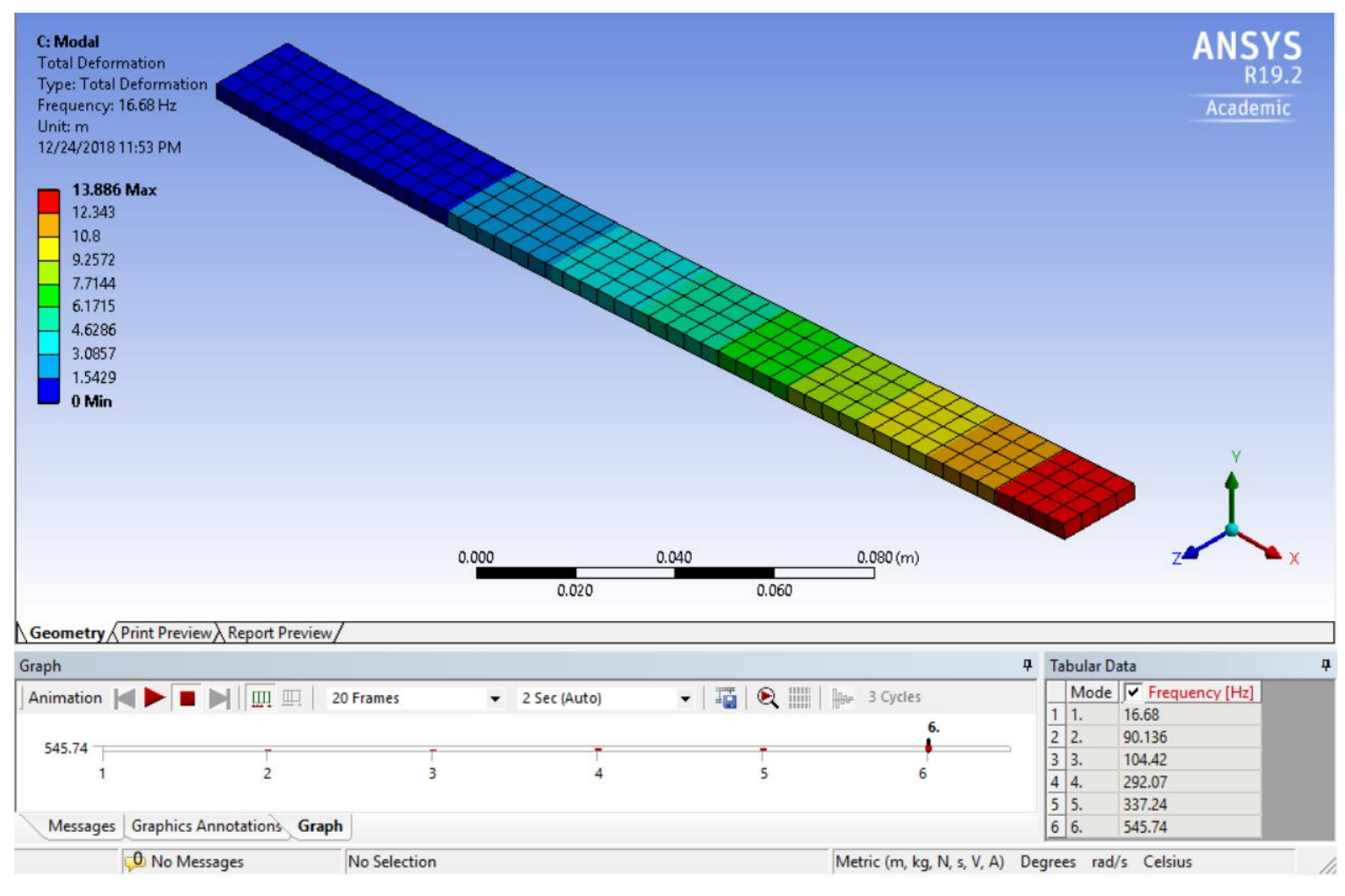



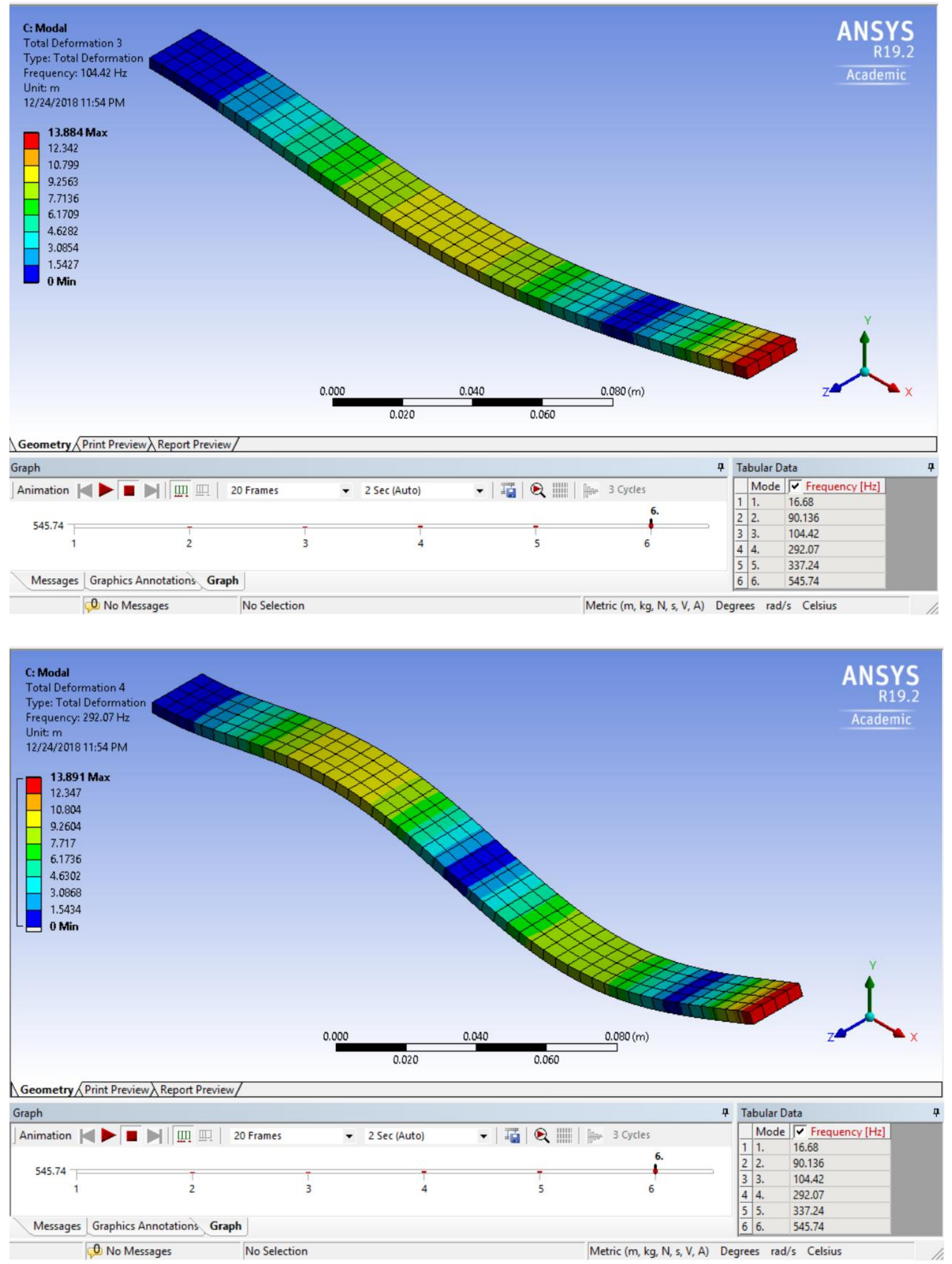


\section{NWYS}

Appendix D3 Build orientation ZXY

\begin{tabular}{|c|c|}
\hline First Saved & Monday, December 24, 2018 \\
\hline Last Saved & Tuesday, December 25, 2018 \\
\hline Product Version & 19.2 Release \\
\hline Save Project Before Solution & No \\
\hline Save Project After Solution & No \\
\hline
\end{tabular}




\section{ANSYS}

R19.2

Academic

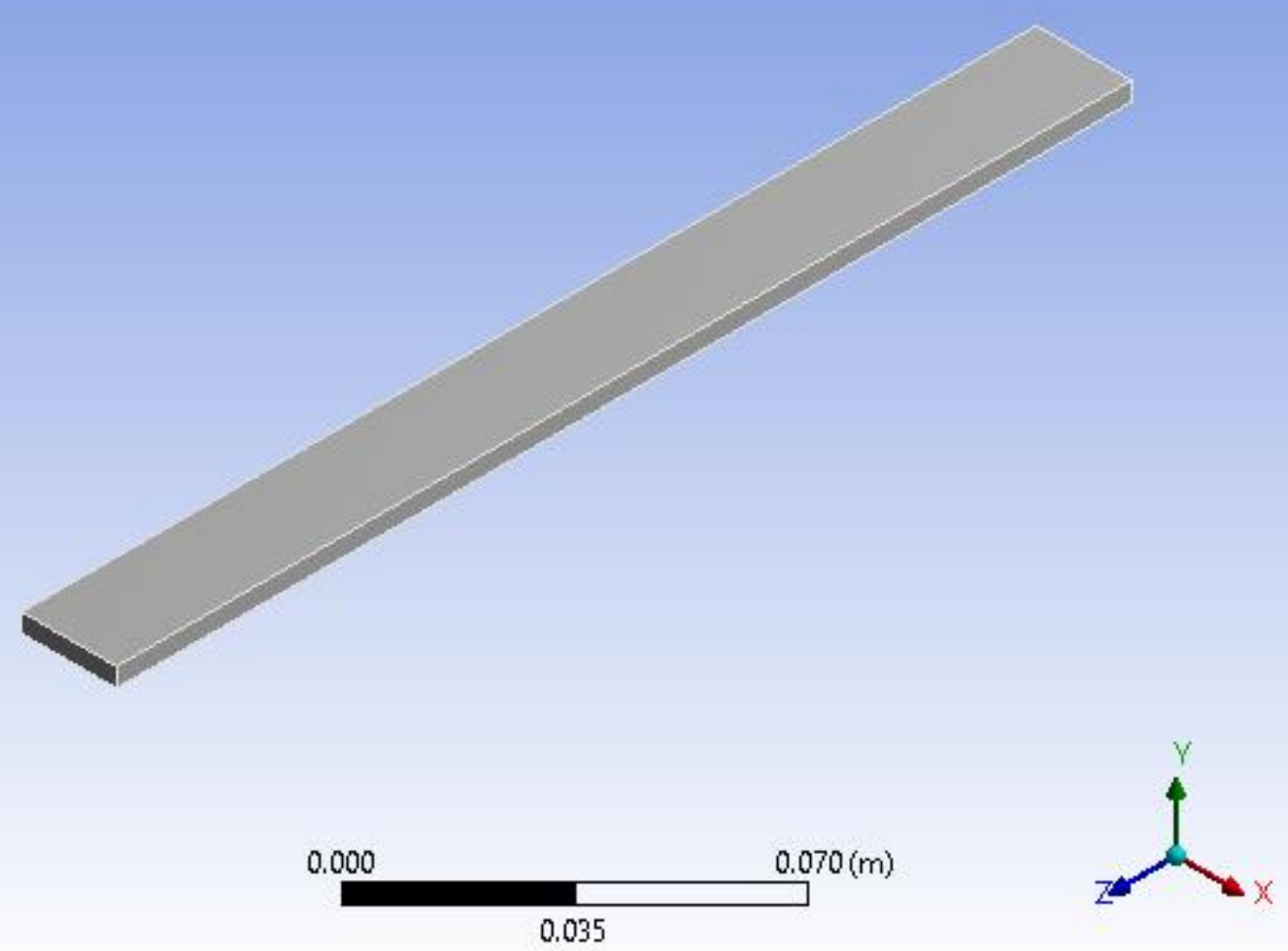

\section{Contents}

- Units

- $\quad \underline{\text { Model (C4) }}$

- Geometry

- $\quad \underline{\text { SYS-5\Solid }}$

- Materials

- ZXY PLA

- $\quad$ ZXY PLA 2

- Coordinate Systems

- Mesh 
$\underline{\text { Modal (C5) }}$

- $\quad$ Pre-Stress (None)

- $\quad$ Analysis Settings

- $\quad$ Fixed Support

- $\quad$ Solution (C6)

- Solution Information

- Results

- Material Data

○ $\underline{\text { ZXY PLA }}$

Units

TABLE 1

\begin{tabular}{|l|l|}
\hline Unit System & Metric $(\mathrm{m}, \mathrm{kg}, \mathrm{N}, \mathrm{s}, \mathrm{V}, \mathrm{A})$ Degrees rad/s Celsius \\
\hline Angle & Degrees \\
\hline Rotational Velocity & $\mathrm{rad} / \mathrm{s}$ \\
\hline Temperature & Celsius \\
\hline
\end{tabular}

Model (C4)

Geometry

TABLE

Model (C4) > Geometry

Object Name

Geometry 


\begin{tabular}{|c|c|}
\hline State & Fully Defined \\
\hline \multicolumn{2}{|l|}{ Definition } \\
\hline Source & 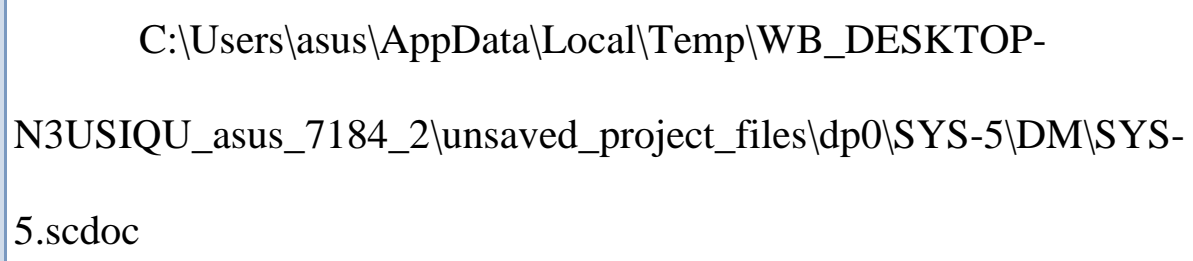 \\
\hline Type & SpaceClaim \\
\hline Length Unit & Meters \\
\hline $\begin{array}{l}\text { Element } \\
\text { Control }\end{array}$ & Program Controlled \\
\hline Display Style & Body Color \\
\hline \multicolumn{2}{|l|}{ Bounding Box } \\
\hline Length X & $2.009 \mathrm{e}-002 \mathrm{~m}$ \\
\hline Length $\mathrm{Y}$ & 4.e- $003 \mathrm{~m}$ \\
\hline Length Z & $0.215 \mathrm{~m}$ \\
\hline \multicolumn{2}{|l|}{ Properties } \\
\hline Volume & $1.7277 \mathrm{e}-005 \mathrm{~m}^{3}$ \\
\hline
\end{tabular}




\begin{tabular}{|l|l|}
\hline Mass & $1.9917 \mathrm{e}-002 \mathrm{~kg}$ \\
\hline Scale Factor & 1. \\
\hline Statistics & \\
\hline Bodies & 1 \\
\hline Active Bodies & 1 \\
\hline Nodes & 6181 \\
\hline Elements & 1008 \\
\hline Surface Bodies & Yes \\
\hline Mesh Metric & None \\
\hline Update Options & \\
\hline Assign Default & \\
\hline
\end{tabular}




\begin{tabular}{|c|c|}
\hline Line Bodies & Yes \\
\hline Parameters & Independent \\
\hline Parameter Key & \\
\hline Attributes & Yes \\
\hline Attribute Key & \\
\hline Named & Yes \\
\hline Selections & \\
\hline Named & Yes \\
\hline Selection Key & \\
\hline Associativity & \\
\hline Material & \\
\hline Advanced Geomerties & \\
\hline
\end{tabular}




\begin{tabular}{|c|c|}
\hline $\begin{array}{l}\text { Coordinate } \\
\text { System Key }\end{array}$ & \\
\hline $\begin{array}{l}\text { Reader Mode } \\
\text { Saves Updated File }\end{array}$ & No \\
\hline Use Instances & Yes \\
\hline $\begin{array}{l}\text { Smart CAD } \\
\text { Update }\end{array}$ & Yes \\
\hline $\begin{array}{l}\text { Compare Parts } \\
\text { On Update }\end{array}$ & No \\
\hline Analysis Type & 3-D \\
\hline $\begin{array}{l}\text { Mixed Import } \\
\text { Resolution }\end{array}$ & None \\
\hline $\begin{array}{l}\text { Clean Bodies } \\
\text { On Import }\end{array}$ & No \\
\hline $\begin{array}{l}\text { Stitch Surfaces } \\
\text { On Import }\end{array}$ & No \\
\hline
\end{tabular}




\begin{tabular}{|r|c|}
\hline Decompose & Yes \\
Disjoint Geometry & \\
\hline Enclosure and & Yes \\
Symmetry Processing & \\
\hline
\end{tabular}

TABLE

Model (C4) > Geometry > Parts

\begin{tabular}{|l|l|}
\hline Object Name & SYS-5ISolid \\
\hline State & Meshed \\
\hline Graphics Properties & \\
\hline Visible & Yes \\
\hline Transparency & 1 \\
\hline Definition & \\
\hline Suppressed & No \\
\hline Stiffness Behavior & Flexible \\
\hline Coordinate System & Default Coordinate System \\
\hline Reference Temperature & By Environment \\
\hline
\end{tabular}




\begin{tabular}{|c|c|}
\hline Behavior & None \\
\hline \multicolumn{2}{|l|}{ Material } \\
\hline Assignment & ZXY PLA \\
\hline Nonlinear Effects & Yes \\
\hline Thermal Strain Effects & Yes \\
\hline \multicolumn{2}{|l|}{ Bounding Box } \\
\hline Length X & $2.009 \mathrm{e}-002 \mathrm{~m}$ \\
\hline Length Y & 4.e-003 m \\
\hline Length Z & $0.215 \mathrm{~m}$ \\
\hline \multicolumn{2}{|l|}{ Properties } \\
\hline Volume & $1.7277 \mathrm{e}-005 \mathrm{~m}^{3}$ \\
\hline Mass & $1.9917 \mathrm{e}-002 \mathrm{~kg}$ \\
\hline Centroid X & $1.045 \mathrm{e}-003 \mathrm{~m}$ \\
\hline Centroid $\mathrm{Y}$ & 2.e-003 m \\
\hline Centroid Z & $0.1075 \mathrm{~m}$ \\
\hline
\end{tabular}




\begin{tabular}{|l|l|}
\hline Moment of Inertia Ip1 & $7.675 \mathrm{e}-005 \mathrm{~kg} \cdot \mathrm{m}^{2}$ \\
\hline Moment of Inertia Ip2 & $7.7393 \mathrm{e}-005 \mathrm{~kg} \cdot \mathrm{m}^{2}$ \\
\hline Moment of Inertia Ip3 & $6.9646 \mathrm{e}-007 \mathrm{~kg} \cdot \mathrm{m}^{2}$ \\
\hline Statistics & \\
\hline Nodes & 6181 \\
\hline Elements & 1008 \\
\hline Mesh Metric & None \\
\hline CAD Attributes & \\
\hline PartTolerance: & \\
\hline Color:143.175.143 & \\
\hline
\end{tabular}

Coordinate Systems

TABLE

Model (C4) > Coordinate Systems > Coordinate System

\begin{tabular}{|l|l|}
\hline Object Name & Global Coordinate System \\
\hline State & Fully Defined \\
\hline
\end{tabular}




\begin{tabular}{|c|c|}
\hline \multicolumn{2}{|l|}{ Definition } \\
\hline Type & Cartesian \\
\hline Coordinate System ID & 0. \\
\hline \multicolumn{2}{|l|}{ Origin } \\
\hline Origin $X$ & $0 . \mathrm{m}$ \\
\hline Origin Y & $0 . \mathrm{m}$ \\
\hline Origin Z & $0 . \mathrm{m}$ \\
\hline \multicolumn{2}{|l|}{ Directional Vectors } \\
\hline X Axis Data & {$\left[\begin{array}{lll}1.0 .0 . & 0 .\end{array}\right.$} \\
\hline Y Axis Data & {$[0.1 .0]$.} \\
\hline Z Axis Data & {$[0.0 .1]$.} \\
\hline
\end{tabular}

Mesh

TABLE

Model (C4) > Mesh

Object Name

Mesh 


\begin{tabular}{|l|l|}
\hline State & Solved \\
\hline Display & \\
\hline Display Style & Use Geometry Setting \\
\hline Defaults & \\
\hline Physics Preference & Mechanical \\
\hline Element Order & Program Controlled \\
\hline Element Size & 3.e-003 m \\
\hline Sizing & Coarse \\
\hline Use Adaptive Sizing & Yesembly \\
\hline Transition & \\
\hline Resolution & Default (2) \\
\hline Mesh Defeaturing & \\
\hline & \\
\hline & \\
\hline & \\
\hline & \\
\hline & \\
\hline & \\
\hline & \\
\hline & \\
\hline & \\
\hline & \\
\hline
\end{tabular}




\begin{tabular}{|c|c|}
\hline Bounding Box Diagonal & $0.21597 \mathrm{~m}$ \\
\hline Average Surface Area & $1.7532 \mathrm{e}-003 \mathrm{~m}^{2}$ \\
\hline Minimum Edge Length & 4.e-003 m \\
\hline \multicolumn{2}{|l|}{ Quality } \\
\hline Check Mesh Quality & Yes, Errors \\
\hline Error Limits & Standard Mechanical \\
\hline Target Quality & Default (0.050000) \\
\hline Smoothing & Medium \\
\hline Mesh Metric & None \\
\hline \multicolumn{2}{|l|}{ Inflation } \\
\hline Use Automatic Inflation & None \\
\hline Inflation Option & Smooth Transition \\
\hline Transition Ratio & 0.272 \\
\hline Maximum Layers & 5 \\
\hline Growth Rate & 1.2 \\
\hline
\end{tabular}




\begin{tabular}{|c|c|}
\hline Inflation Algorithm & Pre \\
\hline View Advanced Options & No \\
\hline \multicolumn{2}{|l|}{ Advanced } \\
\hline Number of CPUs for Parallel Part Meshing & Program Controlled \\
\hline Straight Sided Elements & No \\
\hline Number of Retries & Default (4) \\
\hline Rigid Body Behavior & Dimensionally Reduced \\
\hline Triangle Surface Mesher & Program Controlled \\
\hline Topology Checking & Yes \\
\hline Pinch Tolerance & Please Define \\
\hline Generate Pinch on Refresh & No \\
\hline \multicolumn{2}{|l|}{ Statistics } \\
\hline Nodes & 6181 \\
\hline Elements & 1008 \\
\hline
\end{tabular}

Modal (C5) 
TABLE

Model (C4) > Analysis

\begin{tabular}{|l|l|}
\hline Object Name & Modal (C5) \\
\hline State & Solved \\
\hline Definition & \\
\hline Physics Type & Structural \\
\hline Analysis Type & Modal \\
\hline Solver Target & Mechanical APDL \\
\hline Options & \\
\hline Environment Temperature & \\
\hline
\end{tabular}

TABLE

Model (C4) > Modal (C5) > Initial Condition

\begin{tabular}{|l|l|}
\hline Object Name & Pre-Stress (None) \\
\hline State & Fully Defined \\
\hline Definition & \\
\hline
\end{tabular}




\begin{tabular}{|l|l|}
\hline Pre-Stress Environment & None Available \\
\hline
\end{tabular}

TABLE

Model (C4) > Modal (C5) > Analysis Settings

\begin{tabular}{|c|c|}
\hline Object Name & Analysis Settings \\
\hline State & Fully Defined \\
\hline \multicolumn{2}{|l|}{ Options } \\
\hline $\begin{array}{l}\text { Max Modes } \\
\text { to Find }\end{array}$ & 6 \\
\hline $\begin{array}{l}\text { Limit Search } \\
\text { to Range }\end{array}$ & No \\
\hline \multicolumn{2}{|c|}{ Solver Controls } \\
\hline Damped & No \\
\hline Solver Type & Program Controlled \\
\hline \multicolumn{2}{|c|}{ Rotordynamics Controls } \\
\hline Coriolis & Off \\
\hline
\end{tabular}




\begin{tabular}{|c|c|}
\hline $\begin{array}{l}\text { Campbell } \\
\text { Diagram }\end{array}$ & Off \\
\hline \multicolumn{2}{|c|}{ Output Controls } \\
\hline Stress & No \\
\hline Strain & No \\
\hline Nodal Forces & No \\
\hline $\begin{array}{l}\text { Calculate } \\
\text { Reactions }\end{array}$ & No \\
\hline $\begin{array}{r}\text { General } \\
\text { Miscellaneous }\end{array}$ & No \\
\hline \multicolumn{2}{|c|}{ Analysis Data Management } \\
\hline $\begin{array}{l}\text { Solver Files } \\
\text { Directory }\end{array}$ & $\begin{array}{l}\text { C:IUserslasus\AppDatalLocal|TemplWB_DESKTOP- } \\
\text { N3USIQU_asus_7184_2lunsaved_project_files\dp0\SYS-6\MECH }\end{array}$ \\
\hline $\begin{array}{l}\text { Future } \\
\text { Analysis }\end{array}$ & None \\
\hline
\end{tabular}




\begin{tabular}{|c|c|}
\hline Solver Files & \\
Directory & \\
\hline Save & No \\
MAPDL db & \\
\hline Contact & Program Controlled \\
\hline Summary & \\
\hline Delete & Yes \\
\hline Unneeded Files & \\
\hline Solver Units & Active System \\
\hline Solver Unit & mks \\
\hline TABLE & \\
\hline
\end{tabular}

Model (C4) > Modal (C5) > Loads

\begin{tabular}{|l|l|}
\hline Object Name & Fixed Support \\
\hline State & Fully Defined \\
\hline Scope & \\
\hline
\end{tabular}




\begin{tabular}{|c|c|}
\hline Scoping Method & Geometry Selection \\
\hline Geometry & 1 Face \\
\hline Definition \\
\hline Type \\
\hline Suppressed & Fixed Support \\
\hline
\end{tabular}

Solution (C6)

TABLE

Model (C4) > Modal (C5) > Solution

\begin{tabular}{|l|l|}
\hline Object Name & Solution (C6) \\
\hline State & Solved \\
\hline Adaptive Mesh Refinement \\
\hline Max Refinement Loops & 1. \\
\hline Refinement Depth & 2. \\
\hline Information & \\
\hline Status & \\
\hline
\end{tabular}




\begin{tabular}{|c|c|}
\hline MAPDL Elapsed Time & $3 . \mathrm{s}$ \\
\hline MAPDL Memory Used & $352 . \mathrm{MB}$ \\
\hline MAPDL Result File Size & 2. MB \\
\hline Post Processing \\
\hline Beam Section Results & No \\
\hline
\end{tabular}

The following bar chart indicates the frequency at each calculated mode.

FIGURE

Model (C4) > Modal (C5) > Solution (C6)

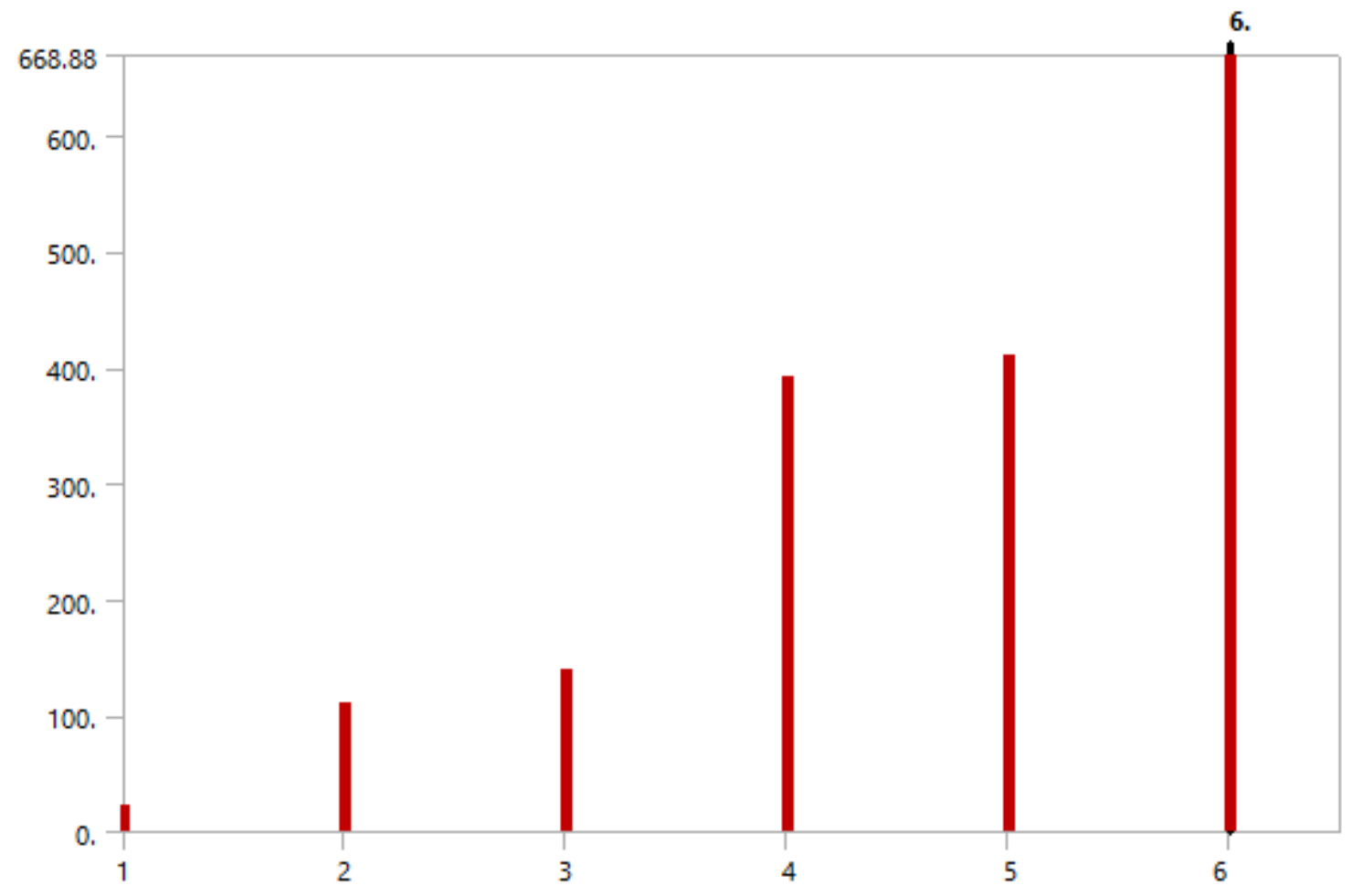


TABLE

Model (C4) > Modal (C5) > Solution (C6)

\begin{tabular}{|c|c|}
\hline Mode & Frequency $[\mathrm{Hz}]$ \\
\hline 1. & 22.392 \\
\hline 2. & 111.2 \\
\hline 3. & 140.08 \\
\hline 4. & 391.4 \\
\hline 5. & 411. \\
\hline 6. & 668.88 \\
\hline
\end{tabular}

TABLE

Model (C4) > Modal (C5) > Solution (C6) > Solution Information

\begin{tabular}{|l|l|}
\hline Object Name & Solution Information \\
\hline State & Solved \\
\hline Solution Information & \\
\hline Solution Output & Solver Output \\
\hline Newton-Raphson Residuals & 0 \\
\hline
\end{tabular}




\begin{tabular}{|l|l|}
\hline Identify Element Violations & 0 \\
\hline Update Interval & $2.5 \mathrm{~s}$ \\
\hline Display Points & All \\
\hline FE Connection Visibility & \\
\hline Activate Visibility & Yes \\
\hline Display & All FE Connectors \\
\hline Draw Connections Attached To & All Nodes \\
\hline Line Color & Connection Type \\
\hline Visible on Results & No \\
\hline Line Thickness & \\
\hline Display Type & Single \\
\hline
\end{tabular}

TABLE

Model (C4) > Modal (C5) > Solution (C6) > Results

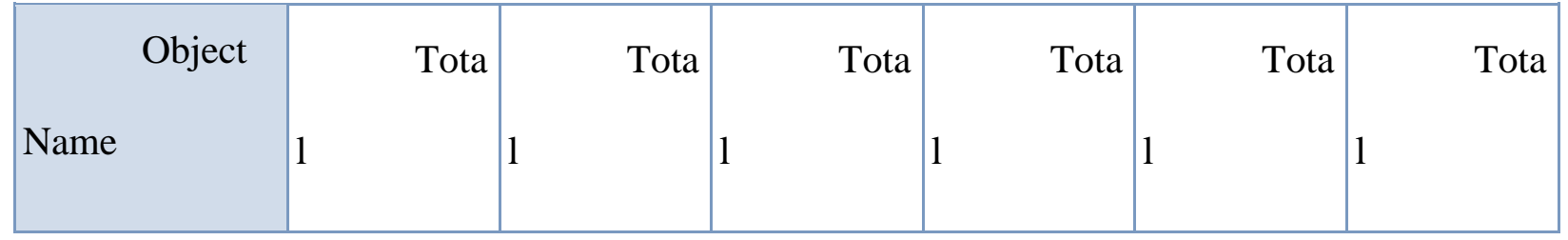




\begin{tabular}{|c|c|c|c|c|c|c|}
\hline & $\begin{array}{l}\text { Deformatio } \\
\mathrm{n}\end{array}$ & $\begin{array}{l}\text { Deformatio } \\
\text { n } 2\end{array}$ & $\begin{array}{l}\text { Deformatio } \\
\text { n } 3\end{array}$ & $\begin{array}{l}\text { Deformatio } \\
\text { n } 4\end{array}$ & $\begin{array}{l}\text { Deformatio } \\
\text { n } 5\end{array}$ & $\begin{array}{l}\text { Deformatio } \\
\text { n } 6\end{array}$ \\
\hline State & \multicolumn{6}{|c|}{ Solved } \\
\hline \multicolumn{7}{|l|}{ Scope } \\
\hline $\begin{array}{l}\text { Scoping } \\
\text { Method }\end{array}$ & \multicolumn{6}{|c|}{ Geometry Selection } \\
\hline Geomet & \multicolumn{6}{|c|}{ All Bodies } \\
\hline \multicolumn{7}{|c|}{ Definition } \\
\hline Type & \multicolumn{6}{|c|}{ Total Deformation } \\
\hline Mode & 1. & 2. & 3. & 4. & 5. & 6. \\
\hline \multicolumn{7}{|l|}{ Identifie } \\
\hline sed & No & & & & & \\
\hline Results & & & & & & \\
\hline
\end{tabular}




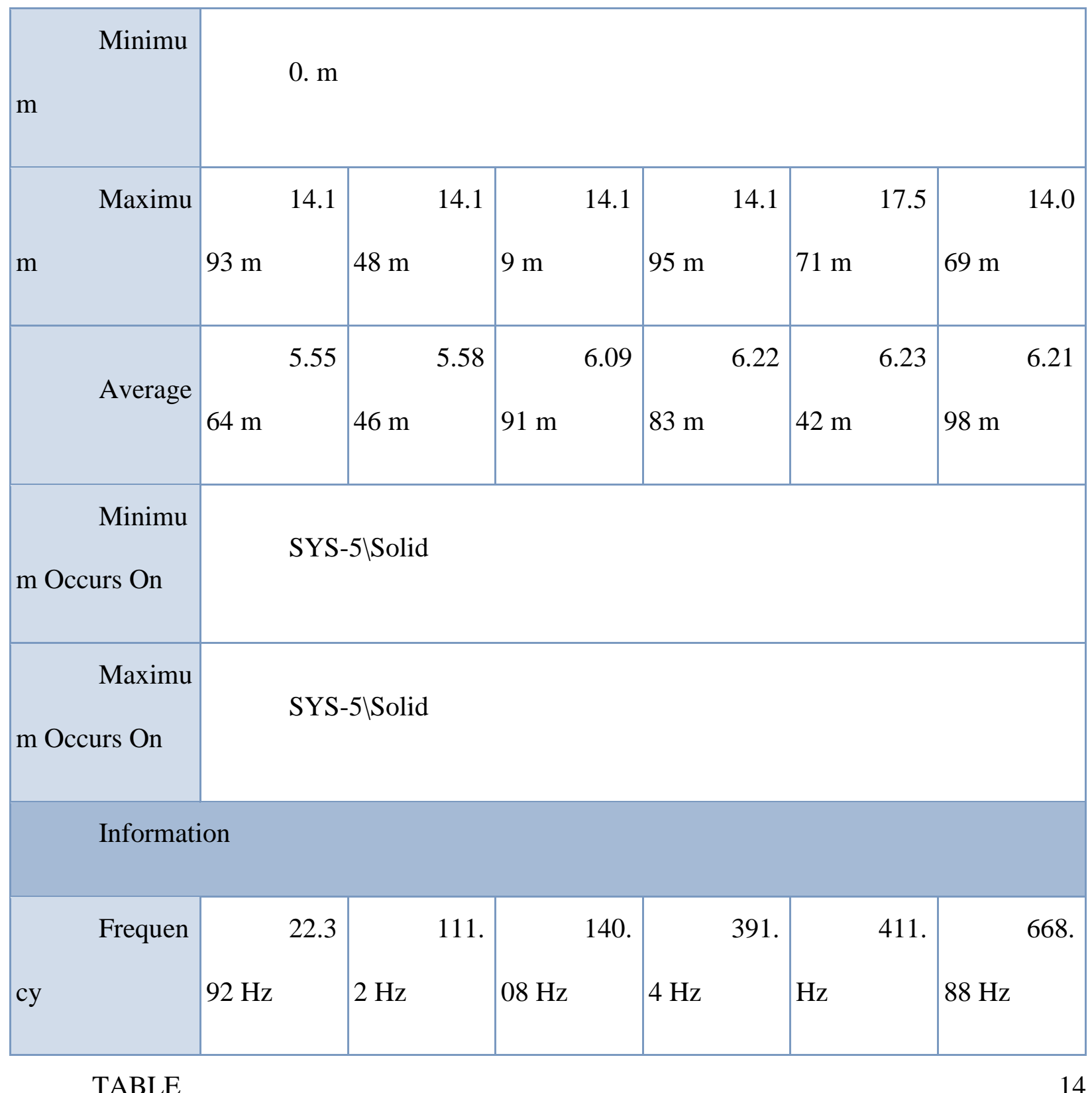

Model (C4) > Modal (C5) > Solution (C6) > Total Deformation

\begin{tabular}{|c|c|}
\hline Mode & Frequency $[\mathrm{Hz}]$ \\
\hline 1. & 22.392 \\
\hline
\end{tabular}




\begin{tabular}{|c|c|}
\hline 2. & 111.2 \\
\hline 3. & 140.08 \\
\hline 4. & 391.4 \\
\hline 5. & 411. \\
\hline 6. & 668.88 \\
\hline
\end{tabular}

TABLE

Model (C4) > Modal (C5) > Solution (C6) > Total Deformation 2

\begin{tabular}{|c|c|}
\hline Mode & Frequency $[\mathrm{Hz}]$ \\
\hline 1. & 22.392 \\
\hline 2. & 111.2 \\
\hline 3. & 140.08 \\
\hline 4. & 391.4 \\
\hline 5. & 411. \\
\hline 6. & 668.88 \\
\hline
\end{tabular}

TABLE

Model (C4) > Modal (C5) > Solution (C6) > Total Deformation 3 


\begin{tabular}{|c|c|}
\hline Mode & Frequency $[\mathrm{Hz}]$ \\
\hline 1. & 22.392 \\
\hline 2. & 111.2 \\
\hline 3. & 140.08 \\
\hline 4. & 391.4 \\
\hline 5. & 411. \\
\hline 6. & 668.88 \\
\hline
\end{tabular}

TABLE

Model (C4) $>$ Modal (C5) $>$ Solution (C6) $>$ Total Deformation 4

\begin{tabular}{|c|c|}
\hline Mode & Frequency $[\mathrm{Hz}]$ \\
\hline 1. & 22.392 \\
\hline 2. & 111.2 \\
\hline 3. & 140.08 \\
\hline 4. & 391.4 \\
\hline 5. & 411. \\
\hline
\end{tabular}




\begin{tabular}{|l|l|}
\hline 6. & 668.88 \\
\hline
\end{tabular}

TABLE

Model (C4) > Modal (C5) > Solution (C6) > Total Deformation 5

\begin{tabular}{|c|c|}
\hline Mode & Frequency $[\mathrm{Hz}]$ \\
\hline 1. & 22.392 \\
\hline 2. & 111.2 \\
\hline 3. & 140.08 \\
\hline 4. & 391.4 \\
\hline 5. & 411. \\
\hline 6. & 668.88 \\
\hline
\end{tabular}

TABLE

Model (C4) > Modal (C5) > Solution (C6) > Total Deformation 6

\begin{tabular}{|c|c|}
\hline Mode & Frequency $[\mathrm{Hz}]$ \\
\hline 1. & 22.392 \\
\hline 2. & 111.2 \\
\hline 3. & 140.08 \\
\hline
\end{tabular}




\begin{tabular}{|c|c|}
\hline 4. & 391.4 \\
\hline 5. & 411. \\
\hline 6. & 668.88 \\
\hline
\end{tabular}

Material Data

ZXY PLA

TABLE

ZXY PLA > Constants

\begin{tabular}{|l|l|}
\hline Density & $1152.8 \mathrm{~kg} \mathrm{~m}^{\wedge}$-3 \\
\hline
\end{tabular}

TABLE

ZXY PLA > Color

\begin{tabular}{|r|r|r|}
\hline Red & Green & Blue \\
\hline 234 & 247 & 209 \\
\hline
\end{tabular}

TABLE

ZXY PLA > Orthotropic Elasticity

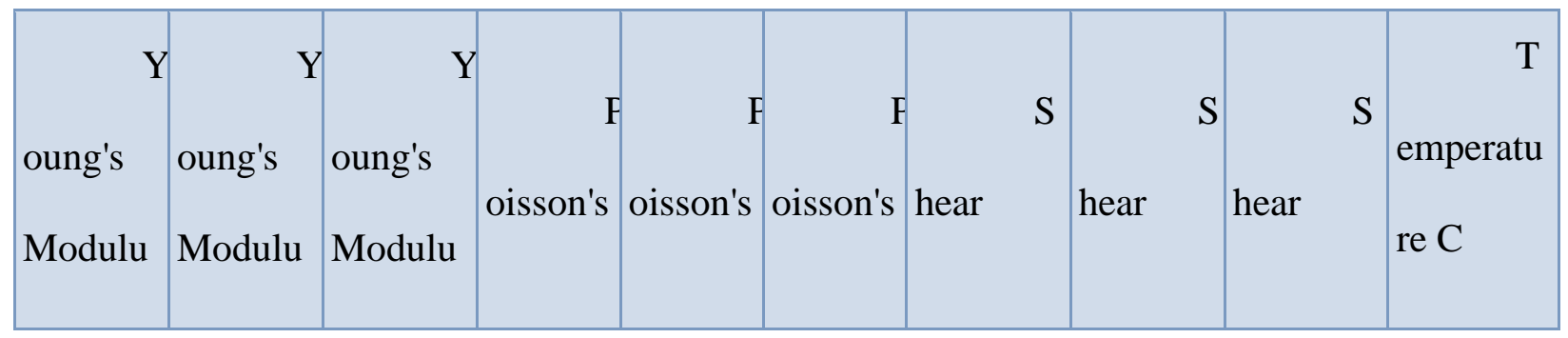




\begin{tabular}{|c|c|c|c|c|c|c|c|c|}
\hline $\begin{array}{l}\text { s } \quad \mathrm{X} \\
\text { directio } \\
\text { n Pa }\end{array}$ & $\begin{array}{l}\text { s } \quad \text { Y } \\
\text { directio } \\
\text { n Pa }\end{array}$ & $\begin{array}{l}\text { s } \mathrm{Z} \\
\text { directio } \\
\text { n Pa }\end{array}$ & $\begin{array}{l}\text { Ratio } \\
\text { XY }\end{array}$ & $\begin{array}{l}\text { Ratio } \\
\text { YZ }\end{array}$ & $\begin{array}{l}\text { Ratio } \\
\text { XZ }\end{array}$ & $\begin{array}{l}\text { Modulus } \\
\text { XY Pa }\end{array}$ & $\begin{array}{l}\text { Modulu } \\
\text { s YZ Pa }\end{array}$ & $\begin{array}{l}\text { Modulus } \\
\text { XZ Pa }\end{array}$ \\
\hline $\begin{array}{r}3 \\
.15 e+00 \\
9\end{array}$ & $\begin{array}{r}3 \\
.12 e+00 \\
9\end{array}$ & $\begin{array}{r}2 \\
.92 e+00 \\
9\end{array}$ & .35 & .35 & .35 & $\begin{array}{l}1 \\
.159 \mathrm{e}+0 \\
09\end{array}$ & $\begin{array}{l}1 \\
.07 e+00 \\
9\end{array}$ & $\begin{array}{l}1 \\
.029 \mathrm{e}+0 \\
09\end{array}$ \\
\hline
\end{tabular}

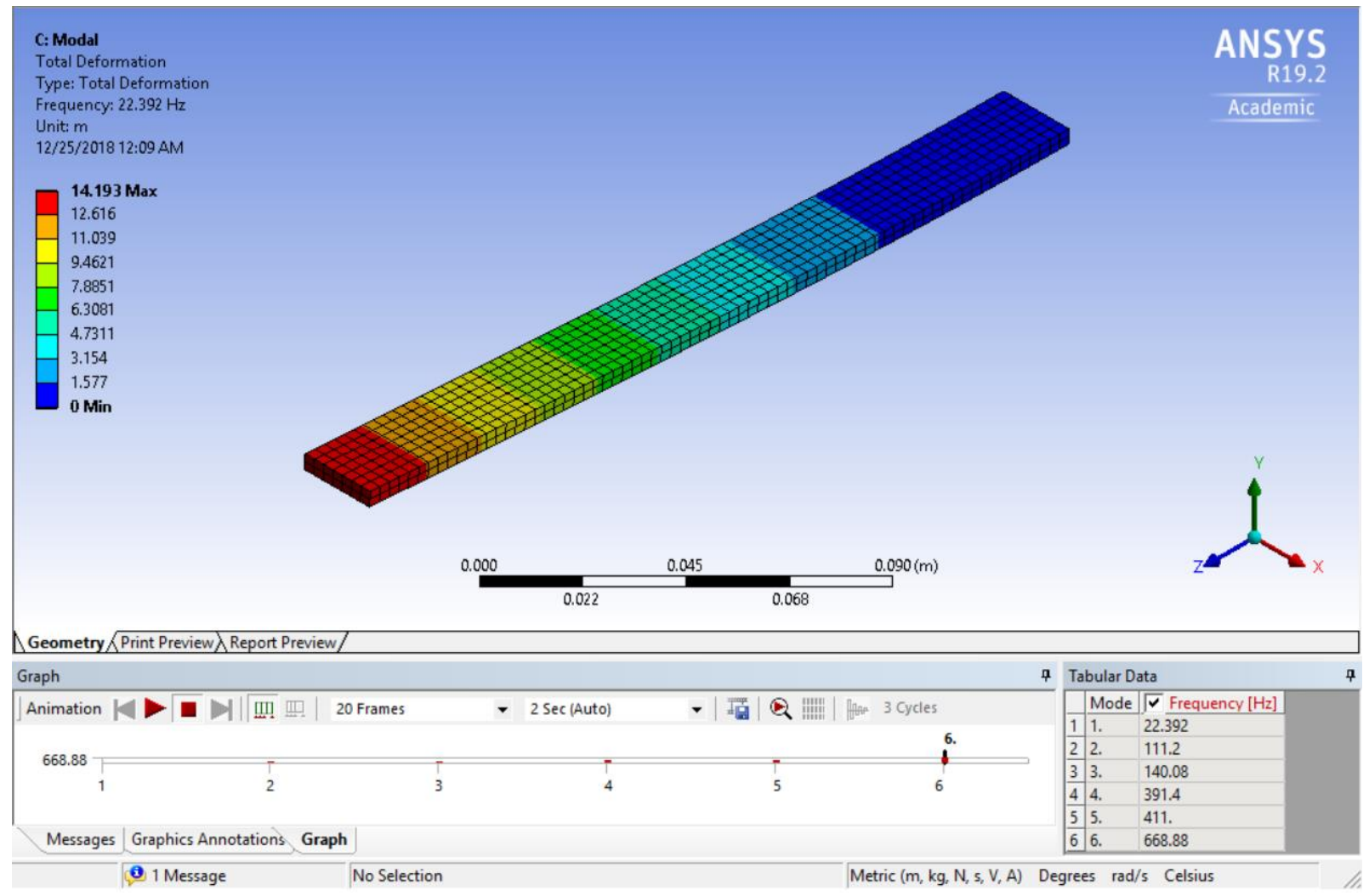



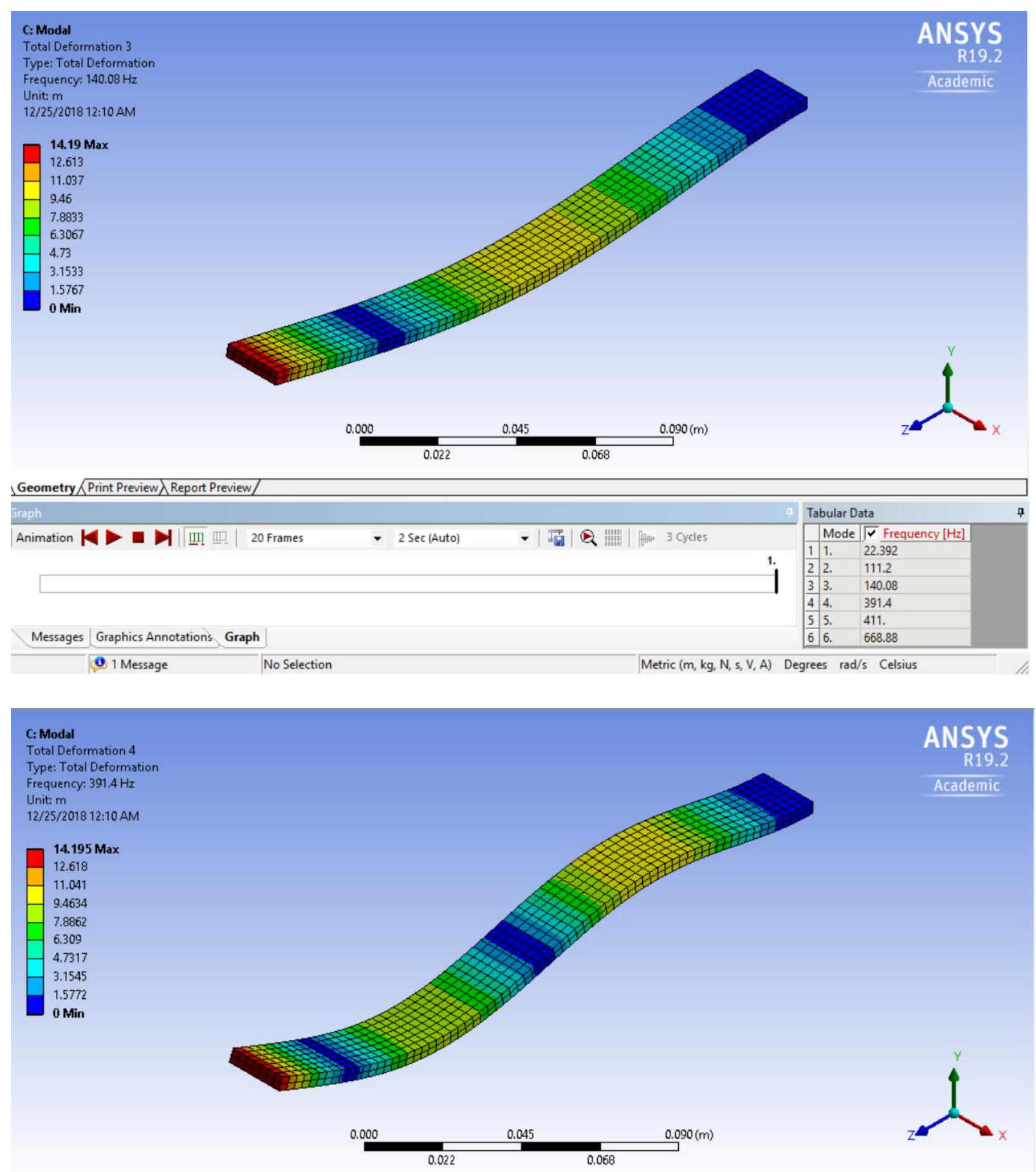

\section{ANSYS \\ R19.2 \\ Academic}

14.195 Max

12.618

9.4634

4.7317

1.5772

$0 \mathrm{M}$

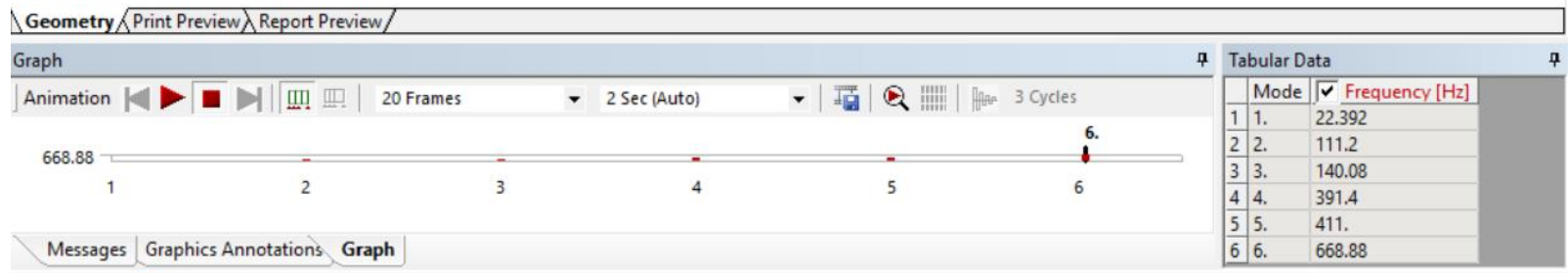

(3) 1 Message

No Selection

Metric $(m, k g, N, s, V, A)$ Degrees rad/s Celsius 


\section{REFERENCES}

ASTM International . (2015). ASTM E1876-15 Standard Test Method for Dynamic Young's Modulus, Shear Modulus, and Poisson's Ratio by Impulse Excitation of Vibration. West Conshohocken, PA.: https://doi-org.ezproxy.lib.ryerson.ca/10.1520/E1876-15.

ASTM International. (2017). ASTM E756-05(2017) Standard Test Method for Measuring Vibration-Damping Properties of Materials. West Conshohocken, PA : https://doiorg.ezproxy.lib.ryerson.ca/10.1520/E0756-05R17.

CHO, C. (2007). Comparison of Three Methods for Determining Young's Modulus of Wood. . Taiwan Journal for Science, 297-306.

Chong Liu. ( (2018)). "Optimization of shape control of a cantilever beam using dielectric elastomer actuators". . AIP Advances 8, 055015.

D. Ridley-Ellis, M. L. (2018). "Impulse excitation measurement of small changes in elastic moduli and damping using R”. International Wood products Journal,Vol. 9, No. 2, 74-79.

Davide S. Paolino, H. G. (2017). “Damaged composite laminates: Assesment of residual Young's modulus through the Impulse Excitation Technique". . Composites Part B 128, 76-8.

Digilov., R. M. (2013). "Flexural Vibration Test of a Beam Elastically Restrained at One End: A New Approach for Young's Modulus Determination”. . Advances in Materials Science and Engineering 329530.

Ewen., J. R. (2007). "Dynamic Stiffness Formulation Using Timoshenko Theory for Free Vibration of Rotating Beams”. . AIAA DOI: 10.2514/6., 2277. 
Gang Wang, N. M. (n.d.). "Free in-plane vibration of rectangular plates". . 19th AIAA Applied Aerodynamics Conference, Fluid Dynamics and Co-located Conferences.

Guan, C. ((2016) ). "Determining shear modulus of thin wood composite materials using a cantilever beam vibration method". . Building and Construction Materials. 121 , 285-289.

Haque., E. A. ( 2018, ). “Tensile properties, void contents, dispersion and fracture behaviour of 3D printed carbon nanofiber reinforced composites". Journal of Reinforced Plastics and Composites, Vol. 37(6), 381-395.

HEYLIGER, P. U. (2001). H. Anisotropic Elastic Constants: Measurement by Impact Resonance. . Journal of Materials in Civil Engineering, 356-363,.

Jianlei Wang, H. X. ((2016) ). "A novel approach to improving mechanical properties of parts fabricated by fused deposition modeling". . Materials and Design 105, 152-159.

John Ryan C. Dizon, A. H. ( (2018) ). "Mechanical characterization of 3D-printed polyers". . Additive Manufacturing 20, 44-67.

Juliana Breda Soares, J. F. ((2018) ). “Analysis of the influence of polylactic acid (PLA) colour on FDM 3D printing temperature and part finishing”. Rapid Prototyping Journal 24/8 , 13051316.

Jun., Z. ((2013) ). “Theoretical Analysis and Experimental study of A Cantilever Beam-type Dynamic Vibration Absorber”. . Applied Mechanics and Materials Vol. 415 , 436-441.

Lotfi Toubal, R. Z. (2018). "Moisture Effects on the Material Properties of a Jute/Epoxy Laminate: Impulse Excitation Technique Contribution”. Journal of Natural Fibers , Vol. 15, No. 1, , $39-52$. 
M.F. Slim and A. Alhussein, A. B. (2017). "On the determination of of Young's modulus of thin films with impulse excitation technique". . J. Mater. Res., Vol. 32, No.3, Feb 14, .

Monti., A. ((2017) ). "Experimental and finite elements analysis of the vibration behavior of a biobased composite sandwich beam”. Composites Part B 110, 466-475.

N.B. Podymova, A. K. (2013). “Quantative evaluation of the effect of porosity on the local young's modulus of isotropic composites by using the laser optoacoustic method". . Mechanics of Composite Materials, Vol 49, No. 4.

P Chiariotti, M. M. (2013). Diagnostic procedure on brake pad assembly based on Young's modulus estimation. Measurement science and technology, 24, 11.

Prasob P.A., S. M. (2018 ). "Static and dynamic behavior of Jute/epoxy composites with ZnO and TiO2 fillers at different temperature conditions”. . Polymer Testing 69, 52-62.

Ramesh., R. (2015). "Study of free vibration characteristics of carbon epoxy based composite beams",.

S.M. Hashemi, M. R. (1987). “A Bernoulli-Euler Stiffness Matrix approach for vibrational analysis of spinning linearly tapered beams". Canadian Acoustics 24 (3), 87.

Shilpesh R. Rajpurohit, H. K. (2018). "Effect of process parameters on tensile strength of FDM printed PLA part". Rapid Prototyping Journal, Vol. 24 Issue: 8, 1317-1324 .

Somen K. Bhudolia, P. P. ((2017) ). "Enhanced vibration damping and dynamic mechanical characteristics of composites with novel pseudo-thermoset matrix system”. . Composite Structures 179 , 502-51. 
V.D. Sagias. ( (2018) ). "Mechanical properties of 3D printed polymer specimens". . Science Direct, Procedia Structural Integrity 10, 85-90.

Valerga., A. ((2017) ). "Preliminary study of PLA wire colour effects on geometric characteristics of parts manufactured by FDM". Procedia Manufacturing 13, 924-931.

Valerga., A. P. (2018). "Influence of PLA Filament Conditions on Characteristics of FDM Parts". . Materials $\cdot$ July 2018 .

Walunj Prashant S, V. C. ((2015) ). "Investigation on modal parameters of rectangular cantilever beam using Experimental modal Analysis”. . Materials Today: Proceedings 2, 2121 - 2130.

Wei Sun, Z. W. ((2018) ). "Inverse identification of the frequency-dependent mechanical parameters of viscoelastic materials based on the measured FRFs". Mechanical Systems and Signal Processing 98, 816-833.

Wenlei Song, Y. Z. ( (2017) ). "Mechanical parameters identification for laminated composites based on the impulse excitation technique". . Composite Structures 162, 255-260.

Wenzheng Wu, W. Y. (2017). "Influence of Layer Thickness, Raster Angle, Deformation Temperature and Receovery Temperature on the Shape-Memory Effect of 3D-Printed Polylactic Acid Samples”. Material, 10, 970;.

Y. Song, Y. L.-Y. ( (2017) ). "Measurements of the mechanical response of unidirectional 3Dprinted PLA". . Materials and Design 123, 154-164. 